\title{
MEASURING THE SOCIAL ATTITUDES AND AESTHETIC AND ECONOMIC CONSIDERATIONS WHICH INFLUENCE TRANSMISSION LINE ROUTING
}

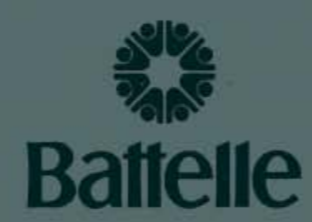

Pacilic Northwest Laboratories Richland. Washington 99352

JULY 1974

This report is intended primarily for internal use by the sponsoring organization and Battelle.

Prepared for the U.S. Atomic Energy Commission under Contract AT(45-1):1830 
NOTICE

The report was prepared as an account of work sponsored by the United States Government. Neither the United States nor the United States Atomic Energy Commission, nor any of their employees, nor any of their contractors, subcontractors, or their employees, makes any warranty, express or implied, of assumes any legal liability or responsibility for the accuracy, completeness or usefulness of any information, apparatus, product or process disclosed, or represents that its use would not infringe privately owned rights.

\author{
PACIFIC NORTHWEST LABORATORY \\ operated by \\ BATTELLE \\ for the \\ U.S. ATOMIC ENERGY COMMISSION \\ Under Contract AT(45-1)-1830
}

\author{
Printed in the United States of America \\ Available from \\ National Technical Information Service \\ U.S. Department of Commerce \\ 5285 Port Royal Road \\ Springfield, Virginia 22151
}

Price: Printed Copy \$7.60; Microfiche \$1.45 
BNWL- 1837

UC-11

\section{MEASURING THE SOCIAL ATTITUDES AND \\ AESTHETIC AND ECONOMIC CONSIDERATIONS WHICH \\ INFLUENCE TRANSMISSION LINE ROUTING}

by
P. L. Hendrickson : $23, \mathrm{P}$
R. W. Bahl
B. A. Gray

W. S. Maynard

July 1974 


\section{FOREWORD}

This report summarizes a study conducted by Battelle, Pacific Northwest Laboratories (Battelle-Northwest) for the Atomic Energy. Commission. It represents an interdisciplinary effort to extend a methodology (recently developed at Battelle-Northwest) for siting. nuclear power plants to the problem of routing electric power transmission lines. The methodology incorporates both public values and technical assessments.

Paul Hendrickson of Battelle-Northwest served as project manager. Chapters II and $V$ were written by Brian Gray of Jones and Jones Landscape Architects in Seattle. William Maynard of the Battelle Human Affairs Research Center in Seattle wrote Chapter IV. Roy Bah1, Professor of Economics and Director of the Metropolitan Studies Program at Syracuse University, wrote Chapter VI. 
FOREWORD ........................... $i$

LIST OF TABLES ........................ iv

LIST OF FIGURES ......................... iv

SUMMARY ..................

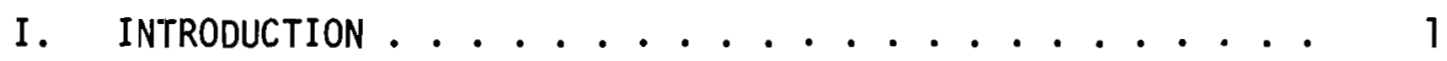

References ................... 3

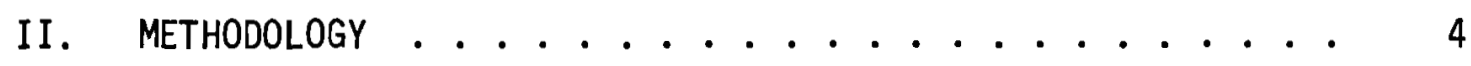

III. REVIEW OF THE STATE-OF-THE-ART OF TRANSMISSION LINE

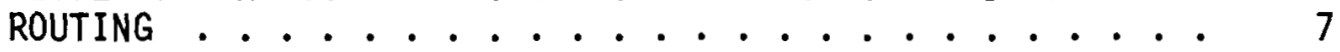

A. Present Capabilities for Measuring and Predicting Transmission Line Impacts ........... 7

B. Requirements for Improvement of Impact Prediction Capabilities .............. 12

References ............... . . 17

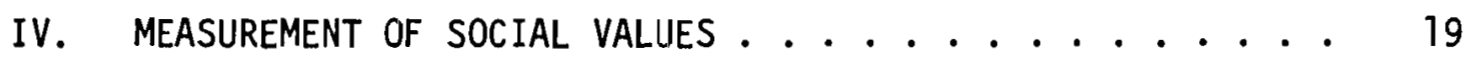

A. Public Participation in Decision Making ..... 19

B. Selection of Respondents ............ 21

C. Selection of Criteria for Evaluating Transmission Line Impacts............... 22

D. Selection of Stimuli............ 27

E. Measurement Techniques . . . . . . . . . 28

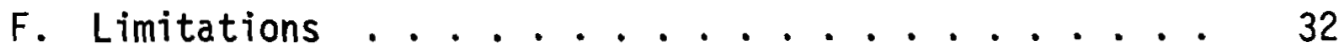

G. Example of Theory Application ........ 34

References ............... . . 38

V. QUANTIFICATION OF AESTHETIC CRITERIA . . . . . . . 40

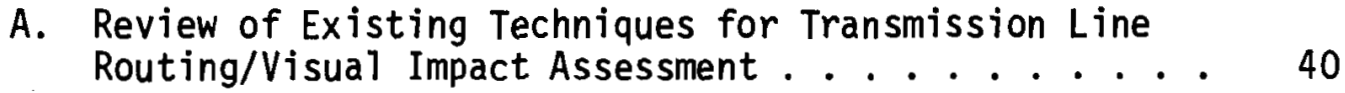

B. Approach/Methodology ............. . 47

C. Data Preparation/Preliminary Analysis ...... 51

D. Evaluation of Visual Quality.......... 64

E. Determination of Visual Impact . . . . . . . 70

F. Example of Method Application ........ 73

References................ 77 
VI. MEASURING THE SOCIAL COSTS OF TRANSMISSION TOWER LINES:

A PROPERTY VALUE APPROACH . . . . . . . . . . . 81

A. The Underlying Theory and the TTL Problem . . . . . 82

B. The Empirical Approach . . . . . . . . . . . 102

C. Alternative Estimation Models . . . . . . . . 106

D. The TTL Literature .. . . . . . . . . . . . 114

References................. 118

ACKNOWLEDGEMENTS ................. 121

APPENDIX A .................... A.1

APPENDIX B....................... B. 1

APPENDIX C . . . . . . . . . . . . . . . C.1 


\section{LIST OF TABLES}

1 Composite Social-Technical Analysis of Two Alternative 5 Transmission Lines .. . . . . . . . . . . . . . .

2 Comparison of Alternative Power Generation-Transmission Systems ....................... 6

3 A Model for Studying the Comprehension of Environments . . . 23

4 Comparison of the Direct and Policy Capturing Approaches to Criteria Weighting ............... 36

5 Landscape/Transmission Visual Compatibility Assessment Checklist ................... 54

6 Comparison of Visual Impacts Between Two Theoretical Alternative Nuclear Power Plant Sitings . . . . . . . 74

7 Analyses of Three Viewscapes by Special-Competence Group . • 75

8 Percentage Depreciation of Property Values Inside and Outside the 35 NNI Contour. . . . . . . . . . . . 96

9 Alternative Estimation Equations for Median Property Values of 167 Census Tracts for the St. Louis Metropolitan

Area: 1960 .................... 108

\section{LIST OF FIGURES}

1 Hypothetical Power Plant and Transmission Line

Alternatives .....................

2 Comparison of a "Common" 138 KV Transmission Tower With a Potentially Enlarged Version to Carry $1500 \mathrm{KV}$, Which May Be Required by 1985. ................... . . . 42

3 Reduction in Demand for Property Inspected by a TTL . . . . 89

4 Indices for a Hypothetical Control Area . . . . . . . . 113

5 Indices for a Hypothetical Project Area . . . . . . . 113 


\section{SUMMARY}

A methodology previously developed by Battelle, Pacific Northwest Laboratories, for siting nuclear power plants has been adapted to the problem of selecting an optimum electric power transmission line route from among selected alternatives. The unique feature of this methodology is the systematic inclusion of public values into the decision-making process.

\section{STATE-OF-THE-ART OF TRANSMISSION LINE ROUTING}

The currently available planning techniques for transmission line routing and impact assessment call for an extensive natural and cultural resource inventory, the use of idealized location strategies and factor weighting combinations, and employment of sophisticated overlay or computerized constraint mapping techniques to aid in route selection and the identification of high impact areas. Our suggestions for improvement in impact prediction capabilities include the need for public participation in the planning process, a clarification of the evaluation procedures to help improve public understanding and involvement, the use of established scaled reference points to permit value comparisons between various impacts, and long range power generation and transmission master planning to minimize a compounding of future environmental impacts. A composite collection of guidelines for transmission line routing is included as an appendix.

METHODOLOGY

The methodology developed in this report has three steps:

(1) Selection of significant criteria influencing the route selection analysis;

(2) Measurements of the relative weight which the public attaches to each criterion; and

(3) Quantification by technical experts of the impact of the alternative transmission line routes for each criterion using a dimensionless scalar index. 
Completion of these steps results in a rating score for each alternative route based on both technical and public judgment and thereby identifies the most desirable route.

Preliminary analysis suggests that seven criteria may adequately describe the impact of transmission lines: aesthetic impact, economic impact, water quality impact, air quality impact, cultural/recreational impact, health/safety impact, and animal/plant impact. It is expected that the public would attach widely divergent weighting factors to the criteria. These criteria were obtained after consideration of environmental impact statements. A technique for incorporating the public into the process of selecting criteria using direct questioning and multidimensional scaling is also included in the report.

MEASUREMENT OF SOCIAL VALUES

To determine the relative weight which the public attaches to routing criteria, a representative sample of viewscapes showing the visual impact of transmission lines would be assembled. Descriptive scenarios accompanying each viewscape would describe relevant criteria such as economic and ecological changes brought about by the construction and operation of a transmission line at that location. Public response testing would require that respondents kiew each scene, read the accompanying description, and make an overall judgment of the acceptability of each scenario. Multiple regression analysis would be used to determine the relationship between the overall evaluations made by the public and the preassigned values for the various criteria. The extent to which the preassigned values "predicted" the overall judgment would serve as a basis for inferring the weight or "importance" of each criterion. Direct estimates of the importance of each criterion would also be obtained for comparison purposes. These would be measured by making the criteria explicit to the respondents and asking for a rank ordering/rating of the importance which they attach to each criterion. 


\section{QUANTIFICATION OF CRITERIA}

The most comprehensive approaches currently available to elevate aesthetics are expanded to incorporate the concept of the relative scarcity of visual resources impacted and the quantification of aesthetics as developed in the nuclear power plant siting study. The procedure calls for identifying the visual characteristics of relevant landscapes and rating the visual compatibility of transmission facilities in each. Scarce and fragile visual resources, transiting and resident viewer sensitivity, mitigation and future land use are mapped and rated to locate zones of high visual constraint for various alternative locations. The visual quality components of intactness, vividness and unity are evaluated for "before" and "after" views from selected viewpoints, and visual or aesthetic impact is then expressed as the product of the ratio of change in visual quality and the size of viewing populations qualified by the scarcity value of the landscapes impacted.

The economics criterion is composed of both direct and indirect costs. Direct costs are expenditures for construction and for acquisition of easements. Indirect costs are the impact of transmission lines on property value. The theoretical considerations for capturing the indirect cost by measuring changes in property value and a sampling of the existing literature on the effect of transmission lines on property value are examined. The existing literature is weak and does not rule out the possibility that transmission lines can have negative effects on property value. 


\section{MEASURING THE SOCIAL ATTITUDES AND \\ AESTHETIC AND ECONOMIC CONSIDERATIONS WHICH \\ INFLUENCE TRANSMISSION LINE ROUTING}

\section{INTRODUCTION}

A recent study ${ }^{(1)}$ (referred to hereinafter as the Siting Study) conducted by the Pacific Northwest Laboratory for the Atomic Energy Commission identified three major weaknesses in the present process for evaluating social, economic, and environmental trade-offs of alternative decisions:

1. The lack of quantification of most effects;

2. Little or no incorporation of community social values into the decision-making process; and

3. No method for integrating social values with techno-economic values.

The Siting Study outlines a technique which potentially can meet these weaknesses and integrate the social values of the general public with the technical assessments made by technologists and economists. The technique was applied to the analysis of the social, economic, and environmental trade-offs inherent in the analysis of alternative nuclear plant siting options. The present study extends that work by outlining a methodology to apply the technique to the evaluation of trade-offs associated with the analysis and selection of alternative electric power transmission line routes.

The routing of electric power transmission lines is an increasingly significant and complex problem in the United States. In 1970 it was estimated that there were approximately 300,000 miles of overhead electric transmission lines in the U.S. $(2$, p. 21) Easements for these transmission lines (which average 110 feet in width) were estimated to require nearly $4,000,000$ acres. By 1990 it is estimated that there will be 500,000 miles of transmission lines, requiring 7,000,000 acres for easements. (2, p. 22) This is an area approximately 10 percent larger than the State of Maryland. 
Prospects for reducing this projected growth in transmission line mileage do not appear to be great. The demand for electricity continues to grow. Moreover, many power plants are being constructed long distances from population centers because of public pressures and the advantage of being near fuel sources.

The National Environmental Policy Act of 1969 [Section 101 (b)] declares it to be the responsibility of the Federal Government to act such that the nation may:

1. fulfill the responsibilities of each generation as trustee of the environment for succeeding generations;

2. assure for all Americans safe, healthful, productive, and aesthetically and culturally pleasing surroundings;

3. attain the widest range of beneficial uses of the environment without degradation, risk to health or safety, or other undesirable and unintended consequences;

4. preserve important historic, cultural, and natural aspects of our national heritage, and maintain, wherever possible, an environment which supports diversity and variety of individual choice;

5. achieve a balance between population and resource use which will permit high standards of 1 iving and a wide sharing of 1 ife's amenities; and

6. enhance the quality of renewable resources and approach the maximum attainable recycling of depletable resources.

Routing new transmission lines consistent with these goals involves a complex series of social, economic, and environmental trade-offs.

A number of techniques have been developed for selecting transmission line routes and are discussed in Chapter III. A significant deficiency in these techniques is that they do not systematically incorporate public views into the process of selecting a route. The methodology developed in this report is designed to provide a framework for dealing with the trade-offs associated with selecting a transmission line route in a manner which systematically incorporates both techno-economic values with community 
social values. Chapter IV discusses incorporation of public attitudes in routing decisions. Chapter $V$ reviews transmission line impact evaluation and discusses an approach to visual assessment. Finally, a property value approach is discussed in Chapter VI to measure the social costs of transmission lines.

\section{REFERENCES}

1. J. B. Burnham, et. al., A Technique for Environmental Decision Making Using Quantified Social and Aesthetic Values, BNWL-1787, Pacific Northwest Laboratories, Richland, Washington, February 1974 (hereinafter cited as the Siting Study).

2. Electric Power and the Environment, sponsored by the Office of Science and Technology, U. S. Governiment Printing Office, Washington, D. C., August 1970. 


\section{METHODOLOGY}

The general approach developed in the Siting Study and followed in this study requires: 1) selection of signficant criteria influencing the siting analysis; 2) measurement of the relative weight which the public attaches to each criterion; and 3) quantification by technical experts of the impact of alternative sites for each criterion category using a dimensionless scalar index. The optimum site can then be determined by comparing the total index scores for the criteria, adjusted for the social weighting factor, for all alternative sites.

Eight criteria were initially selected in the Siting Study as significant considerations in the analys is of nuclear plant siting options: economics, water quality, air quality, animal/plant, cultural/recreational, health/safety, aesthetics, and land use. An examination of the land use criterion in the siting Study revealed that its impact can be captured by the other seven criteria and that it could consequently be eliminated from the list. Our preliminary analysis suggests that the seven remaining criteria are also sufficient to distinguish the impact of alternative transmission line routes. A detailed discussion of techniques to select criteria is presented in Chapter IV. General descriptions of the impacts associated with the above seven criteria for overhead transmission lines are included in Appendix $C$.

The application of the general approach is $i 11$ ustrated by Figure 1 and Table 1. In Figure $1, A(1)$ and $A(2)$ represent the two most desirable transmission routes or corridors from power plant $A$ to a trunk line. It can be assumed that they were selected using one of the corridor selection approaches discussed in Chapter III and the routing guidelines in Appendix A. The societal weighting factors were derived by using one or more of the approaches discussed in Chapter IV.

A high score indicates a large impact and hence an undesirable route. Route $A(2)$ is consequently the least desirable alternative based on the unweighted techno-economic total scores, but it is the most desirable alternative when the societal weighting factors are applied. 
The simple addition of the weighted scores in Table 1 may not be the ideal approach. The scores for individual criteria can also be thought of as vectors in multidimensional space. In this case, a root-mean-square sum would be a preferable approach.

\section{TABLE 1. Composite Social-Technical Analysis} of Two Alternative Transmission Lines

\begin{tabular}{|c|c|c|c|c|c|}
\hline \multirow[b]{2}{*}{ Criteria } & \multirow[b]{2}{*}{$\begin{array}{c}\text { Societal } \\
\text { Weighting } \\
\text { Factor } \\
\end{array}$} & \multicolumn{2}{|c|}{$\begin{array}{l}\text { Dimensionless } \\
\text { Techno-Economic }\end{array}$} & \multicolumn{2}{|c|}{ Composite Scores } \\
\hline & & $\begin{array}{l}\frac{S c}{\text { Route }} \\
\text { A(1) }\end{array}$ & $\begin{array}{l}\text { Soute } \\
\text { A(2) }\end{array}$ & $\begin{array}{l}\text { Compo: } \\
\text { Route } \\
\text { A(1) }\end{array}$ & $\begin{array}{l}\text { Scores } \\
\text { Route } \\
A(2)\end{array}$ \\
\hline Aesthetic Impact & 0.3 & 20 & 90 & 6 & 27 \\
\hline Water Impact & 0.8 & 40 & 50 & 32 & 40 \\
\hline Air Impact & 0.5 & 30 & 40 & 15 & 20 \\
\hline Economic & 0.4 & 40 & 50 & 16 & 20 \\
\hline Cul tural/Recreational & 0.3 & 40 & 80 & 12 & 24 \\
\hline Heal th/Safety & 0.7 & 90 & 20 & 63 & 14 \\
\hline Anima $1 /$ Plant Impact & 0.7 & 70 & 30 & 49 & 21 \\
\hline Technical Total & & 330 & 360 & & \\
\hline Composite Total & & & & 193 & 166 \\
\hline
\end{tabular}

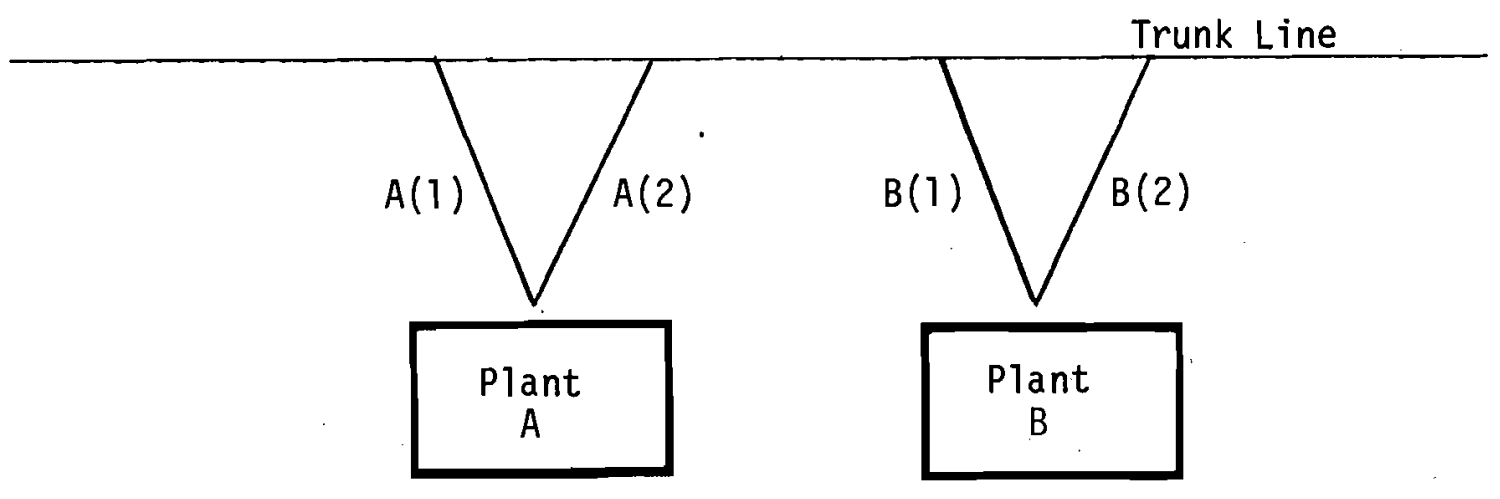

FIGURE 1. Hypothetical Power Plant and Transmission Line Alternatives 
The approach shown in Table 1 could also be used to compare alternative routes $B(1)$ and $B(2)$ and for alternative plant locations $A$ and $B$. Comparison of the total composite scores for both transmission corridor and plant location leads to the selection of A-2 as the optimum generationtransmission combination as shown in Table 2.

The addition of the transmission corridor score and the generation plant score to yield a total composite score is a simplified approach. It would be desirable to determine a weighting factor for each score to reflect both social and technical considerations.

TABLE 2. Comparison of Alternative Power Generation-Transmission Systems

\begin{tabular}{|c|c|c|c|c|}
\hline System & $\underline{A-1}$ & $\underline{A-2}$ & B-1 & $\underline{B-i}$ \\
\hline $\begin{array}{l}\text { Composite Transmission } \\
\text { Corridor Score }\end{array}$ & 193 & 166 & 184 & \\
\hline $\begin{array}{l}\text { Composite Generation } \\
\text { Plant Score }\end{array}$ & 204 & 179 & & \\
\hline Total Composite Score & 397 & 345 & 379 & \\
\hline
\end{tabular}

The technical quantification of two criteria - aesthetic and economics - is discussed is Chapers $V$ and VI respectively. Chapter V adapts the methodology developed in the Siting Study for quantification of the aesthetic impact of nuclear power plants to transmission lines. Chapter VI discusses the impact of transmission lines on property values. This is the indirect component of the economics criterion. The direct component is the actual cost of construction and acquisition of easements. 


\section{I. REVIEW OF THE STATE-OF-THE-ART OF TRANSMISSION LINE ROUTINE}

This chapter reviews the state-of-the-art of transmission line routing. The various techniques and their strengths and weaknesses are described in the following sections.

- Present capabilities for measuring and predicting transmission line impacts.

- Requirements for improvement of impact prediction capabilities.

\section{A. PRESENT CAPABILITIES FOR MEASURING AND PREDICTING TRANSMISSION LINE} IMPACTS

In the past, sound engineering and economic considerations guided the location of transmission systems in much the same mariner as they guided the construction of highways, dams and other civil engineering works. Suggested design guidelines and performance standards for transmission line routing were not formally proposed until $1966^{(1)}$ and have only recently been officially adopted for use by regulating agencies and utilities. $(2,3,4,5)$ Although these guidelines and standards are a necessary requirement in the development of environmentally responsive transmission route planning, they do not immediately suggest a systematic planning approach that allows for their direct application to corridor or route selection of least envirormental impact; nor are they particularly useful in documenting the decision-making process. With the growing recognition of environment-related problems and in response to mandates to identify the environmental impacts of their proposed actions, regulating agencies and utility companies have retained landscape architects and environmental planners to help develop comprehensive planning methodologies. These methodologies incorporate natural and cultural resource inventories and analyses as well as guidelines and standards, engineering and economic concerns into the facility-siting process. A resultant increase in the complexity of factors to be considered, along with the need to publicly document and defend planning decisions based on minimizing environmental impact, has required that the planning process 
provide new tools for spatially displaying environmentally sensitive zones of the landscape and for comparing and quantifying the relative importance of the interrelationships between various environmental criteria. Hence "intuitive" (or rather undocumented) decision making and planning have given way to the use of hand-drawn overlay maps and in many instances to the use of digital computers for constraint mapping and the rapid manipulation of environmental data.

Hand-drawn overlay maps have been found to be a direct way to display various environmental factors and are less expensive to produce than computerized mapping when the study area is small and few intricate correlations of data are required. The use of digital computers has proven to be valuable when the study area is large and complex and a number of intricate correlations of data are required, such as the testing of various planning strategies and impact identification of a number of alternate routes. A1though computer methods require extensive digitizing of data, they have the advantage of being able to rapidly and accurately generate new information through manipulation of base data to conveniently allow for the updating of data, and to be useful in establishing a data bank for a given territory. ${ }^{(6)}$ Both methods have been proposed for use by studies reviewed for this report. References $6,7,8,9,10,11$ and 12 discuss or apply computerized methods, while References 13,14, 15, 16 and 17 deal with hand-drawn overlay mapping studies or their components. Reference 18 utilizes a hybrid of the two methods, mapping information at the same scale for comparison and display, but using a computer program to help quantify the impacts of various transmission route segments.

The transmission corridor and route selection studies reviewed all tend to operate within a similar planning framework:

1. Determine the geographic boundaries of the study area:

2. Select mapping and data-handling techniques.

3. Enumerate and map natural and cultural baseline data.

4. Formulate desirable location strategies and map areas of environmental constraint to these strategies by combining baseline data. 
5. Rate the relative importance of each constraint in order of sensitivity to modification and combine constraint maps into a composite suitability map.

6. Identify alternative transmission routes following paths of highest suitability (least overall constraint).

7. Field check alternate routes and select those appropriate for further study.

8. Undertake detailed studies of potentially suitable routes and develop special recommendations for areas where highly sensitive areas would be crossed.

9. Make final route decisions and recommendations.

10. Prepare environmental impact statement and present information to appropriate agencies and the public.

Items 3 through 6 represent planning procedures which have gained emphasis in the more recent transmission-planning methodologies; previously, these steps were generally done in a less systematic, less permanent and less visible form that relied heavily on the individual planner's knowledge, judgment and experience. Overlay mapping and computer techniques have made it possible to select and portray the routes of least environmental impact and to defend the selection before public hearings and regulatory agencies. Step 3 requires the collection of baseline natural and cultural data and mapping the information at the same scale. Examples of the types of natural data that have been considered include:

- Depth to bedrock

- Depth to underground water table

- Steepness of slope

- Topographic features

- Natural features of interest

- Surface drainage pattern

- Flood plains

- Lakes, bays and wetlands 
- Areas of soil instability

- Age, size, density and dominant seasonal color of vegetation

- Exposed soil/vegetation color contrast

- Vegetative restoration potential

- Forestry productivity

- Agricultural productivity

- Wildlife habitat.

Cultural data have included such considerations as:

- Residential areas

- Commercial areas

- Industrial areas

- Public and quasi-public areas

- Cultivated Tands

- Recreational areas and parks

- Cemeteries

- Open space

- Roads, railroads and airports

- Historic and archeologic sites

- Special places of interest

- Underground and overhead utilities

- Scenic roads and overlooks

- Land value

- Land ownership

- Population density per square mile.

In many instances, both existing and proposed (planned) land uses are considered.

In step 4 location strategies are formulated based upon idealized goals of the chosen transmission route. Strategies for computerized transmission planning techniques may be quite specific in detail and intent; the studies of the type reviewed $(6,7,9,14,16,19)$ included one or more of the following strategies or goals: 
- Minimization of disruption to existing urban areas and human settlement

- Minimization of disruption to agricultural lands

- Minimization of disruption to recreational/historic lands

- Minimization of disruption to natural ecosystems

- Maximization of utilization of right-of-way

- Minimization of visual impact

- Minimization of financial investment

- Minimization of disruption of forested lands

- Minimization of impact upon projected areas of human settlement

- Maximization of system reliability

- Maximization of system accessibility

- Minimization of disruption to extractive and starage resources. (10)

The baseline data which would prevent realization of each strategy are assembled, combined, weighted and mapped as areas of constraints to the location and siting of transmission facilities in view of each individual strategy.

In step 5, weights are assigned to the relative importance of each constraint based on the relative sensitivity of each to modification, and a final suitability map is produced. The computer is particularly well suited to testing various weighting decisions. It quickly maps alternative suitability maps if there is disagreement on which weighting factors are appropriate.

Step 6 involves locating the paths of least-combined constraint (or highest suitability) for transmission structures. Typically, this involves tracing various paths along the map through areas shaded from black (highly unsuitable) through grey to white (highly suitable); very often a route or corridor will cross an area of high sensitivity and these zones of high impact may be selected for further detailed study.

Computer methods facilitate data conversion into environmental impact statements, since they allow a great variety of data, weighting factors and sensitivity indices to be assembled along a given route or corridor. Since 
computerized information is typically applied at a regional or subregional scale, however, it must usually be supplemented with overlay mapping techniques and more detailed studies to make final transmission centerline location and design decisions.

\section{B. REQUIREMENTS FOR IMPROVEMENT OF IMPACT PREDICTION CAPABILITIES}

The art of transmission line routing appears to be more comprehensive, more sophisticated, more highly developed and applied more consistently across the country than resource inventory and analysis of any other singular type of man's development activities. However, there remain gaps and shortcomings which require additional research and testing to improve upon present planning techniques and impact prediction capabilities. While there are many potential areas for improvement, four major interrelated concerns will be discussed:

1. Public Participation

2. Ease of Communicating the Planning Process

3. Quantitative Scaling of Impacts

4. Minimization of Compounded Impacts in the Future

\section{Public Participation}

1966: "Confident of their firmly established, high priority role in society, their engineers armed with clear and convincing statistics in demand and supply, the power suppliers have forced their rights-of-way onto the landscape. The undeniable need for electricity imposes its strong and assertive towers upon the otherwise quiet and pastoral farmlands, the open plains and dense forests. City and industry cry for power. Natural landscape, the food for poets, lies accepting in the background." $(1, p .36)$

1973: "Unless the American people unite to put enough pressure on electric utility companies to bury their lines, the investment in these monstrous overhead lines will have progressed so far that it will be impossible to arrest their march across our land." $(20, p .14)$

Written seven years apart by different authors, these two battle cries carry with them an underlying feeling of frustration, helplessness and perhaps resentment that the public plays virtually no direct role in transmission line routing selection. A public poll taken in 1973 revealed that a substantial majority of people feel that the decision makers of electric 
companies should listen to their customers' attitudes, but slightly less than half believe that electric companies would actually consider their feelings if they made them known. (21) A time period is provided for review and public response to a transmission line location proposal as a normal part of the environmental impact statement filing process, and public hearings may be held. However, public participation at this stage is apt to be comprised of a vocal minority of landowners whose property is directly affected by the proposal rather than of a group of citizens whose environment will be impacted in a slightly less direct manner but whose concerns should be known. In fact, only one of the nine major studies reviewed actually utilized public participation as a major input to the plarining process. Ontario Hydro $(16,17)$ uses a questionnaire to determine local attitudes and identify sensitive zones of the landscape as seen through the eyes of the local resident population. (See Chapter $V$ for further discussion of this technique.)

Several of the studies reviewed depend on interdisciplinary teams which represent "expert" opinions and judgments to apply weighting factors and identify potential problem areas; nonetheless, it is often difficult for trained staff to determine the weighting factors which serve the best interests of the public, particularly in the highly complex issues faced during the transmission route planning process. If the public cannot be directly involved in the planning process, the process should at least respond to knowledge of information generated from studies of user preference and public values. Chapter IV of this report proposes a method to measure social values associated with transmission line routing, while Chapter $V$ and Appendix $B$ pertain to the quantitative measurement of aesthetic impacts based on public response testing. Impact prediction is meaningless until it becomes truly responsive to the attitudes and opinions of the public whose interests the predictions are attempting to serve and protect.

Ease of Communicating the Planning Process

Transmission line route selection requires the consideration, analysis and evaluation of many types of data (See Chapter III.A.). The 
complexity of the problem has necessarily required a fairly complex planning procedure. There is perhaps a tendency toward obscuring the clarity of baseline data as higher levels of data compilation and abstraction are reached, first in the preparation of constraint maps and ultimately in the weighting of constraint maps and production of the final suitability map. This apparent obscuring of data is somewhat less pronounced in the overlay mapping methods than in the computerized mapping process, in which the progression from baseline data to constraint map to suitability map may be less easily perceived by the untrained observer. In addition to the aura of "mystery" that the computer may hold to some observers and since computers are excellent devices for manipulating a large number of factors, their use sometimes may result in a loss of clarity of the specific "reasons" for the final configuration and shading of the suitability map. Hence it is important to clearly outline the planning procedure in a manner that may be grasped by those concerned. It is also important to trace the potential corridors selected back onto constraint maps and baseline data maps so that one may specifically identify the high-impact problems encountered at each zone of conflict. Chapter $V$ illustrates this procedure as used in the evaluation of specific areas of high visual impact.

\section{Quantitative Scaling of Impacts}

"Changes or impacts should be measured against an established reference point so that the value assigned to one impact can be compared with the value assigned another impact." (22, p. 42)

Quantification of impact is a difficult issue, for true environmental impact quantification must deal with changes in both the quantity and quality of a given resource, the significance of changes in one resource relative to changes in other resources, and the significance of the collective environmental changes related to the baseline conditions of the overall environment. True quantification of environmental impacts in this manner is rarely (if ever) achieved in a completely satisfactory way, and in fact many environmental impact statements fall short of even the most basic of these levels, i.e., the establishment of a qualitative or quantitative reference point within each resource parameter under investigation. 
It is vitally important that a scale of quantitative or qualitative reference be established within each of the major environmental parameters considered (such as economics, water quality, air quality, ecology, cultural/recreational, health/safety, and aesthetics). Until the spectrum of quality and quantity is identified within each parameter it is exceedingly difficult for "experts" or the public to assign weighting factors which determine the value of each parameter in relation to all others. This may easily be accomplished by establishing a scale which compares the baseline conditions ("before") with the postaction conditions ("after"); the difference in the position of "before" and "after" on the scale represents the impact."

It is also important to respond to and record the significance of the resource (as well as its quantity and/or quality) relative to a broader frame of reference. A resource's relative scarcity or its key position in the larger economic, ecologic, historic or cultural scheme may well give it a value disproportionate to its magnitude or quality. "Significance" in this sense can only truly be interpreted by measuring public values and comparing the results with those obtained from a group of "experts" or members of special-competence groups. Chapter IV describes a technique for measuring social values to aid in the scaling of impacts.

Minimization of Compounded Impacts in the Future

"It is conservatively estimated that in the next ten years one hundred thousand miles of new transmission lines will be built in the United States - a hundred thousand miles of heavy metal conductors and 12story high skeletons whose stark shapes will be silhouetted against forested mountainsides and fertile farmlands. Each mile of right-ofway passing through a densely wooded area requires the sacrifice of about ten thousand trees.... A hundred thousand miles of right-of-way is comparable to crisscrossing back and forth 30 times from coast to coast. In the 1980's another hundred thousand miles will be constructed and in the 1990's another.... Slowly but inexorably, these harsh steel structures are replacing the delicately interwoven pattern of the living forests. And, like giant robots reproducing themselves, they are creating the forests of the future." $(20, p .11)$

${ }^{a}$ See Chapter $V$ for the 100 -point visual quality rating scale suggested and methods for expressing the ratio of change in visual quality. 
The 1973 poll mentioned earlier found that only $30 \%$ of the public is presently aware of transmission structures in their area, and that the public is not well aware that more transmission lines will be needed in the next ten years; $43 \%$ of those interviewed thought that "just a few" more will be constructed, $18 \%$ thought that none will be needed, $17 \%$ said "a great many," and 23\% didn't know. (21) The broad gap between the planning forecast and public awareness indicates that the future impacts of population growth, industrial and urban expansion, and power generation and distribution technology and planning problems are not responsibly being identified and communicated to the consumer-at-large. Transmission line planning forecasts tend to be projected no further than 10 to 15 years into the future. The lack of a comprehensive overview or master plan for the energy distribution system promises right-of-way and line intersection congestion and a widespread need for new transmission corridors with wider rights-of-way for larger tower structures carrying lines of higher voltages across increasingly developed and densely populated lands. Although underground transmission will probably begin to replace overhead lines in certain critical locations, the majority of new transmission lines to be constructed by 1990 will in all probability be strung overhead. This is due to technological problems and the high cost of undergrounding.

Environmental impact prediction capabilities can be no more accurate or specific than the transmission systems for which they are intended to measure. If an energy distribution master plan is not drawn up to coordinate and guide the considerations for long-term or ultimate transmission system development, environmental impact statements can only address shortterm impacts and will become outdated even sooner than the lines which they evaluate. Moreover, future impacts will be severely compounded from lack of early identification. If the unknowns regarding future energy system options and policies are not identified and their considerations included in the everyday transmission route planning process, the impending energy crisis will exhibit all of the characteristic features and problems of misplanning: too little/too soon/too much/too late. 


\section{REFERENCES}

1. Stanton, Boles, Maguire and Church, A Report on Appearance Planning for BPA, Portland, Oregon, 1966.

2. Johnson, Johnson and Roy, Inc., Transmission and Distribution Rightsof-Way Selection and Development, Consumers Power Company, Jackson, Michigan, 1970.

3. U. S. Federal Power Commission, Guidelines for the Protection of Natural, Historic, Scenic, and Recreation Values in the Design and Location of Rights-of-Way and Transmission Facilities, Appendix A, 1970.

4. New York State Department of Environmental Conservation, Environmental Guideline for Electric Transmission Lines (Above Ground) Ābany, New York, October 1973.

5. U.S. Department of Interior, Environmental Criteria for Electric Transmission Systems, U.S. Government Printing Office, Washington D.C., 1970.

6. Eckbo, Dean, Austin and Williams, Proposed Transmission Line Routing, Pacific Gas and Electric Company, San Francisco, 1971.

7. Harold P. Hulett, "Transthetics," Journal of the Power Division, Proceedings of the American Society of Civil Engineers, Vol. 98, No. P01, pp 103-116, June 1972.

8. Harold P. Hulett and Arnold D. Poppens, "Transthetics: Environmental Transmission - Line Routing, "Proceedings of the American Power Conference, Vol. 35, pp 1255-1259, 1973.

9. Landscapes, Limited, EDAP: Environmental Decision Alignment Process, Madison Gas and Electric Company and Wiscons in Power and Light Company, Madison, Wisconsin, Undated.

10. Landscapes, Limited, PERMITS Methodology: Process of Energy Routing to Minimize Impact from Transmission Systems, Borineville Power Administration.

11. Bernard J. Niemann, Jr. and Bruce H. Murray, "T LMELES: Transmission Implementation and Management of Environmental Location of Energy Systems," Article, Undated.

12. Herbert R. Schaal, "Constraint Maps - The Newest Tool in R/W Selection," Transmission Distribution, April 1972. 
REFERENCES (cont.)

13. B. Christian, "Visual Impact-Interim Report, Port Arthur GS and R.0.W. Study," Forestry Department, Ontario Hydro, Toronto, January 1974.

14. Eckbo, Dean, Austin and Williams, Environmental Transmission Routing Study, Border Field to Miguel Substation, San Diego Gas and Electric Company, San Francisco, January 1974.

15. F. T. Podealuk, "Visual Impact Assessment for the Proposed $115 \mathrm{KV}$ Marathon to White River Right-of-Way, "Forestry Department, Ontario Hydro, Toronto, May 1974.

16. Alan V. Vaughan, A Background Paper Prepared for the Workshop on Visual Impact, Forestry Department, Ontario Hydro, Toronto, Undated.

17. Alan V. Vaughan, A Visual Analys is System to Assist in Locating Transmission Corridors, Forestry Department, Ontario Hydro, Toronto, January 1974.

18. Wirth Associates, A.P.S. $345 \mathrm{KV}$ Transmission Location and Impact Evaluation, Cholla to Saguaro, Arizona Public Service Company, Phoenix, Arizona, Phase II Report, 1973.

19. Carl N. Peters, "Methodology Development for Transmission Line Route Selection," Proceedings of the American Power Conference, Vo1. 35, pp 1260-1267, 1973.

20. Louise B. Young, "Forests of the Future," Sierra Club Bulletin. Vol. 58, No. 8, pp 11-14+, September 1973.

21. Joe C. Pohiman, "What is the Public's Opinion on Transmission Towers and Poles?" Electric Light and Power, T/D Edition, pp 59-61, Apri1 1973.

22. Marilyn D. Bagley, Cynthia A. Kroll and Kristin Clark, Aesthetics in Environmental Planning, Stanford Research Institute, Environmental Protection Agency Report No.EPA-600/5-73-009, Washington, D.C., November 1973. 


\section{MEASUREMENT OF SOCIAL VALUES}

The justification for obtaining estimates of the importance which the public attaches to transmission line routing criteria is that such a procedure allows for social values to be represented in routing decisions. Decisions which require, for example, a balancing of concern for preservation of aesthetic qualities in the environment with concern for economic contraints should reflect the values held by the public ultimately affected by these decisions.

\section{A. PUBLIC PARTICIPATION IN DECISION MAKING}

Several issues are involved in public involvement or participation in decision making. A first question is, "Why should the public be involved in decision making, particularly when the topic under consideration concerns issues of a complex and technical nature?" Carrol1, ${ }^{(1)}$ in discussing technology assessment, suggests that public input is important both for practical and for more philosophical reasons:

...technology assessment has a dimension beyond the identification and analys is of the impacts of technology. This is the dimension of evaluation of the social desirability of such impacts...

and ...extensive citizen participation and representation in the assessment process are necessary both for practical reasons and for reasons of democratic theory. There are two practical reasons. First, citizen participation in the early stages of the development of a technology may help to avoid belated citizen opposition to a technological development after heavy costs have been incurred. Second, "objective evaluation" is impossible unless the diverse views of interested parties have been considered. On the level of political theory...it is necessary to consider the views of those who will be affected by a particular course of action. 
A second issue concerns the kind of public involvement which may be most useful both to the planner or decision maker and ultimately to the community affected by the decision. This issue concerns the amount of decision-making power or control which is relinquished to the public. In some instances, a high level of public participation and decision-making power may be desirable. Some of the Great Society programs during President Johnson's administration, e.g., Federal housing and anti-poverty programs, were originally designed to incorporate the "maximum participation feasible" of those groups who would be directly affected by the outcomes of these projects. At the other end of a participation continuum, highly technical and complex problems may warrant relatively little direct public participation. In dealing with questions of a highly complex nature, some intermediate level of public involvement in decision making may be more feasible. Such an intermediate level of citizen participation is described as "consultation" by Arnstein. (2) At this level, attitudes and opinion are solicited from members of the public who will be affected by the outcomes of decisions. Data obtained can then be used by planners in evaluating decision al ternatives.

Another issue concerns the timing of public involvement in the planning or decision-making process. Obviously, public values and attitudes can be incorporated at various points in time. From the perspective of an administrator or decision maker, early input probably is preferable to later input (which sometimes takes the form of intervention). The procedures outlined in Chapter IV.C would be classified as one way of obtaining input early in the planning and decision-making process. Measurements would be made of the values or levels of priority which people assign to various environmental impacts created by transmission lines. Such measurements would furnish planners with information which could then be used in evaluating various routing al ternatives.

A final consideration in public involvement in decision making concerns the problem of obtaining judgments from informed respondents. In the case of a technological environmental issue such as the routing of transmission lines, it is unlikely that the general public is sufficiently 
knowledgeable about specific effects of transmission line routing to make well-informed judgments. One alternative in dealing with this problem is simply to ask for general attitudes and opinions, recognizing that the results obtained may be useful only as indices of rather vague feelings or reactions. Another approach is to communicate a body of information to respondents about the topic of interest and have them react to the topic. This method has the advantage of equalizing the leve 1 of awareness in the group of respondents who are polled; a potential disadvantage of this procedure is that the responses obtained may be largely influenced by the body of information which is communicated. The proposed methodology for studying values associated with transmission line routing assumes that information should be communicated to respondents prior to eliciting their judgments. How best to communicate such information is discussed in several sections which follow.

\section{B. SELECTION OF RESPONDENTS}

Questions concerning sampling strategies involve a set of trade-offs between 1) optimum sampling and 2) the extent to which complex questions or judgment tasks are required of the respondent. Sampling to obtain results which stand the greatest chance of generalizing to a larger population usually involves some type of random or representative sampling pro-

cedure. Sample surveys, ${ }^{(3)}$ including public opinion polling, usually require the respondent to deal with relatively few stimuli. For example, questions in public opinion polling are generally of the form, "For which candidate would you vote?" When more complex judgment tasks must be presented to the respondent, random sampling is less feasible. In such cases, more time is required of each respondent in order to present complex and perhaps unfamiliar information. Logistical and technical problems, coupled with the greater demand placed on the respondent's time, greatly reduce the feasibility of selecting respondents on a random basis. The research strategy proposed for studying values associated with transmission lines involves: 1) communicating information to respondents and 2) eliciting 
judgments from them concerning this information. In this respect, the method would tend to fall in the category of complex judgment tasks.

A mode1 developed by Craik ${ }^{(4)}$ for studying the comprehension of physical environments furnishes a framework for considering the problem of respondent selection and other issues which are relevant to this planning study. Table 3 presents an adaptation of Craik's model by Zube, et al. (5) The four categories presented in this model can be used to consider alternative study designs. Specifically, the model suggests approaches for selection of respondents (Observers), methods of communicating information to respondents (Media of Presentation), methods for eliciting responses (Format of Responses), and selection of stimuli to present (Environmental Dimensions). Review of the observer category suggests that a broad spectrum of respondents should be included in a study of responses to transmission line impacts. Enlarging somewhat on the observer list on Table 3, the selection process should include a number of groups characterized by: special interest (e.g., environmenta 1 interest groups); occupation (e.g., environmental planners); and demography (e.g., groups of individuals living in view of transmission lines versus individuals suspected to have little visual contact with lines); etc. Careful selection of several groups of respondents from varied backgrounds, interests, and demographic characteristics would provide a satisfactory alternative to random sampling procedures. This selection procedure would also permit exploration of value differences based on group membership.

\section{SELECTION OF CRITERIA FOR EVALUATING TRANSMISSION LINE IMPACTS}

A fundamental question underlying the selection of criteria is whether the criteria we think are important in describing transmission line impacts are in fact the dimensions people actually use in responding to or evaluating transmission line routes. For example, the diverse and lengthy lists of criteria to which the preparers of environmental impact statements address themselves may suffice in accounting physically for most of the effects caused by construction and operation of the proposed facility. 
TABLE 3. A Model for Studying the Comprehension of Environments

Observers
Special competence groups
architects
geographers
planners and designers
real estate appraisers
building and "space"
managers
interior decorators
landscape artists
and painters
natural resources
managers
Special user-client groups
elderly persons
migrant workers
college students
wilderness area
campers
flood plain dwellers
Groups formed on the
basis of relevant
personality measures
Everyman, to general
public

Media of Presentation

Direct presentation

looking at

walking around and through

aerial views

Tiving in

Representation

sketches, drawings, maps

models, replicas

photography

cinema

television

Imaginal presentation
Formats of Responses Descriptive reponses

free

standardized

ratings

adjective checklists

mood and activity checklists

Q-sort checks

Global responses

thematic potential analysis

empathic

interpretation

symbolic and

multisensory

equivalence

graphic presention

Inferential responses

Attitudinal responses

Preferential responses
Environmental Dimensions

Taxonomy of everyday language

Objective physical and geographic measures

Sequential notational

systems

Modal behavioral

attributes

descriptive assessments

evaluative assessments

predictive assessments

From Craik (1968) adapted by Zube, et al., (1974) 
Whether this same list of criteria will adequately characterize the psychological dimensions people actually use when they think about the facility is another matter. The problem is one of whether the categories, criteria, or attributes used by the researcher or decision maker to describe some objects are in fact the same ones used by the person asked (perhaps for the first time) to respond to the object.

Various methods for selecting transmission 1 ine routes such as those by Peters, ${ }^{(7)}$ Voytko, ${ }^{(8)}$ and Hulett and Poppens ${ }^{(9)}$ show a high degree of similarity in the major categories and subcategories used to evaluate transmission line routing. Consideration of the criteria used in the Siting Study suggests that the same categories may suffice for measurement of public values toward transmission lines. Eight criteria were initially selected in the Siting Study as being significant considerations in the analysis of nuclear plant siting options: economics, water quality, air quality, animal/plant, cultural/recreational, health/safety, aesthetic and land use. Examination of environmental impact statements for proposed transmission lines showed that the land use impact of a potential plant was captured by the other seven criteria; consequently, land use was eliminated from the list of criteria.

General descriptions of the impacts of overhead transmission lines for each of the seven remaining criteria are included in Appendix $C$. The descriptive material is general in nature and would need to be adapted for specific transmission route alternatives prior to actual measurement of criteria weighting factors. Additional information would also be needed if underground lines were under consideration. This study is primarily concerned with electric power transmission lines rather than distribution lines. At the present time, nearly all underground lines are lower voltage distribution lines.

A basic difficulty in the Siting Study was the problem experienced by the public respondents in distinguishing the criteria. The criteria tended to overlap in the minds of the respondents and consequently interpretation of their weighting factors was clouded. One possible way to alleviate this difficulty is to provide more detailed descriptive information of the 
impact of the criteria, such as included in Appendix $C$. The danger of providing too detailed information is that it will be beyond the grasp of the respondents.

It is likely that the criteria which will have the greatest differential impact for alternative transmission 1 ine routes are economics and aesthetics. These criteria would, therefore, be expected to have a significant influence in the selection of the most desirable route. Other criteria might have equally large weighting factors but be relatively constant for all alternatives.

Final selection of criteria to use in the study of values associated with transmission lines should be based on: 1) ability of criteria to encompass most of the effects created by a transmission line in any given location, 2) ability of criteria to reflect differences between different locations of transmission lines, and 3) psychological meaningfulness of criteria to respondents.

The seven criteria above were selected without public participation. There are at least two ways of incorporating public respondents into the selection of criteria. One is to ask respondents directly what criteria are important. This procedure is used by Nieman and Murray $(11)$ in their method for planning transmission line routing systems. Individuals, groups, and agencies are asked to mention the aspects they feel are important in transmission alignment. Twelve categories are defined :

- Route of least disruption to existing urbanized land use settlements

- Route of least disruption to agricultural land use practices

- Route of least disruption to natural systems

- Route of least visual impact

- Route of least disruption to recreationar land use

- Route of maximum utilization of rights-of-way

- Route of least financial investment

- Route of least impact on projected human settlement

- Route of greatest system reliability

- Route of greatest accessibility

- Route of least disruption to extractive and storage resources

- Route of least disruption to forestry practices 
These categories bear some resemblance to the major criteria used in environmental impact statements, e.g., emphasis on land use issues. This approach is based on inputs from sources who probably have a good understanding of transmission 1 ine routing problems. However, a different list might be generated if the general population were polled. This approach illustrates an attempt to use categories reflecting respondents' thinking rather than imposing a preselected set of criteria upon them.

A second approach of identifying criteria which are meaningful to respondents is a psychological measurement method, multidimensional scaling (MDS). (12) MDS is useful in two situations: first, when the researcher does not know the criteria or dimensions people employ in responding to a set of stimuli and when the objective of the research is to determine the relevant dimensions; second, when the investigator knows (or thinks he knows) what the major psychological dimensions are but is not sure how people think about those dimensions. Problems faced in the study of transmission line routing may represent a blend of both of these situations. MDS is a procedure in which respondents judge the degree of similarity of several pairs of stimuli (for example, photographs of transmission line viewscapes). No attempt is made to suggest how or on what basis the person is to judge the similarity or difference of these pairs. In effect, the person uses whatever "criteria" seem important to him. Data reduction techniques are used to analyze a number of similarity judgments and the results are interpreted to identify those dimensions or criteria which were actually considered by the respondent. The main point is that no attempt is made to influence the respondents' choice of evaluative criteria; the criteria used are respondent generated.

Applying this procedure to the transmission line routing problem, pairs of photographs of transmission lines, accompanied by a general discussion of the impacts (but not a categories list of impacts as in the 
Siting Study), could be presented to respondents. Analysis of similarity judgments should reveal which photograph tended to be dismissed from consideration.

The main point of the above discussion is that careful consideration should be given to the question of selecting the criteria for which estimates of public values or importance will be obtained. A preliminary stage in the actual research would involve a pilot test to identify these criteria. Agreement on criteria is of methodological significance; in a broader sense, this issue may also help explain some of the difficulties encountered when "technocrats" attempt to communicate complex or technical information to the general public.

\section{SELECTION OF STIMULI}

The problem of conveying information about transmission lines to respondents can be divided into two related questions: 1) What kind of stimuli to present, and 2) how to present them.

Selection of stimuli to depict the impact of transmission lines involves an initial choice between two general alternatives: Presentation of entire transmission line routing systems or presentation of several discrete segments of transmission lines. The second alternative would involve choosing representative examples of static viewscapes showing the impact of transmission lines upon these viewscapes.

A consideration of the problems involved in presenting several entire transmission line corridors to respondents and obtaining meaningful judgments with respect to the criteria of interest suggests that this approach would constitute an unwieldy and overly complex task. The proposed method therefore is to select representative samples of static viewscapes showing - the impacts of transmission 1 ines upon these viewscapes.

The model presented in Table 3 deals with the second question posed above, choice of media of presentation. Alternative methods would include on-site viewing of transmission lines and various representations of transmission lines, such as motion pictures or photographs. In view of the 
likely logistical problems involved in transporting large numbers of respondents to transmission 1 ine corridors, some type of representation of transmission lines would be more feasible. Several researchers have considered whether photographs or slides would serve as adequate proxy for field observations. $(13-15)$ The results indicate that carefully prepared color photographs or slides taken with wide angle to normal lenses will accurately portray actual landscapes.

Prior to conducting the actual study, a sample of photographs should be validated against the sites depicted by the photographs. (16) Photographs would be validated by asking a group of respondents to make several evaluative judgments (e.g., scenic quality) of: 1) photographs of transmission lines in several locations and 2) the actual transmission lines shown in the photographs. Comparison of the judgments made to the photographs and to the actual transmission lines would indicate the extent to which the photographs portrayed the actual scenes.

Sites to be presented to respondents would be selected on the basis of 1) transmission line-landscape scenes which are representative of those likely to be viewed by the public, 2) capacity of the sites to reflect differences among the criteria of interest, such as high and low aesthetic impacts and optimum versus suboptimum land use, and 3) areas of particularly significant impact.

In summary, color photographs of "before" and "after" landscape scenes would be used to depict the aesthetic impact of transmission lines. A written description would accompany each photograph, depicting all criteria of interest.

\section{E. MEASUREMENT TECHNIQUES}

A number of approaches could be used to obtain weights or importance estimates which respondents attach to the transmission line criteria. Three alternatives will be briefly described and recommendations will be made.

The first approach is to simply list and describe the criteria to respondents and ask that judgments be made of the relative importance or 
weight which should be given to each criterion. This method, which might be labelled the "direct approach," may have merit for the proposed study, but reviews of literature dealing with the measurement of "importance" $17-18)$ suggest that attitudes or values regarding importance are cognitively complex and difficult to measure directly. The measurement operation itself is quite simple; however, it demands that respondents make very complex judgments. Results from this approach have generally been disappointing.

A second approach involves the indirect measurement of importance using multiple regression analysis. Multiple regression analys is, which could be labelled the "indirect approach" for obtaining importance estimates, was employed in the Siting Study mentioned earlier. A review of the procedures used in that Study will illustrate how it could be used in a study of transmission lines. In the Siting Study, respondents first rated the "acceptability" of a power plant's impact on eight aspects of the environment (e.g., aesthetics, air quality). Respondents then rated the "overall acceptability" of a power plant. Regression analysis, which took into account both 1) the correlation between each environmental impact category rating and the overall rating and 2) the degree to which the eight impact categories were related to each other, produced regression weights which represented to some degree the "importance" of each impact category in influencing the overall judgment of acceptability.

If the criteria used to predict some global or overall rating such as overall acceptability of a power plant are independent of one another, both in the physical world and in the mind of the respondent, then the regression weights obtained will reflect the importance of each criterion. Interpretation of regression weights for the criteria becomes more difficult, however, if the criteria are related to or overlap one another. For example, if criteria such as aesthetics and air quality are related to one another either conceptually or in the mind of the respondent, the regression weights will reflect this relatedness. In the example described, aesthetic considerations might receive a larger importance weight than air quality impacts if the respondent regarded air quality impacts as simply one aspect of aesthetic issues. Kaplan's $(19)$ argunent for identifying 
relevant psychological dimensions also deals with the issue of indirect measurement of importance.

In the Siting Study, the regression weights obtained were based on groups of respondents. Three separate groups of respondents participated in that Study, and the analyses performed resulted in a set of regression weights for each group.

The third approach to be described for obtaining importance estimates is a variation of the procedure described above. Multiple regression analysis is used, but the focus is upon the individual's weights or importance estimates rather than upon group weights. This technique has been used to study the way people make decisions and particularly the strategies or "policies" a person uses in arriving at a particular decision. It has been referred to as a "policy-capturing mode1."(20) This approach differs from the Siting Study procedure in two ways: 1) regression weights are calculated for individuals rather than for groups; and 2) the respondent makes only one overall rating of the material (e.g., transmission line viewscape) and need not rate the various criteria such as aesthetics and air quality.

Application of the "policy-capturing" model to the study of transmission line routing criteria would involve the following steps: 1) A set of "before" and "after" viewscape photographs would be assembled showing the visual impact of transmission lines, accompanied by a general description of the various positive and negative environmental impacts to be expected; 2) each photograph and accompanying description would be examined by a panel of individuals with technical knowledge of the various environmental impacts (e.g., aesthetics-landscape architects; economicseconomists). Each pair of photographs and descriptions would be evaluated by the pane1, judgments would be made about the impact of the transmission line on that location, and a set of numbers would be assigned describing the transmission line impact in terms of each criterion of interest; and 3 ) the set of photographs and accompanying descriptions would then be presented to respondents who would be asked to view, read, and evaluate each stimulus and make a single rating of the overall acceptability of a transmission line in each location. Regression analyses would be 
computed for each individual across all sets of photographs/descriptions. The preassigned values for each category of environmental impact would be used as predictors of the respondents' acceptability judgments for the set of photographs/descriptions. The results for each study participant would be a set of weights describing how much influence each of the underlying criteria (which had been rated by the expert panel) had in affecting his global ratings of acceptability for the entire set of photographs/ descriptions.

A final step in applying the policy-capturing procedure to the study of transmission lines would involve grouping or clustering individuals together based on similarity of their patterns of regression weights attached to each criterion. This clustering procedure would allow for an identification in the general population of the major "weighting systems" used in reacting to transmission 1 ines. For example, it might be found that in the total sample of respondents, there were perhaps two or three main patterns of weights. Analys is of the characteristics of people in each of these major patterns might suggest why people react as they do toward transmission lines. One pattern of importance weights might characterize a set of highly educated, environmentally concerned individuals while another set might represent a group of urban dwellers who rarely view transmission lines in pristine locations. To summarize, a grouping procedure would be used to gain a better understanding of why certain aspects of transmission 1 ine routing are important.

A variation of the policy-capturing approach was used by Shafer, Hamilton, and Schmidt ${ }^{(21)}$ in a study of the landscape variables which affected overall preferences of the public for those landscapes. Landscape photographs were judged by technical experts who rated each photograph with respect to 46 characteristics. Respondents were asked to express their preferences for sets of these photographs. The preassigned scores from the 46 characteristics were used in multiple regression analysis to predict overal1 landscape preference.

In summary, three approaches for obtaining importance estimates were reviewed. The direct approach is relatively easy to apply, but the results obtained from this method are much more difficult to substantiate. 
Two approaches involving multiple regression analysis were described, the approach used in the Siting Study and the Policy Capturing Model. The procedure used in Siting Study presents respondents with the list of criteria as well as information describing these criteria. The respondent is asked to judge the acceptability of each criterion and also rate the overall acceptability of the transmission line location. Analyses to obtain multiple regression weights for the criteria are conducted on groups of respondents. The policy-capturing method presents information about the criteria (without necessarily making these criteria explicit to the respondent) and would require that the respondent make one global judgment concerning the acceptability of a transmission line in a given location. Analyses are conducted on individuals and the weights which are obtained describe the importance estimates for that individual.

In a study of the values attached to transmission line impacts, the proposed approach would involve applying both the policy-capturing model and a direct measurement approach for obtaining importance estimates. The policy-capturing model would be used for the following reasons: 1) relative ease of administration, since respondent would be required to make fewer responses; 2) greater flexibility in analysis and interpretation of results since the focal point could be either the individual (whose pattern of weight could be clustered with other similar patterns to identify major "weighting systems") or upon the intact groups as originally sampled. In spite of the limitations inherent in the direct approach, it is a relatively simple procedure to use and requires little additional time of the respondent. In the direct approach, the criteria of interest to the researcher and decision maker would be described to respondents and they would be asked to judge the relative importance of each criterion using ranking or rating procedures.

\section{F. LIMITATIONS}

A method has been described for obtaining estimates of societal values associated with transmission line routing. This method assumes that in order to obtain meaningful and informed judgments from members of the society, specific information about transmission lines must first be com- 
municated to them. One potential problem with this approach is that the information communicated may largely determine the responses obtained. Estimates of the relative importance of various routing criteria might be biased, for example, if biased information were presented to respondents. This problem can be partially alleviated by insuring that the information presented is accurate, unbiased, and relatively neutral in its persuasion; and that where there is disagreement or controversy in the scientific community concerning specific impacts, attempts be made to render a balanced description.

A second limitation concerns the stability of weights or importance estimates over time. Literature in the field of selection and employment testing, for example, contains many examples of fluctuating relationships between test scores and subsequent job performance as a function of changes in the situation and changes in the person. Social values are probably susceptible to change over time, and it would be unwise to make one set of measurements and use them forever. The solution to this problem is to monitor such changes over time by making periodic measurements. In the case of transmission line routing, it seems feasible to re-evaluate weights for all major new lines.

A third limitation concerns the somewhat abstract nature of the task presented to respondents. In effect, the experimental situation asks respondents to react to transmission line impacts in an "as if" fashion rather than to react to transmission lines as they would directly affect them. To illustrate, respondents might react one way to photographs of transmission lines in an urban area but respond quite differently if a line were actually routed in front of their home. Another problem with abstract or hypothetical judgment tasks is that people may change over time in their evaluation of a situation. The way a person evaluates a landscape or transmission tower from a photograph or upon first viewing the actual site may be quite different from the way the same characteristics would be evaluated if the person were in daily contact with it. What initially may be an eyesore on the landscape may gradually come to be viewed as a landmark, or vice versa. Again, one solution is to monitor changing attitudes and values toward such characteristics. Wohlwi11(22) 
has noted that the role of human adaptation and adjustment to changing environments is an area of potential research in and of itself.

Finally, this methodology focuses on obtaining.estimates of the weight which the public attaches to various transmission line criteria. However, this methodology does not address itself to how much "weight" the "public weight" should receive in the actual planning and decision process. As in the case of assessing human adaptation to environmental change, the question of how much importance should (or is) given to public desires represents an area of research unto itself.

\section{G. EXAMPLE OF THEORY APPLICATION}

Application of the procedures just described can be illustrated by a hypothetical example which might confront a decision maker who must choose a route for a transmission line. Suppose the selection of routes between points $A$ and $B$ has been narrowed to two alternatives: one alternative is 50 miles long and cuts directly across a forested mountain; while the other is 100 miles long, skirts the mountain, and passes alongside a river. Both routes probably have advantages and disadvantages from the standpoint of a technical expert or from the "public's" point of view. How may social or public values be incorporated into the decision-making process? Below, the steps necessary to implement the methods described in this chapter are presented in expanded-outline form.

1. Select criteria for evaluating the two alternate routes. Several lists of criteria were cited earlier in this chapter. An arbitrary decision could be made to use one of these existing lists, such as the criteria used in the Siting Study or the list described by Nieman and Murray. (11) As an option or addition to using an existing set of criteria, a multidimensional scaling experiment could also be performed if time and resources were available. Such an experiment might shed additional light on what criteria would be most salient to members of the public.

2. Selection of stimuli. Photographs or accompanying descriptions would be assembled which depict typical and representative examples of transmission line impacts upon the landscape. These photographs should 
illustrate variation in the criteria which are used (e.g., high versus low aesthetic impact; high versus low dollar costs for construction).

3. Selection of respondents. Table 3 presents a brief list of characteristics which might be used as a basis for drawing samples. As an example, five groups of respondents might be chosen, each group containing 50 individuals: members of environmental interest/recreationists organizations; representatives of the business community; special competence groups, such as designers, planners, landscape architects, and civil engineers; members of social/fraternal organizations; and students from area schools. While such a sampling procedure would not yield a random sample of respondents, it would sample across a spectrum of interests and backgrounds.

4. Measurements. Two procedures were described earlier: ranking and policy capturing. Application of each method will be briefly described here. In the policy capturing approach, respondents would judge each photograph/description and make a single judgment as to the "acceptability" or "desirability" of a transmission line in the location portrayed. Predetermined values for each criterion (assigned by an expert panel) would be analyzed in relation to the respondent's acceptability judgments; the analyses would yield 'weights' which reflected the influence of each criterion upon the respondent's judgments.

In the direct ranking approach, respondents would be presented with the list of criteria, shown the photograph solely as a means of illustrating the criteria, and asked to rank the criteria as to their importance in routing transmission lines.

5. Interpretation. The results of the two measurement approaches would be used to complement one another. The weights generated by the policy capturing approach could be used to better "calibrate" the results of the ranking approach. To illustrate, if the eight criteria from the Siting Study were applied to the present problem, the group averages for the criteria would assume values between 1 and 8 . In reality, however, some of the criteria might be considerabiy more important (in the minds of the respondents) than other criteria. Results from the policy capturing 
exercise would better reveal the actual intervals between criteria. The diagram below presents hypothetical results and illustrates how the results from the two measurement procedures could be compared.

TABLE 4. Comparison of the Direct and Policy Capturing Approaches to Criteria Weighting

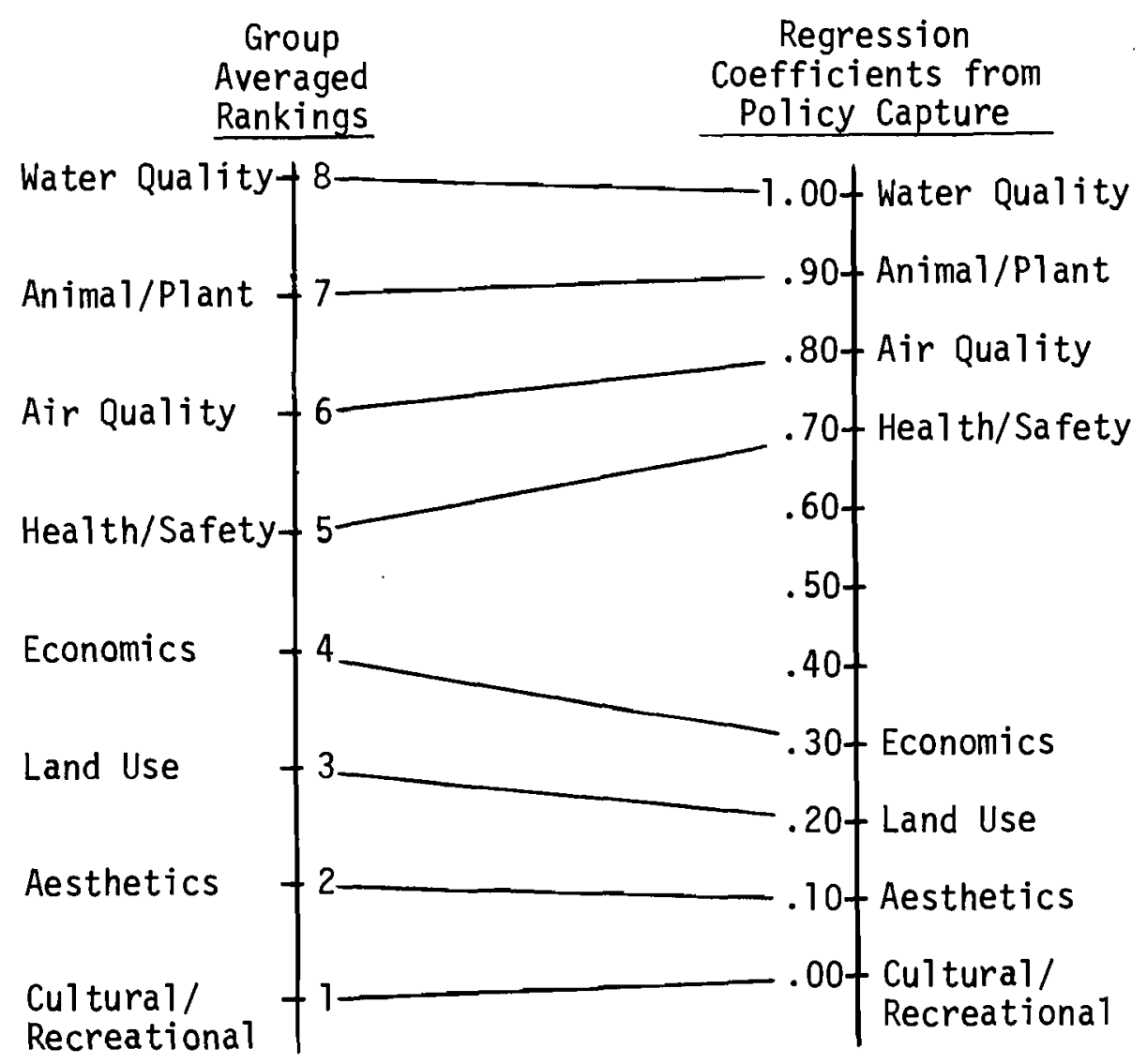


In effect, both procedures might show relative ordering as to importance, but the use of both approaches would better indicate the actual differences between criteria regarding importance.

From the viewpoint of the decision maker, an "ideal" set of results would be one set of importance weights for all groups and all individuals who were sampled. In practice, it is likely that more than one ranking of priorities of criteria might emerge. For example, one group of respondents might place great emphasis upon aesthetics, while another group might give economics top priority. In such a case, the methods described here do not indicate which individual or group of individuals in society should have the greatest voice or influence. What this approach does accomplish is to help the decision maker evaluate alternatives with more explicit sources of data.

6. Application of criteria weights to route alternatives. The final steps in the choice process are to: 1) use panels of experts to obtain "scores" for each route alternative on each of the criteria being considered, and 2) impose onto these "technical" scores for each criterion the attached social weights. Oversimplifying in the example given at the beginning of this section, Option 1, the shorter, more direct route over a mountain might have a greater adverse impact on aesthetic quality and land use considerations than Option 2, the longer route, yet involve lower construction costs and possess less of a health and safety hazard. If, as in Table 4, the social weights produced by the methodology indicated that aesthetics $(0.10)$ and land use $(0.20)$ were much less important than economics $(0.30)$ and safety considerations $(0.70)$, then the choice would be shifted in favor of Option 1 . 


\section{REFERENCES}

1. J. D. Carrol1, "Participatory Technology," Science, pp. 647-653, February 19, 1971.

2. S. Arnstein, "A Ladder of Citizen Participation," American Institute of Planners Journal, p. 217, July 1969.

3. P. J. Runkel and J. E. McGrath, Research on Human Behavior. New York: Holt, Rinehart, \& Winston, p. 108, 1973.

4. K. H. Craik, "The Comprehension of the Everyday Physical Environment," Journal of the American Institute of Planners, Vol. 34, No. 1, January 1968.

5. E. H. Zube, D. G. Pitt and T. W. Anderson, "Perception and Measurement of Scenic Resources in the Southern Connecticut River Valley, "Publication No. R-74-1, Institute for Man and His Environment, University of Massachusetts, Amherst, Massachusetts, 1974.

6. R. Kaplan, "Some Methods and Strategies in the Prediction of Preference," Landscape Assessment: Values, Perceptions, and Resources, E. H. Zube, J. G. Fabos and R. 0. Brush, editors, 1974.

7. C. N. Peters, "Methodology Development for Transmission Line Route Section," Proceedings of the American Power Conference, Vol. 35, pp. $1250-6 \overline{6}, 1973$.

8. J. D. Voytko, "How Do You Quantify Power Line Impact," Electrical World, 178:46-48, November 15, 1972.

9. H. P. Hulett and A. D. Poppens, "Transthetics: Environmental Transmission-Line Routing," Proceedings of the American Power Conference, Vol. 35, pp. 1255-59, 1973 .

10. J. B. Burnham, et al., A Technique for Environmental Decision Making Using Quantified Social and Aesthetic Values, BNWL-1787, Pacific Northwest Laboratories, Richland, Washington, February 1974.

11. B. J. Niemann and B. H. Murray, "TIMELES: Transmission Implementation and Management of Environmental Location of Energy System," Landscapes Limited, Madison, Wisconsin.

12. J. C. Nunnally, Psychometric Theory, New York: McGraw-Hi11, 1967.

13. K. H. Craik, "Psychological Factors in Landscape Appraisal," Environment and Behavior, Vol. 4, pp. 255-266, September 1972. 
14. R. E. Coughl in and K. A. Goldstein, "The Extent of Agreement Among Observers on Environmental Attractiveness," Discussion Paper No. 37 , Regional Science Research Institute, Philadelphia, PA, 1970.

15. E. H. Zube D. G. Pitt and T. W. Anderson, op. cit.

16. K. H. Craik, Sept. 1972, op. cit.

17. E. E. Lawler, III, Pay and Organizational Effectiveness: A Psychological View, McGraw-Hi 11 , New York, 1971.

18. S. M. Nealey, Importance of Job Factors to Navy Personnel, Final Report, Department of Psychology, Colorado State University, May 1972.

19. R. Kaplan, op. cit.

20. P. Slovic and S. Lichtenstein, "Comparison of Bayesian and Regression Approaches to the Study of Information Processing in Judgment," Human Judgment and Social Interaction, L. Rappoport and D. Summers, editors, Holt, Rinehart, \& Winston, New York, 1973.

21. E. L. Shafer, J. F. Hamilton and E. A. Schmidt, Journal of Leisure Research, Vo1. 1, No. 1, pp. 1-19, Winter/1969.

22. J. F. Wohlwill, "Human Adaptation to Levels of Environmental Stimulation," Human Ecology, Vo1. 2, No. 2, pp. 127-147, 1974. 


\section{QUANTIFICATION OF AESTHETIC CRITERIA}

This chapter on quantification of aesthetic criteria includes a review of techniques for transmission line impact assessment, discussion of approach, methodology and data preparation, and determination of visual quality and impact. Finally, an example of the application of this procedure is given.

\section{A. REVIEW OF EXISTING TECHINQUES FOR TRANSMISSION LINE ROUTING/VISUAL IMPACT ASSESSMENT}

Before discussing the aesthetic evaluation component of the various transmission line routing studies reviewed, it is important to gain an overview of the prevailing underlying policies and attitudes regarding the aesthetic role of transmission lines in the landscape. One such attitude is that transmission lines should be concealed. In a 1966 study, A Report on Appearance Planning for BPA, (1) four comments are made on the philosophy of concealment of transmission facilities.

First, concealment is in many cases very expensive, particularly for undergrounding conductors which must carry higher voltages. Since transmission lines may well become outdated within the next 50 years, their burial could be anachronistic.

Second, concealment of transmission lines implies that electrical equipment is necessarily ugly; nonetheless, men have found that "a wellshaped, technically correct, honest expression of a utilitarian object can be the subject of pleasure...." (1, p.12) Another author disagrees, however, calling transmission facilities "the ugly mechanics of our civilization" $(2)$ and insists that such objects clutter the landscape of our outdoor living spaces. There is little doubt that the general public will increasingly request that future transmission and distribution systems be placed underground regardless of the success of transmission routing guidelines and visual impact studies. A recent study involving response testing confirmed that power lines always have a negative effect on scenic resource values. (3) 
Third, the authors argue that partial concealment of transmission lines is psychologically a bad tactic:

"If an object is completely hidden from view so that no one is aware of it, there is no problem, but if it is only partially concealed, attention is drawn to it by a natural human curiosity and desire to complete things.... to resolve an unfinished understanding, which is partially cut off by the concealment. As a matter of fact, this same principle is used by public relations firms to attract attention." (1,p.12)

Fourth, the authors observed that:

"....conscious concealment implies either of two motives on the part of the concealer: one, that the concealed object is meant to harm or defraud the observer, or, second that it is believed to require hiding. In our society the first is far from the truth, although many people believe it to be true. Then, if electrical equipment is concealed often enough because it is believed, by some, to be ugly, the public will soon believe it too." (1, p. 13)

A 1973 pol1 ${ }^{(4)}$ indicates that the general public has an inadequate knowledge of the electric utility industry, its operations and its problems. This basic misunderstanding is perhaps the source of some of the public dissatisfaction and anxiety toward transmission lines. The luxury of concealment or even partial concealment of facilities is becoming less and less available (see Figure 2), and aesthetic conflicts from an environmentally aroused general public are inevitable as future lines are constructed.

Given these background considerations, it is possible to group visual impact studies and transmission line routing selection methodologies into four main categories: $(6,7)$

1. Performance guidelines

2. Visual exposure sensitivity and viewing population assessment

3. "Landscape image" disruption evaluation

4. Visual quality/impact evaluation

Performance Guidelines

Performance Guidelines are lists of environmental "do's" and "don'ts" which have been compiled from practical experience in siting and evaluating visual impacts of transmission facilties over a broad spectrum of situations 
and scales of concern. These range from policy statements on the use of existing rights-of-way whenever possible down to site-specific suggestions such as the treatment of particular road crossing situations and construction and management specifications to minimize erosion and postconstruction impacts.

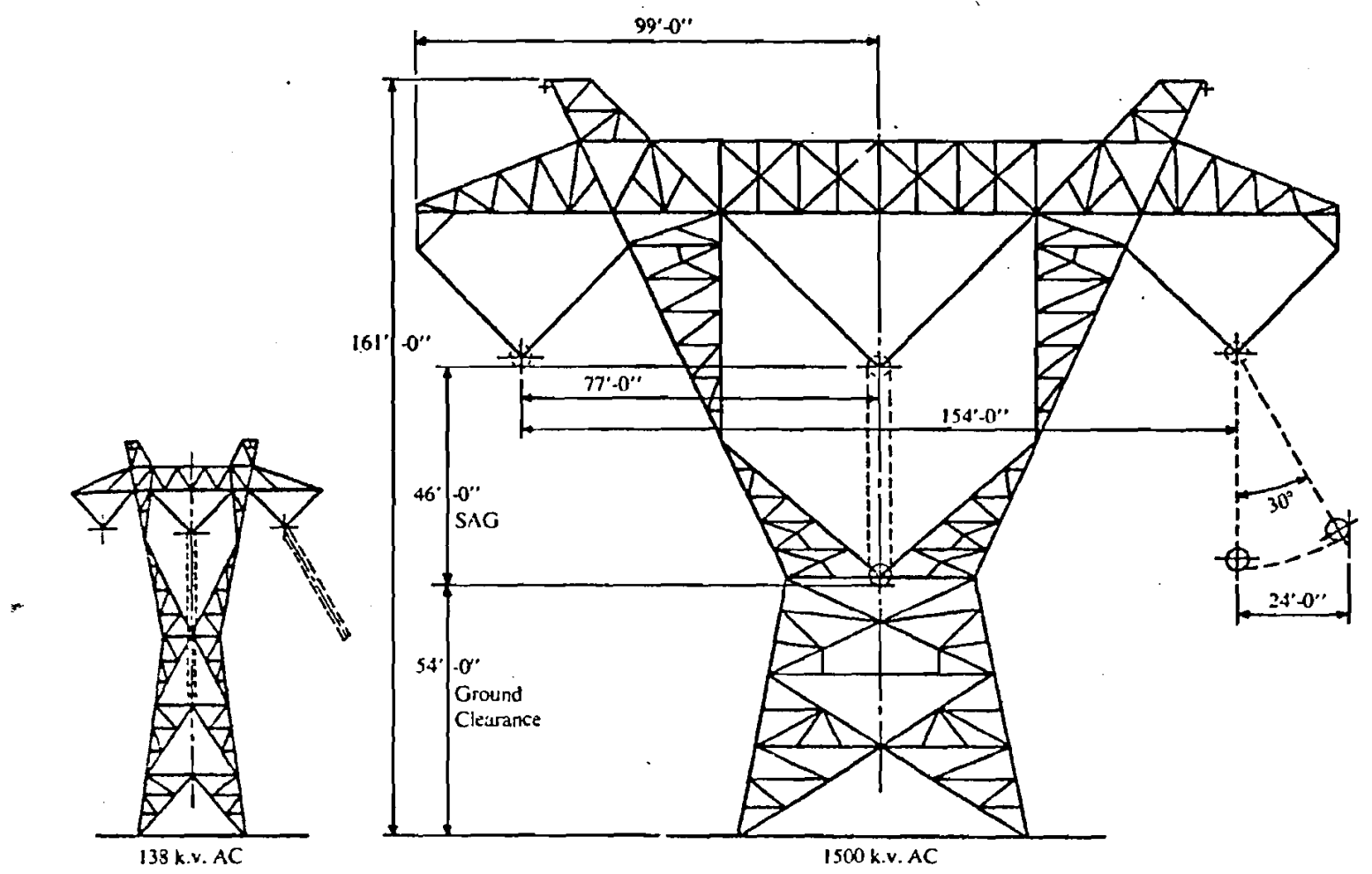

FIGURE 2. Comparison of a "common" $138 \mathrm{KV}$ transmission tower with a potentially enlarged version to carry $1500 \mathrm{KV}$, which may be required by 1985. Over half the length of a football field high, such uhv structures would be problematic in the attempt even for "partial concealment" in the landscape.

Source: Hammond, Metz, and Maugh, Energy and the Future, 1973(5)

Perhaps the greatest problem encountered in the use of such guidelines is in applying the guidelines to a particular situation where special conditions may warrant a slightly different solution. Another problem with existing lists of guidelines reviewed is their apparent lack of organization. Although typically arranged in sections which apply to (a) selection of a proposed route or corridor, (b) design, (c) clearing, (d) construction, (e) cleanup and restoration, and ( $f$ ) maintenance, there is considerable 
overlap between these categories which makes their exclusive use and application incomplete. Within each category guidelines appear to be placed in seemingly random order, requiring the user or reviewer to constantly shift his concern from one guideline to the next. Appendix A, Some Environmental Performance Guidel ines for Transmission Lines, was compiled for this study from five sources and is organized and cross-referenced in a manner which hopefully will facilitate its use in the planning, design or evaluation stages. The guidelines are placed in five categories:

General Planning Policy

Physiography

Vegetation

Sensitive Areas

Roads

Within each category guidelines are arranged from the general to more specific concerns, and the user is referred to preceeding guidelines which should apply to that particular level of concern.

Although guidelines and standards are a necessary requirement in the development of environmentally responsive transmission route planning, they cannot substitute for a systematic planning-orientation approach and may only serve as idealized goals which apply to specific situations. As such, however, they may fit neatly into one of the broader planning processes discussed below.

\section{Visual Exposure Sensitivity and Viewing Population Assessment}

These studies are perhaps the most commonly used in transmission 1 ine routing and visual impact prediction. One of the main criteria considered is the potential visibility of transmission facilities in the landscape, which may be based on (a) topographic features, (b) vegetation, and in some cases (c) complexity (scattered, somewhat open woods combined with a variety of natural and man-made visual elements may be more capable of absorbing an additional element than landscapes which are more simple and uniform). These studies also consider the types of existing and proposed land uses traversed by transmission facilities (residential, commercial, industrial, recreation, transportation) and particular areas of sensitivity (lands seen 
from scenic roads and important overlooks) in order to identify areas or land uses where transmission facilities would create conflicts in context. Another consideration is the number of viewers who would be exposed to the facilities, which may include travelers on roads, railroads, boats or trails as well as residential population within a given distance from the route or within the corridor's viewshed. While the components of this level of study are undoubtedly important and useful, neither the actual visual impact upon the landscape nor recognition of the landscape's visual quality is addressed.

\section{"Landscape Image" Disruption Evaluation}

An excellent visual analysis system recently developed by Ontario Hydro ${ }^{(6,7)}$ considers the processes "by which man perceives and forms images of the environment, and his technique for remembering those images. Visual impact in this context is defined as the predicted disruption to the existing image of the area caused by a proposed development" $(7, p .3)$. The system includes and extends the capabilities of the first two study types while providing a rational order for and theoretical background explanation of each factor considered.

First, the visual characteristics ("landscape clues") of each landscape setting within the study area are identified and the degree to which the visual character of transmission towers and rights-of-way would alter or visually dominate the image of each setting is evaluated. Hence, each landscape unit is mapped and rated as to its specific compatability with transmission facilities.

Second, recognizing that an observer will be more attentive or sensitive in certain areas of the landscape than in others, those areas of the landscape where viewer sensitivity or visual awareness is increased are identified. Such areas occur near boundary edges between different landscape types, at overlooks which present vistas and panoramas of large segments of the landscape at a glance, near natural or cultural landmarks which dominate the image of the surrounding area, and in advertised scenic, natural or historic areas. While the above set of sensitivity factors are most valid for travelers within an area, an additional level of sensitivity discrimination is 
achieved by the use of resident questionnaires to identify landmarks of regional and local significance as seen through the eyes and attitudes of the community affected; this innovative technique for public participation is perhaps this system's most significant contribution to transmission line visual impact analysis. These sensitivity areas are mapped and evaluated as high-impact areas. To assist in considering the specific location of a given route, a list of performance guidelines is also used at at this stage.

Third, a consideration of paths which provide the visual structuring sequence of elements along their adjacent landscape corridors is made. From traffic volume data map interpretation and field observation, the use intensity levels of roads, railroad lines, boatways and trails are identified and the number of viewers along each path is determined; high-use areas are weighted as being highly sensitive. When this analysis is applied to specific routing decisions, the viewsheds of all high-use roads are mapped for comparison with those various alternative routes.

Fourth, the potential constraints for remedial actions which would allow mitigation of the visual impacts of a transmission line within each major landscape unit are evaluated and mapped, based on the appropriateness and availability of screening devices or concealment tactics for each landscape.

Fifth, projected future land uses are considered to aid the long-term outcome of the visual characteristics, probable travel patterns and viewing populations of potentially developed areas. The future image of an area may affect the decision for location of transmission facilities and evaluation of their probable visual impact; hence, future land uses are mapped and their compatability with transmission facilities evaluated.

Finally, the five overlay maps are comprised to produce a suitability map. Since each individual map may contain a maximum of three levels of constraint ranging from high to low, combinations of these areas are scored by combining the individual constraint scores.

This visual analysis system is the most comprehensive visual study reviewed for this report. While many of the concepts and procedures have 
been used in other types of visual analysis studies, this particular system combines and presents, these ideas convincingly and clearly. In particular, the supporting document, A Background Paper Prepared for the Workshop on Visual Impact by Alan Vaughan, ${ }^{(6)}$ is a rational compilation and discussion on visual perception theory.

If one wanted an accurate and easily applied visual analysis system to aid in transmission line routing decisions, it would at first appear that this approach meets all the requirements; further investigation of the results of this system do, however, reveal the need for an established reference point to aid comparison and evaluation of the impacts of various transmission routing alternatives (See Chapter III.B). The inherent problem is that the actual quality value of a given landscape character is never directly assigned, but only implied. Hence, this system is excellent for selecting and evaluating routes of minimum visual disruption within a given study area but cannot actually quantify the severity level of a "minimum visual disruption". While paying strict attention to the "image" of the landscape, it pays no attention to the "visual quality" of the landscape. With the addition of a visual quality index, the Ontario Hydro Visual Analysis System could be a formidable tool; in essence, the system proposed in Section $E$ of this chapter attempts to add this necessary dimension.

\section{Visual Quality/Impact Evaluation}

This evaluation potentially represents the most thorough and responsive of the four levels of studies discussed. It would ideally encompass the above study types and add the visual quality analysis necessary to establish a reference point for comparison of the impacts of alternative routes traversing different types of landscape (even in different study areas). It would also aid the assigning of weights to the importance of the visual impact component relative to the importance of other environmental impact evaluations. A detailed proposal for such a system may be found in the remaining pages of this chapter. 


\section{B. APPROACH/METHODOLOGY}

This section presents an approach to predictively evaluate the visual impact resulting from the introduction of transmission facilities into a landscape. Preferably the methodology wi11: 1) allow comparison between a range of transmission alternatives within a given landscape or traversing a range of landscape types; 2) be effective and suitable for use by a small number of evaluators while providing a framework for public participation when desirable; 3 ) be applicable to any landscape-transmission facility combination; and 4) be compatible for use in combination with the methodology to assess the visual impacts of nuclear power plants previously outlined by the authors. (9)

Assumptions and Concepts

The visual impact evaluation procedure presented here for transmission lines is an adaptation of a previous technique developed by Jones and Jones with Battell,e-Northwest for the AEC to evaluate the visual impacts of nuclear power plant siting. ${ }^{(9)}$ The previous study was broken into three major sections:

Data Preparation Preliminary Analys is

Evaluations of Visual Quality

Determination of Visual Impact

The first section described a method for locating representative viewpoints surrounding a proposed nuclear power generating station site and photographing the view towards the facility. Two sets of slides or photos were prepared, one set "before" and one set touched up to simulate the "after" appearance with the facility in place.

The second section described three slightly different approaches to evaluate visual quality of a view using a questionnaire on which the individual quality indicators of intactness (apparent degree of natural condition), vividness (memorability of the visual impression received from an image), and unity (compositional integrity, harmony and coherence) were separately rated for the "before" and "after" photos. A rating was also given to the visual importance of each element in the view. 
The third section combined the ratings for intactness, vividness, unity, and visual importance in an equation which yielded a numerical score for visual quality on a 1-100 scale; one score was determined for "before" and one for "after" views. These two scores were then placed into a ratio to express the severity of the change in visual quality relative to the "before" quality score. "Visual impact" was then expressed as a product of the ratio of change in visual quality and the size of the viewing population.

The study presented here uses the same visual quality and visual impact evaluation procedures described in the second and third sections of the siting Study, and the reader is urged to refer to sections in that work for the specific details of the approach. This chapter will primarily adapt the first section (data preparation and preliminary analysis) for use with and application to transmission facilities.

In many ways, determination of the visual impacts of transmission facilities is more highly involved than for nuclear power plants. First of a11, transmission facilities produce linear impacts (as opposed to pointsource impacts from nuclear power plants) which may traverse a wide range of landscape settings and be visible from a variety of viewpoints; hence, identification of specific zones of high impact is very important, as selection of representative viewpoints for detailed qualitative visual impact evaluation must depend upon the specific occurrences of these zones in the landscape. Secondly, since visual analys is is being used more and more in the selection of transmission corridors as well as in the visual impact evaluation of an actual selected route alternative, the methodology must be flexible in application as well as consistent in its use of data at various scales during all phases of the planning process. For these reasons, the data preparation/preliminary analysis must apply to a broader range of issues than were encountered with nuclear power plant sitings.

Since the visual impact of transmission facilities will vary from one landscape to the next, a method of landscape classification (based on classes of landform and land cover pattern) is applied to the study area. Each 
landscape type mapped is then rated according to the degree to which it may compatably absorb transmission facilities without suffering a major change in its image. Scarce visual resources within the study area are identified and may take on a significance value according to their relative scarcity within a larger context. Visually fragile landscape areas are identified under the categories of edges, special land use districts, landmarks and overlooks; the "viewshed" (surrounding lands which are visible) around landmarks and from overlooks are constructed and mapped to determine whether or not these fragile areas will be visually impacted.

The sensitivity of transiting and resident viewers is considered. Viewsheds of major roads are mapped to aid in the planning of transmission facilities, or the viewshed of a proposed transmission route alignment is mapped to locate areas of visual conflict with paths. A questionnaire is sent to residents of a potentially impacted area to record and protect their preferred local visual environments. Factors which would tend to mitigate visual impacts over time are also considered, including remedial tactics (such as screening, special right-of-way treatment, and tower design and color) and future land uses which might tend to diminish (or increase) the severity of the transmission impacts over a longer period.

The above information is integrated on a single map for use in selecting corridors or specific alignments or in identifying high-impact zones for detailed visual impact evaluation. Viewpoints in these areas are selected and the visual quality of views from these points determined "before" and "after;" the procedure is identical to that presented in the last two sections of the Siting Study.

This study draws from and owes much to earlier visual analysis work done by others; References 1,6, 7, and 10-21 (which deal with transmission: impacts) were reviewed and portions of them incorporated into this work. In particular, the excellent visual analysis system devised by Alan Vaughan and others for Ontario Hydro $(6,7,10,18)$ helped to clarify and formulate the core of the data preparation/preliminary analysis procedure. The authors have 
applied the visual quality evaluation procedure (using the parameters of vividness, intactness and unity first described in the Siting Study) to several studies and have found it to be a very useful and accurate tool. $(22,23,24)$

\section{Equations for Visual Impact Assessment}

A questionnaire (Appendix $B$ ) is employed to assess visual quality of each viewscape before and after the facility is introduced into it. Measurement Level 1 gives a direct score for visual quality on a scale of 1-100, and therefore needs no calculation. Measurements Levels 2 and 3 both depend on the basic formula:

$$
V Q=1 / 3(I+V+U)
$$

where

$$
\begin{aligned}
V Q & =\text { Visual quality of the viewscape } \\
I & =\text { Intactness } \\
V & =\text { Vividness } \\
U & =\text { Unity }
\end{aligned}
$$

The ratio of change in visual quality $(R)$ in a viewscape from before $\left(V Q_{b}\right)$ to after $\left(V_{a}\right)$ is expressed as:

$$
R=\frac{V Q_{a}-V Q_{b}}{V Q_{b}}
$$

Visual impact measured at a given viewpoint is:

$$
\text { visual impact }=R \times P
$$

where

$$
\begin{aligned}
& \mathrm{R}=\text { ratio of change in visual quality for viewscape } \\
& \mathrm{P}=\text { population contact per year at that viewpoint }
\end{aligned}
$$

For further elaboration of the application of these equations, and for the definitions and scaling of intactness, vividness, and unity, see the Siting Study ( $p p .82-85,107-147$ ). 


\section{DATA PREPARATION/PRELIMINARY ANALYSIS}

In order to carry out the visual analysis, the following preparatory data are required:

- Location, topographic maps, and stereo aerial photography of potential study area or alternative to be evaluated.

- Depending on the nature and scale of the study, the appropriate identification of the alternatives or study areas to be evaluated, the voltage and number of circuits proposed, the route origin and/or destination points, the range of tower designs and sizes which might be selected for use.

- Population data by settlement and/or per square mile and traffic volume data on major roads (greater than 1000 cars/day) within the study area.

- Regionar maps to aid in the understanding of the position and scarcity of the study area with regard to the broader Tandscape.

- Natural historic or cultural points of interest and land uses within the study area.

- Future land use plans for the study area.

- Names and addresses of a sample of the resident population within the study area.

With these data and with access to the lands potentialiy traversed by transmission lines for photography and onsite evaluation, the visual analysis can proceed in the following stages: 1) landscape classification and visual compatibility, 2) scarce and fragile visual resources, 3) viewer sensitivity, and 4) mitigation potential and future impacts. Based on analysis in these stages, four overlay maps can be prepared which will be useful in the next stage, identification of alternative transmission locations and high-impact zones. The final stage involves viewscape photography - before and after transmission lines.

\section{Landscape Classification and Transmission Visual Compatibility}

During the first stage of the visual assessment, two steps must be taken: a) classification of the landscapes potentially traversed by transmission facilities, and $b$ ) evaluation of the compatibility between the visual characteristics of the proposed transmission facilities and the visual characteristics of each landscape. 


\section{Landscape Classification}

The visual characteristics of each landscape setting which the transmission facilities would traverse need to be known to evaluate the relative compatibility (or severity) of visual impacts caused by the introduction of transmission lines along the various settings of a given alignment. Landscape classification techniques have been devised and applied at various scales by a number of authors. $(6,7,22-33)$

Large-scaled regional studies often depict on a map the type and quality of landscapes to be found in different areas. The visual characteristics of any landscape may be identified and generally categorized under the headings of landform (mountains, hills, valleys, plains) and land cover pattern (vegetation, waterforms and human settlement). While this regional and subregional scale of classification is ideal for the location and visual impact assessment of potential transmission corridors, the addition of more detailed information of the visual character of a specific location in the landscape will aid alignment decisions and impact assessment from specific transmission siting alternatives.

In order to group areas of similar landscape character based on landform, the broadest useful category of classification is the physiographic region which groups together landscapes of the continent according to areas of similar topography and geologic origin. This information is readily available in a geography or geology textbook. Within each large physiographic region smaller distinctive subregions may be identified according to differences in landform pattern and drainage basins (watersheds). The subregions may be subdivided into ridges, valleys, plateaus, gorges, escarpments, etc; these in turn may be further classified by relative relief according to the level of classification desired.

Land cover classification falls under the general categories of vegetation (forests, shrublands, grasslands, heaths, marshes), waterform (oceans, sounds, bays, lakes, rivers, ponds, glaciers), and human settlement (roads, utility networks, urban, suburban, agricultural, wilderness). Each of these land cover variables may be combined and/or subdivided depending on the scale of classification desired. 
Once landform and land cover patterns have been mapped separately, the - two maps may be combined and the resultant landscape units classified in a hierarchical manner.

Transmission Visual Compatibility Assessment

Having become familiar with the visual characteristics of each landscape unit, it becomes a relatively easy task for the evaluator to determine the potential visual compatibility (contrast between visual images) for a given transmission facility/landscape unit combination. Many of the ideas for compatibility assessment may be found in the list of environmental performance guidelines for transmission lines presented in Appendix $A$; other considerations can be added as an evaluator finds an important consideration which merits inclusion.

There are two major sets of visual characteristics of transmission facilities: (1) the towers, footings and conductors which are the physical transmission "objects" or visible elements, and (2) their right-of-way or corridor, the lineal space along which vegetation and the ground surface may appear as being distinctly different from the surrounding landscape. Depending on the visual characteristics of the landscape setting and the observer's distance from the facilities, either or both of these components may be visible or relatively nonvisible. For instance, a sequence of transmission towers and conductors silhouetted against the sky may be quite visible in a relatively level open landscape, while its corridor right-of-way may be barely distinguishable from the surrounding grasslands; on the other hand, the towers seen at a distance in a forested, mountainous landscape may be barely distinguishable from their wooded background, but the distinctively cleared band of the right-of-way may be highly apparent.

The visual impact of a tower on the landscape is dependent upon its size, complexity, design and color. One author makes the following recommendations in considering and evaluating new tower designs:

"Structure designs that are most usually acceptable in the environment are those of the simplest form....simplicity in overall outline, a balanced or symmetrical arrangement of elements relative to the vertical support, parallel and orderly placement of elements within the overall outline and the minimization of pole-top elements are design criteria upon which to evaluate structure 
designs. Attempts at increasing the attractiveness of towers have sometimes led to exotic designs that only attract more attention than those of less complex silhouette. A more appropriate design purpose would be to achieve designs that are so simple as to be unoffensive and unnoticeable."(13, p.6)

A1though much attention, effort and ingenuity is being placed on the improvement of tower designs to diminish their visual impact, the tower and conductors represent only a portion of the visual impact of transmission facilities in many landscape settings. The impact of the linear corridor and the context in which the transmission facilities are viewed are considerations of prime importance. For this reason, the same authors conclude that:

"Careful siting of rights-of-ways for minimum visibility and least physical and visual disruption of the landscape offers the greatest opportunity for success...." (ibid).

Hence, both sets of characteristics require consideration for the assessment of visual compatibility; this may be done with the checklist shown in Table 5 .

TABLE 5. Landscape/Transmission Visual Compatibility Assessment Checklist

Landscape Unit: Rating

Towers and Conductors vs. Landscape Unit:
a) Scale Compatibility
b) Land Use Setting
c) Foreground Screening Potential (Landform/vegetation)
d) Background Screening Potential (Landform/vegetation)

\section{TOWER MEAN SCORE:}

Right of Way vs. Landscape Unit:
e) Landform Conformity Potential
f) Vegetative Pattern Continuity
g) Land Use Pattern Continuity

RIGHT OF WAY MEAN SCORE:

Factor Rating Scale: $5=$ Very Compatible

$$
\begin{aligned}
& 4=\text { Compatible } \\
& 3=\text { Neutral } \\
& 2=\text { Incompatible } \\
& 1=\text { Very Incompatible }
\end{aligned}
$$


Four factors should be considered in connection with the appearance of the transmission towers and conductors in each landscape unit.

1) Scale Compatibility: How similar in size and scale are the structures with the landscape elements of the unit? Would the structures dominate or tend to "dwarf" the tallest trees and manmade elements?

2) Land Use Setting Compatibility: How visually compatible would transmission facilities be with the visual characteristics of the land use settings? Using a three-man panel, one author ${ }^{(34)}$ has attempted to evaluate the visual compatibility between the visual characteristics of transmission components and those of various land uses. On a five-point scale similar to the one proposed here, land uses were ranked in terms of their incompatibilities:

$\quad$ LAND USE
Commercial
Industrial
Recreational/0pen Space
Residential
Transportation
Special Considerations
Recreation/Parks-Playgrounds
Agriculture
Public and Quasi-Public

It must be emphasized that this evaluation is not based on attitudes regarding the sanctity of certain land uses for transmission corridors as opposed to others (which will be evaluated later in this chapter) but rather was done purely in terms of their apparent visual compatibility with transmission facilities. This evaluation tactic needs broader testing and further study.

3) Foreground Screening Potential: Are there apparent opportunities in the landscape unit to generally screen transmission facilities from view by existing landforms and/or vegetation? 
4) Background Screening Potential: Are there sufficient topographic relief, vegetation height and spatial enclosure to generally prevent the transmission facilities from being silhouetted or partially silhouetted above the skyline?

A second group of factors which pertain to the right-of-way appearance should also be evaluated:

1) Landform Conformity Potential: In keeping with the environmental guidelines regarding physiography (Appendix A), would the corridor have to oppose the contours and patterns of topographic features, crossing hills at right angles to the contours? Could a useful corridor follow lower valley depressions through hills and mountainous terrain? Must it cross steep slopes in order to connect the generating source and load centers?

2) Vegetation Pattern Continuity: Would the right-of-way be visually we11-defined due to dense even-growth forests which it traverses? Would vegetation along the corridor be visually distinct from the surrounding patterns? Would the corridor be barely noticeable due to the absence of a regular, even pattern of vegetation?

3) Land Use Pattern Continuity: Would the right-of-way parallel and reinforce existing patterns of development, or would it necessarily cross them diagonally? Could the right-of-way be located along edges between land uses?

Once these questions are answered and the compatibility rating completed, the evaluator should prepare a map depicting the classified landscape units with their visual compatibility ratings with transmission facilities.

\section{Scarce and Fragile Visual Resources}

At the second stage of visual assessment, both scarce visual resources of each landscape unit in the study area and visually fragile landscape areas are identified and mapped together. 


\section{Scarce Visual Resources}

Visual resources which are peculiar to or most characteristic of a given landscape locale or region need to be identified. Within the framework of the landscape classification system applied to the study area in the first stage, this survey should seek those landscape units, subunits or landscape features which are unique relative to a larger area. Investigation of topographic maps and stereo aerial photography will facilitate this survey, and a follow-up ground survey should be performed to investigate particular areas which appear to contain scarce visual resources. The comparison should be considered at both a microscale (search for scarce resources within the smallest landscape unit defined) and on a macroscale (determine the scarcity of each landscape unit's visual resources relative to other landscape units within a subregion or region, as well as the scarcity of the landscapes of that subregion or region in comparison with those of other areas). Since familiarity with a broad range of landscapes and landscape features is a valuable asset in this comparative study, visually oriented persons familiar with the larger landscape are best qualified to undertake this survey. In considering the scarcity of landscape features, it is convenient to categorize features, as those of waterform (waterfalls, geysers, glaciers, rivers, streams, creeks, springs), landform (peaks, ridges, knolls, valleys, basins, gorges, cliffs, drumlins, eskers, kames, rock outcrops), vegetation (rare endemic species, unique plant communities, edges between different vegetation types), or cultural (archeologic or historical sites); this categorization will further aid the evaluation of visual impact in a later step.

Any significant scarce visual resource identified should be expressed in terms of its scale of reference. For example, a recent survey of the nine-mile long South Platte River Canyon revealed that the canyon is physically and visually unique to the 400-mile mainstem of the South Platte River, and in fact is unique to the entire North and South Platte River system combined; only two other canyons in the front range of the Rockies 
contain rivers of comparable size and, of the three, the South Platte Canyon is the least developed and visually encroached by man; and a proposed dam in the upper canyon would inundate the river's most violent and visually dramatic segment of chutes and rapids. (23) Similar expressions should be used to express the significance of scarce landscape visual resources identified in the survey. If necessary, the degree of scarcity may be expressed as a rating or a ratio. $(23,24,35)$

\section{Visually Fragile Landscape Areas}

Visual contents of city images (physical forms) can be classified into five types of elements: edges, districts, landmarks, paths and nodes. (36) These elements may be identified within many types of environmental images or landscapes. Since these elements are used by the observer as reference framework for visual orientation within the landscape, his awareness is heightened near these critical areas and thus they are particularly sensitive to alterations such as the introduction of transmission lines. $(6,7)$ At this stage of determining the visually fragile areas of the landscape, edges, special districts, landmarks, and overlooks should be identified and mapped. (Paths and nodes in the landscape will be discussed in the next step.)

Edges are the interfaces or boundary areas between distinctly different landscape types. The visual transition between landscape units may be abrupt or gradual, but to some degree a viewer's awareness will increase in crossing an edge boundary as new visual information must be assimilated and categorized. Hence the image at or near major edge boundaries between landscape units wil1 be quite vivid, and transmission facilities located in these areas are likely to be more readily perceived. Some edges which visually bound landscape units are very prominent, such as continuous ridgelines, hills, or woods which are visible for some distance from the surrounding area; these highly visible skyline edge elements are particularly visually fragile to landscape alterations from transmission lines.

The term "district" refers in general to geographic areas"... which the observer mentally enters 'inside of', and which are recognizable as having 
some common, identifying character." $(36$, p. 47) Hence any identifiable landscape unit is a district; however, at this stage the primary concern should be special land use districts which may include advertised scenic, historic, natural or recreational areas, or human settlements, which have a specific expected or anticipated image in the eyes of the public. Wildiife refuges, wilderness areas, national, state or local parks, public recreation areas, scenic roads, cemeteries, historic and culturally significant areas (and occasionally towns and farm complexes) usually have a preconceived image associated with them which does not include transmission lines. Their introduction into such areas would have a significant visual impact far out of proportion to the actual degree of visual alteration.

Landmarks are usually point-references which, due to their prominence, singularity, isolation, contrast or focal location, tend to dominate their setting and hence imprint a vivid impression of that scene in the mind of the viewer. $(6,7)$ Power lines appearing in such scenes will tend to be imprinted and remembered. Hence, the surrounding areas of the landscape seen or associated with a landmark are particularly fragile. Landmarks may include both natural and cultural elements, such as mountain peaks, prominent rock outcrops, a prominent distinctive grouping or singular vegetative feature, waterfalls, towers, city skylines, etc. These are easy to locate and map. Those elements which bear special associations and significance to resident populations will be identified by questionnaire in the next stage of the study.

Overlooks are special places which present to the viewer vistas and/or panoramas of an extensive area of the landscape. Since visual comprehension of the overall landscape pattern is easily and quickly possible from overlooks, the lands surveyable from them are especially fragile. Some overlooks may occur within the special land use districts which have advertised scenic, historic, natural or recreational associations attached to them, and overlooks from within these areas should in particular be identified. 
In selecting alternative corridor alignments, it is important to construct the "viewshed" of the identified landmarks and overlooks to locate the lands from which landmarks are visible and the lands viewed from an overlook, since these supporting landscape areas are highly fragile. A detailed instruction for hand-plotting a viewshed (sight-line analysis) may be found in the Siting Study. A computer program is available to aid viewshed construction using digitized topographic data. $(37-40)$ These visually fragile viewshed lands within a three to five mile radius of a potential corridor should be mapped, along with the edges and special land-use districts discussed above, and combined on the same map with the scarce visual resources. Viewer Sensitivity

The third map produced should display those portions of the landscape in which viewer sensitivity is particularly high. These lands may include portions of the scarce and fragile visual resources identified on the previous map with the addition of: (a) lands viewed from paths and nodes by the transiting viewer, and (b) local landmarks and fragile areas as determined by sensitivity survey of the residents of a potentially impacted area.

\section{Transiting Viewer Sensitivity}

People are aware of the regional landscape as a sequence of views along a fairly narrow corridor as seen from a series of given paths: roads, railroads, boat courses and commercial airways. The transiting viewer is apt to be very sensitive to the visible presence of transmission lines anywhere along these paths; in recognition of this, a large number of the environmental guidelines for transmission lines treat various road crossing conditions, approaches and parallel transmission alignments (See Appendix A).

In selecting possible alternative corridor alignments, it is most useful to plot the viewshed of the major network of paths (most often, roads) within the study area in order to avoid these areas or seek optimum conditions for crossing or parallelling them. Viewer sensitivity will be particularly heightened where the path viewsheds overlap major landscape edges, advertised scenic/recreation districts, landmarks, overlooks or at intersections with other paths (road crossings and interchanges); these 
overlapping areas constitute strategic landscape nodes of concentrated visual events. Viewing populations along roads can be determined from traffic volume data and will be usefur in quantifying the frequency and significance of views from various paths.

\section{Resident Viewer Sensitivity}

To invite public participation with regard to visually fragile portions of the local landscape, Vaughan has successfully employed a resident questionnaire as a part of Ontario Hydro's visual analysis system. $(6,7)$ The questionnaire requests that ten of the most interesting or typical local landmark or landscape scene(s) be nominated, ranked in order of personal preference, and located on a township map; the location of the respondent's home is also to be marked on the map. When the questionnaire data are compiled for an area, the number of times an object is named is a relative indication as to its scale of importance (regional or local). If carefully designed, the questionnaire might be expanded to determine other public attitudes such as concerning the appropriate and nonappropriate visual land use context for transmission lines. This information will probably be most useful at the actual route alignment design stage when it can help determine and avoid sensitive local landscape areas within a broad potential corridor.

\section{Mitigation Potential and Future Impacts}

Although the initial visual impacts may be severe in a given landscape character type, some landscape types lend themselves more readily to remedial tactics than others. It may be very difficult or inappropriate to establish screening vegetation (such as foreground trees) in flat shrubland or grassland landscapes; however, this tactic could be successfully employed in a mixed forest or a wooded/agricultural landscape. Hence, each landscape unit identified should be rated as to the ease, success and appropriateness of such screening tactics.

Other remedial tactics include the careful use of color, materials, tower design and right-of-way treatments to help diminish the vividness of 
power lines and rights-of-way and to unify them with their landscape settings; these and other remedial tactics (including undergrounding) may be found in Appendix A, and may be considered at the corridor selection process stage or as remedies to specific problems along a chosen alignment.

A future change in land use, if planned or predictable, can drastically change the visual character of a landscape setting and may affect the decision whether or not to locate transmission facilities in a given area. Hence future land uses are important considerations which may permit the tolerance of a high short-range impact or prevent transmission siting in a future zone of high impact.

Alternative Transmission Locations and High-Impact Zones

The four overlay maps produced from the above include:

1) Landscape Classification and Transmission Visual Compatibility

2) Scarce and Fragile Visual Resources

3) Viewer Sensitivity

4) Mitigation Potential and Future Land Use.

These maps should be overlayed and the information transferred onto a single map which integrates the data while retaining all of the various condition combinations. (If computer maps have been used, this step is particularly easy to achieve). This map may then be used to select alternative corridors or alignments and to identify particular high-impact zones which deserve more detailed evaluation. These high-impact zones may include corridors or viewsheds of alignments passing through any of the following conditions:

- Through landscape units of low visual compatibility

- Across a number of major landscape unit edge boundaries

- Through areas of scarce visual resources

- Through visually fragile special land-use districts 
- Across viewsheds of significant landmarks or overlooks

- Across viewsheds of major paths

- Near significant local landscape features and human settlements

- Through areas of low remedial-tactic potential

- Through areas of incompatible future land uses.

Any alignment which crosses a number of these potential high-impact areas (particularly in concentrated areas of overlap) may be judged to be of higher visual impact than an alternative which crosses fewer of these zones; inevitably, however, some areas of high visual impact will occur, and these are the areas which should be selected as viewpoints for detailed quantified visual impact evaluation when such is required.

The actual selection of viewpoints should be determined by two basic criteria: (a) representative views of the transmission facility in its setting of most severe visual impact, and (b) size of viewing population. The first requirement can easily be met by considering the viewshed of the proposed alignment along with the conditions named above, the direction of view, and the distance and position of the observer. These variables are then compared with the environmental guidelines presented in Appendix A. The size of the viewing population is readily available as population statistics or density per square mile for settlement areas (resident viewers) and as traffic volume data (transiting viewers).

Observer position and observer distance variables are discussed in the Siting Study. However, viewpoint selection for specific transmission line impacts should be dependent upon the actual conditions within each highimpact zone identified rather than follow an idealized distribution pattern as recommended for viewpoint selection around nuclear power plant sites. Direction of view considerations and visual conditions discussed in the Siting Study should basically apply to transmission lines, but the primary consideration should be the depiction of the full visual impact of the proposed transmission facility for proper evaluation, route selection, and mitigation. 
Viewscape Photography - Before and After

After the high-impact zones have been identified and representative viewpoints within them selected, the panoramic viewscape from each viewpoint must be photographed. At this stage it is important that the photographer have a complete understanding of the parameters and appearance variables of transmission line routing so that he may be accurate and inclusive in his photography. It is suggested that three-frame color photo panoramas be taken from a leveled tripod and enlarged and spliced together to approximately $5 " \times 14 "$ ". At least two sets of photos should be prepared, one set to represent "before" and the second set to be touched up with the transmission facilities and right-of-way to represent "after." It is important that the touch-up artist be qualified to perform accurate and convincing representations of the transmission facilities in the landscape, since these photos will be used to simulate their actual postconstruction appearance for visual quality evaluation.

D. EVALUATION OF VISUAL QUALITY

Evaluation of visual quality of each before and after viewscape should be made by at least five evaluators, who will be asked to view colored photographs and record their visual evaluations on a questionnaire (see Appendix B). The following portion of this section is adapted from the Siting Study. Portions of that work would be given to each evaluator prior to the visual evaluation to help define and illustrate the concepts of intactness, vividness, unity and importance, which will be rated and recorded on the questionnaire for each viewscape.

Three Leve1s of Visual Quality Measurement

The viewscape questionnaire actually consists of three levels of visual measurement for each viewscape:

Level 1 - Pre-evaluation Measurement

Level 2 - Overall Visual Attribute Measurement

Level 3 - Elemental Visual Attribute Measurement. 
These three measurement levels were derived earlier during the Siting Study as three slightly different approaches to the evaluation of a viewscape's visual quality. Although these approaches are not mutually exclusive, a11 three were used successfully by a special-competence group in the evaluation of three viewscapes $(9, \mathrm{pp} \mathrm{140-147)}$. Of the three measurement levels, agreement in scores was closest between Leve 11 and Leve1 3. The visual impact scores derived from Level 3 were consistently between Levels 1 and 2. Level 1 depended more upon the evaluator's familiarity with a wide range of landscapes than Levels 2 and 3 (and is therefore more susceptible to bias). Therefore, it appears that Level 3 could be used alone in the assessment of visual impact. The Visual Quality Evaluation Questionnaire(Appendix $B$ ) could thus be shortened to include only those questions pertinent to Leve1 3. However, further testing and comparison between the approaches are necessary.

Level 1 - Pre-evaluation Measurement: This approach allows the evaluator to directly record his immediate visual response to the viewscape, rating its visual quality from 1 (very high visual quality) to 100 (very low visual quality) through Item $A$ of the questionnaire. Consideration is given to the degree of viewscape is distinctive, memorable, stimulating, and overall visually harmonious. Level 1 requires that the evaluator be familiar with a wide range of landscapes and is considerably less specific in its requirements than Levels 2 and 3 . Since it does not force the evaluator to objectively analyze the visual attributes of the elements which comprise the viewscape, Level 1 is more susceptible to bias than Levels 2 or 3.

Level 2 - Overall Visual Attribute Measurement: In this approach, the evaluator's responses to the intactness, vividness, and unity of the overall viewscape are combined into a total visual quality rating for the viewscape. With the questionnaire, the evaluator is given definitions and illustrations of the concepts of intactness, vividness, and unity. The before and after viewscape ratings thus recorded may be combined by use of the formula:

$$
V Q=1 / 3(I+V+U)
$$


where:

$$
\begin{aligned}
& V Q=\text { Visual quality of the viewscape } \\
& I=\text { Intactness from Question B. }(\text { a }) \\
& V=\text { Vividness from Question C. } 1 \\
& U=\text { Unity, as averaged from Questions D. I and D.2; i.e., } \\
& U=\frac{D .1+D .2}{2}
\end{aligned}
$$

Of the three measurement levels, special-competence group scores derived from Level 2 did not agree closely with scores from Levels 1 and 3 . This measurement level may therefore prove to be the least representative of visual impact.

Level 3 -Elemental Visual Attribute Mea surement: This approach combines the evaluator's responses to the intactness, vividness, and importance of each major element of the viewscape with that of unity into a total visual quality rating for the viewscape. Level 3 may be seen to vary from Level 2 in its application of two visual quality attributes (intactness and vividness) to each major viewscape element instead of to the overall viewscape. This is accomplished by graphically subdividing the viewscape into its major elements of sky, landform, vegetation, waterform, and manmade elements and rating each individually rather than collectively. Also, the visual importance score for each major viewscape element is required to put the elements into proper context with each other. These scores are then numerically combined by use of the formula:

$$
V Q=1 / 3(\bar{I}+\bar{V}+U)
$$

where:

$$
\begin{aligned}
V Q= & \text { Visual quality of the viewscape } \\
\bar{I}= & \text { Summation of the intactness scores for each major element } \\
& \text { (from Question B.2) individually multiplied by the importance }
\end{aligned}
$$

\footnotetext{
${ }^{a}$ The Questions referred to in this section are included in Appendix $B$.
} 
scores for each major element (from Question E), divided by the summation of the importance scores of each major element, i.e.,

$$
\bar{I}=\frac{I_{A}\left(\operatorname{IMP}_{A}\right)+I_{B}\left(\operatorname{IMP}_{B}\right)+I_{C}\left(\operatorname{IMP}_{C}\right)+\ldots+I_{Z}\left(\operatorname{IMP}_{Z}\right)}{I M P_{A}+\operatorname{IMP}_{B}+I_{C}+\ldots+I_{C} P_{Z}}
$$

Where the subscripts $A, B, C$, etc., represent each major viewscape element identified in Question B.2.

Similarly: $\bar{v}=$ summation of the vividness scores for each major element (from Question C.2) individually multiplied by the importance scores for each major element (from Question E), divided by the summation of the importance scores of each major element, i.e.,

$$
\bar{v}=\frac{V_{A}\left(I_{A P}\right)+V_{B}\left(I M P_{B}\right)+V_{C}\left(I_{C P}\right)+\ldots+v_{Z}(I M P)_{Z}}{\operatorname{IMP}_{A}+\operatorname{IMP}_{B}+\operatorname{IMP}_{C}+\ldots+\operatorname{IMP}_{Z}}
$$

Where the subscripts $A, B, C$, etc. represent each major viewscape element identified in Question C.2; and

$U=$ Unity as averaged from Question D.1 and D.2.

Level 3 appears to be the most reliable of the three measurement levels presented, judging from the special-competence group analyses of three viewscapes. Although further testing is required for statistical verification, an unbiased evaluation of visual quality may prove to be most accurately undertaken through Level 3 , the elemental visual attribute measurement.

\section{Intactness Evaluation}

The intactness of a viewscape is a measure of its apparent degree of natural condition as judged by its level of urbanization and the degree to which encroachment is present. Level of urbanization is a measure of the presence of man-made development in the viewscape. Degree of encroachment is a measure of the presence or absence of undesirable, 
visually disturbing elements in the viewscape. Encroachment includes such visual disturbances as: garbage heaps, junk yards, trash and/or litter, confusing and inharmonious signs and billboards, mazes of overhead wires, the sources or visual results of air or water pollution, as well as the apparent level of man's physical alteration or visual obscurity of sky, land, or waterforms, as by strip mining, clear cutting, road cuts/fills, wetland or shoreline filling or alterations, diking, riprapping or culverting of streams or rivers, or visual intrusions and unhealed scars in the viewscape.

Overall intactness will be the only factor scored on the questionnaire. This is a combination of level of urbanization and degree of encroachment. It should be apparent that one viewscape may display a very high degree of man-made development with very little visual disturbance (as in a well-designed, carefully maintained urban setting), while another may display a very high degree of visual disturbance and alteration with little apparent man-made development (as in a forested area recently devastated by fire). Hence, it is important to gauge the intensity of development along with the severity of visual disturbance and alteration when measuring the overall intactness of a viewscape.

In general, overall intactness is likely to be scored somewhere between the scores for level of urbanization and degree of encroachment. Seven levels of overall intactness are to be distinguished when scoring this category:

1. Very highly intact

2. Highly intact/little alteration

3. Moderately highly intact/moderately little alteration

4. Moderately intact/moderately altered

5. Moderately low intactness/moderately highly altered

6. Low intactness/highly altered

7. Very low intactness/very highly altered.

Vividness Evaluation

Vividness is the memorability of the visual impression received from the viewscape or its elements. Vividness relates to the level of distinc- 
tion or prominence resulting from contrast or mutual accentuation of diverse viewscape elements. In scoring the overall vividness of the before and after viewscape or its elements, eight complementary effects should be considered: 1) definition of viewscape boundary, 2) diversity of spatial enclosure, 3) degree of topographic relief, 4) diversity of vegetative pattern, 5) prominence of natural features, 6) prominence of waterforms, 7) vividness of sky, and 8) vividness of man-made elements. (See Litton ${ }^{(40)(29)}$ for further discussion of Items $1-6$. A11 items are treated in detail in the Siting Study:) Vividness in the viewscape should be rated on the following scale, before and after the facility is introduced:

1. Very highly vivid

2. Highly vivid

3. Moderately highly vivid

4. Moderately vivid

5. Moderately low vividness

6. Low vividness

7. Very low vividness.

Unity Evaluation

Unity is the degree to which individual elements in the viewscape join together to form a single, coherent, harmonious visual unit. Unity does not require similarity or blandness of interrelated elements; rather, it may depend on an organized balance between visually dominant and subordinate viewscape elements. Vividness depends upon visual contrasts and distinction between diverse viewscape elements, while unity quantifies their visual coherence and compositional integrity. A viewscape of high visual quality is often likely to possess richness and diversity, making it highly vivid, while at the same time possessing a high degree of visual unity.

The overall unity of viewscape elements may be distinguished at seven levels:

1. Very high

2. High

3. Moderately high 
4. Moderate

5. Moderately low

6. Low

7. Very low.

Overall unity and the unity between man-made and natural elements are not necessarily the same as the level of urbanization or degree of encroachment, which together comprise viewscape intactness. Intactness is the relative degree of natural condition of the viewscape, while unity is indifferent to the degree of natural condition and is only concerned with visual integration of the viewscape composition. The degree of unity between man-made and natural elements in the viewscape may also be distinguished at the same seven levels.

Elemental Visual Importance Evaluation

The visual importance of an element in the viewscape is an evaluative rating of its level of visual contribution to the overall viewscape. Visual importance may be related to size, number, singularity, contrast or position. The element of highest visual importance in a viewscape is the one which, if removed from the viewscape (or severely altered), would change the viewscape to the greatest degree. Using this simple guideline, each "after" viewscape element may be assigned a score for visual importance based on the same seven-level scale ranging from very high to very low.

\section{E. DETERMINATION OF VISUAL IMPACT}

Parameters have been given to determine population visual contact and to select representative viewpoints of the proposed facility location by analysis of the facility's viewshed. Questionnaire scoring criteria have been given to evaluate the visual quality of the viewscape from each representative viewpoint before and after the facility is introduced. This section describes the final determination of visual impact using the results of the questionnaire.

Visual Quality - Summation of Measurement Levels

Scores for visual quality obtained from the three measurement levels (Pre-evaluation, Overall Visual Attribute and Elemental Visual Attribute 
Measurements) for before and after viewscapes of each site-facility combination should be compared. Where close agreement exists, the three scores could be averaged for visual quality before and after. Since the scores from the three levels may not be in basic agreement, it may be necessary to depend solely on scores derived from Level 3, because these appear to be the most reliable and indicative of visual quality. For purposes of comparison and scaling, visual quality scores obtained from measurement Levels 2 and 3 must be converted from a 1 to 7 scale to a scale from 1 to 100 .

Ratio of Change in Visual Quality

The change in visual quality (Delta $V Q$ ) of a viewscape before $\left(V_{b}\right)$ and after $\left(V_{a}\right)$ the facility is introduced is the difference between these two scores:

$$
\text { Delta } V Q=V_{a}-V_{b}
$$

In order to record the severity of change relative to original visual quality, it is not adequate to merely express the difference in visual quality before and after the facility is introduced. For example, a facility to be constructed on a pristine lake shore might change a viewscapes's visual quality score from 10 to 26 ; the same facility, built on a semi-developed lakeshore, might change the visual quality score from 20 to 36 ; while if constructed at a more intensively developed lake site, the change in a viewscape's visual quality score might be from 40 to 56. Although the numerical change in visual quality would be a 16 point loss in each case, no acknowledgement of the relative degree of original visual quality of each site is expressed by these scores. However, through the use of ratio, an expression of the relative degree of original visual quality can be retained. This ratio, called the Ratio of Change in Visual Quality $(R)$, is represented as:

$$
R=\frac{V Q a-V Q b}{V Q b}=\frac{D E L T A V Q}{V Q b} .
$$


The value of $R$ will vary according to the relative severity of change in visual quality. If there is no change, $R$ will equal zero. In the three lake site examples given above, the ratio of change would be expressed as:

$$
\begin{aligned}
& R=\frac{26-10}{10}=1.60 \\
& R=\frac{36-20}{22}=0.72 \\
& R=\frac{56-40}{44}=0.36
\end{aligned}
$$

Pristine lakeshore site, 16-point loss of visual quality.

Semi-developed lakeshore site, 14-point loss of visual quality.

Intensively-developed lakeshore site, 12-point loss of visual quality.

The use of $R$ rather than Delta $V Q$ implies that a 16 point decrease in visual quality at a pristine site is less desirable than a 16 point loss at a developed site. Use of $\mathrm{R}$ thus reflects a conservation outlook; i.e., that unique visual resources should be preserved. One could also adopt the view that equivalent decreases in visual quality have the same impact regardless of the original visual quality. In this case, Delta VQ should be used. In making the final route selection, $R$ can either be used directly or converted to a 0-100 scale as shown in Table 1.

\section{Total Visual Impact Determination}

Visual impact is partially a function of the number of people who are present (or may be present in the future) to view the landscape alteration from the surrounding viewshed and partially a measure of the loss or destruction of scarce and fragile visual resources present at the site itself. In order to compare visual impacts of various transmission alternatives, it is necessary to compare the ratios of change in visual quality (designated as $\mathrm{R}$ ) from representative viewpoints of each alternative, multiplied by some factor which accounts for the different viewing populations at each viewpoint (designated as $P$ ). By considering the products of $P \times R$ for the visual impacts encountered at each viewscape evaluated, as well as the number of critical high-impact zones and the scarcity of the visual resources threatened, visual impacts of each alternative route may be compared. 
To illustrate this method, Table 6 displays a tabulated comparison between two theoretical nuclear power plant site alternatives. Visual quality scores for before and after would be those derived by averaging scores from the three measurement levels (or solely derived from Level 3) after all were placed on a scale from 1 to 100 . The ratio of change in visual quality is derived by subtracting $V_{b}$ from $V_{a}$ and dividing the difference by $V_{b}$. Instead of multiplying the ratio of change in visual quality by the total population visual contacts per year, the seventh root of visual contact per year is used (arbitrarily) to reduce the size of the product of $R \times P$. Table 7 displays the analyses of these viewscapes (before) into which a nuclear power plant was introduced (after) by a special group of design and planning professionals. For further discussion and explanation, the reader is urged to see the Siting Study. (9)

\section{F. EXAMPLE OF METHOD APPLICATION}

In the visual impact analysis for a sample case such as that described in Chapter IV(G), the following steps would be carried out to quantify the aesthetic criterion.

Step 1: Prepare four overlay data maps, each shaded or colored to display:

a) Landscape classification and transmission visual compatibility values

b) Scarce and fragile visual resource values

c) Viewer sensitivity values

d) Mitigation potential and future land use values

Step 2: Combine the above maps and integrate the data on a single map to aid in route corridor selection and to identify zones of potentially high visual impact. Select representative viewpoints within each high-impact zone for more detailed visual impact evaluation, photograph these views and prepare sets of 5 " by 14" panoramic color photos to visually represent "before" and "after" viewing appearance for each selected view. 

TABLE 6. Comparison of Visual Impacts Between Two 9 Theoretical
Alternative Nuclear Power Plant Sitings $(9)$

\begin{tabular}{|c|c|c|c|c|c|c|c|}
\hline 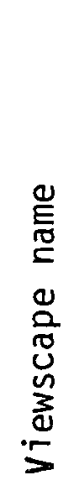 & 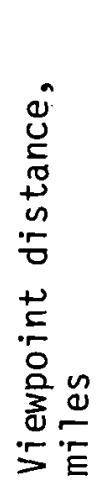 & 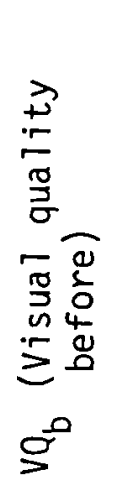 & 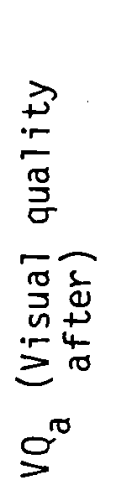 & 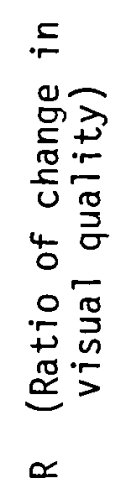 & 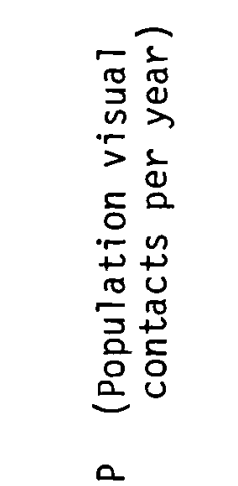 & 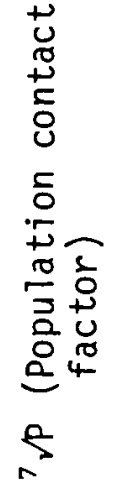 & 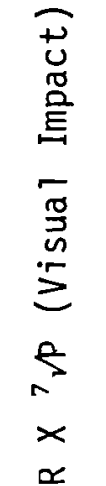 \\
\hline A & 0.5 & 20 & 45 & 1.25 & $2,000,000$ & 8 & 10.0 \\
\hline B & 1 & 25 & 50 & 1.00 & $4,000,000$ & 8.7 & 8.7 \\
\hline$C$ & 1.5 & 30 & 50 & 0.67 & $3,000,000$ & 8.4 & 5.6 \\
\hline $\mathrm{D}$ & 2 & 20 & 50 & 1.50 & $8,000,000$ & 9.7 & 14.6 \\
\hline$E$ & 2 & 45 & 60 & 0.33 & 500,000 & 6.6 & 2.2 \\
\hline $\mathrm{F}$ & 3 & 60 & 70 & 0.16 & $10,000,000$ & 10 & 1.6 \\
\hline G & 4 & 40 & 60 & 0.50 & $2,000,000$ & 8 & 4.0 \\
\hline$H$ & 5.5 & 35 & 50 & 0.43 & $4,000,000$ & 8.7 & 3.7 \\
\hline
\end{tabular}

Average Visual Impact, Alternative 1

6.3

\begin{tabular}{llllrrrr}
\hline$A^{\prime}$ & 0.5 & 30 & 60 & 1.00 & 500,000 & 6.6 & 6.6 \\
$B^{\prime}$ & 1 & 25 & 40 & 0.60 & $5,000,000$ & 9.1 & 5.5 \\
$C^{\prime}$ & 2 & 45 & 55 & 0.22 & $8,000,000$ & 9.7 & 2.1 \\
$D^{\prime}$ & 2.5 & 40 & 60 & 0.50 & 400,000 & 6.3 & 3.2 \\
$E^{\prime}$ & 3 & 20 & 45 & 1.25 & $10,000,000$ & 10 & 12.5 \\
$F^{\prime}$ & 3.5 & 15 & 35 & 1.33 & $8,000,000$ & 9.7 & 12.9 \\
$G^{\prime}$ & 4 & 20 & 35 & 0.75 & $7,000,000$ & 9.5 & 7.1 \\
$H^{\prime}$ & 5 & 35 & 55 & 0.57 & $10,000,000$ & 10 & 5.7 \\
\hline
\end{tabular}

Average Visual Impact, Alternative 2 
TABLE 7. Analyses of Three Viewscapes by Special-Competence Group(9)

Viewscape A
Visual Quality Before After

1 Pre-Evaluation Measurement

2 Overall Visual Attribute

3 Elemental Visual Attribute Average of Measurement Levels 35
63

62

65

63
Ratio of Visual Change

0.96

0.63

0.91

0.80
Viewscape B

1 Pre-Evaluation Measurement

2 Overall Visual Attribute

3 Elemental Visual Attribute

Average of Measurement Levels 40 \begin{tabular}{l} 
Visual Quality \\
Before After \\
\hline
\end{tabular}

39

46

35

60

55

51

55

Visual Quality Before After
Ratio of Visua 1 Change

0.53

0.20

0.45

0.37
Viewscape C

1 Pre-Evaluation Measurement

25

48

35

29

3 Elemental Visual Attribute Average of Measurement Levels 30
47

47

47
Ratio of Visual Change

0.92

0.34

0.62

0.56 
Step 3: Select a panel of at least five evaluators, which may include one member with a professional design background, the balance to be selected from the general public. A series of pretest screening exercises could be given to a larger group to help select evaluators based on interest and ability to respond objectively and accurately within the questionnaire format, and which would also help to normalize responses within the rating scale used.

Step 4: Conduct the visual quality evaluation, with the panel viewing "before" and "after" photos of each view, objectively scaling their responses on a questionnaire (Appendix B) as to the vividness, intactness, and unity of the views represented.

Step 5: Calculate the ratio of change in visual quality for each viewpoint, and multiply this ratio of change by a factor representing the number of viewer contacts per year at each viewpoint. (See Table 7 for a related power plant siting example.) Compare the visual impacts of each route as a function of the frequency and relative severity of negative visual impacts and the scarcity of the landscapes affected. 


\section{REFERENCES}

1. Stanton, Boles, Maguire and Church, A Report on Appearance Planning for BPA, Portland, Oregon, 1966.

2. Louise B. Young, "Forests of the Future," Sierra Club Bulletin, Vol. 58, No. 8, pp. 11-14 +, September 1973 .

3. Ervin H. Zube, David G. Pitt, and Thomas W. Anderson, Perception and Measurement of Scenic Resources in the Southern Connecticut River Valley, Publication No. R-74-1, For Nor thwest Utilities Service Company, Hartford, Connecticut, by Institute for Man and His Environment, University of Massachusetts, Amherst, January 1974.

4. Joe C. Pohlman, "What is the Public's Opinion on Transmission Towers and Poles?", Electric Light and Power, T/D Edition, pp. 59-61, Apri 11973.

5. Allen L. Hammond, William D. Metz, and Thomas H. Maugh, III, Energy and The Future, American Association For the Advancement of Science, Washington, D.C., pp. 101-108, 1973.

6. Alan V. Vaughan, A Background Paper Prepared For the Work-Shop on Visual Impact, Forestry Department, Ontario Hydro, Toronto, Undated.

7. Alan V. Vaughan, A Visual Analysis System to Assist in Locating Transmission Corridors, Forestry Department, Ontario Hydro, Toronto, January 1974 .

8. Peter Jacobs and Douglas Way, Visual Analys is of Landscape Development Department of Landscape Architecture, Harvard Graduate School of Design, 1968.

9. J. B. Burnham, et. al., A Technique for Environmental Decision Making Using Quantified Social and Aesthetic Values, BNWL-1787, Pacific Northwest Laboratories, Richland, Washington, February 1974.

10. B. Christian, "Visual Impact-Interim Report, Port Arthur GS and R.0.W. Study," Forestry Department, Ontario Hydro, Toronto, January 1974.

11. Eckbo, Dean, Austin \& Williams, Proposed Transmission Line Routing, Pacific Gas and Electric Company, San Francisco, 1971.

12. Eckbo, Dean, Austin \& Williams, Environmental Transmission Routing Study, Border Field to Miguel Substation, San Diego Gas \& Electric Company, San Francisco, January 1974. 
13. Johnson, Johnson \& Roy, Inc., Transmission and Distribution Rightsof-Way Selection and Development, Consumers Power Company, Jackson, Michigan, 1970.

14. Landscapes, Limited, EDAP: Environmental Decision Alignment Process, Madison Gas and Electric Company and Wisconsin Power and Light Company, Madison, Wisconsin, Undated.

15. Landscapes, Limited, PERMITS Methodology: Process of Energy Routing to Minimize Impact From Transmission Systems, Bonneville Power Administration.

16. Richard Macias, "A Land Analysis Procedure For Extension of New Energy Networks," Landscape Architecture Quarterly, pp. 240-245, Apri1 1972.

17. New York State Department of Environmental Conservation, Environmental Guidel ine For Electric Transmission Lines (Above Ground) A7bany, New York, October 1973.

18. F. T. Podealuk, "Visual Impact Assessment For the Proposed $115 \mathrm{KV}$ Marathon to White River Right-of-Way, "Forestry Department, Ontario Hydro, Toronto, May 1974.

19. Herbert R. Schaal, "Constraint Maps - The Newest Tool in R/W Selection," Transmission Distribution, April 1972.

20. U.S. Department of Interior, Environmental Criteria For Electric Transmission Systems, U.S. Government Printing Office, Washington, D.C., 1970 .

21. Wirth Associates, A.P.S. $345 \mathrm{KV}$ Transmission Location and Impact Evaluation, Cholla to Saguaro, Arizona Public Service Company, Phoenix, Arizona, Phase II Report, 1973.

22. Jones \& Jones, Scenic and Recreational Highway Study, 1974, Preliminary Draft, State of Washington Legislative Transportation committee, 01 ympia, Washington, Study in Progress.

23. Jones \& Jones, "Visual Impact Assessment, " Foothills Project Environmental Impact Statement, Board of Water Commissioners, Denver, Colorado, Two Volumes, April 1974.

24. Jones \& Jones, "Visual Impact Assessment," Draft Environmental 4(f) Statement, Administrative Action For Project I-90, 1(35) 16Coeur D'ATene to Wolf Lodge Bay, FHWA-IDA-EIS-72-05-F, State of Idaho Department of Highways, Boise, 1973. 
25. K. D. Fines, "Landscape Evaluation: A Research Project in East Sussex," Regional Studies, Vol. 2, No. 1, pp. 41-55, 1968.

26. Grant R. Jones, The Nooksack Plan (An Approach to the Inventory and Evaluation of a River System With Recommendations For the Implementation of a Total Recreation Plan Within the Framework of Ecosystem Management), Jones \& Jones, Seattle, 1973.

27. Grant R. Jones, Preliminary Report For Classification and Evaluation of Visual Landscape, Research paper for the Massachusetts Department of Commerce and Development, Department of Landscape Architecture Research Office, Graduate School of Design, Harvard University, December 1966.

28. Land Use Consultants, "A Planning Classification of Scottish Landscape Resources," Countryside Commission For Scotland Occasional Paper No. 1, Battleby, Perth, August 1971.

29. R. Burton Litton, Jr., et. al., An Aesthetic Overview of the Role of Water in the Landscape, National Water Commission Contract NWC 70-032, University of California, Berkeley, 1971.

30. Kenneth J. Polakowski, et. a1., A Scenic Highway System, Upper Great Lakes Region, Draft Copy, University of Michigan, ApriT 1974.

31. Research Planning and Design Associates, Inc., North Atlantic Regional Water Resources Study, Study of Visual and Cultural Environment, Preliminary Issue, Amherst, Massachusetts, November 1967.

32. Research Planning and Design Associates, Inc., Vermont Scenery Classification and Analysis, Vermont State Planning Office, 1971.

33. Vineyard Open Land Foundation, Looking At the Vineyard, A Vineyard Open Land Foundation Report, West Tisbury, Massachusetts, 1973.

34. P. H. Lewis and B. Murray, Southern Cal ifornia Edison Power Alignment Study, Landscapes Limited, Madison, Wisconsin.

35. Luna B. Leopold, Quantitative Comparison of Some Aesthetic Factors Among Rivers, GeologicaT Survey Circular 620, Washington, D.C., 1969.

36. Kevin Lynch, The Image of the City, The MIT Press, Cambridge, Massachusetts, 1964.

37. Elliot L. Amidon and Gary H. Elsner, Delineating Landscape View Areas--A Computer Approach, USDA Forest Service Research Note PSW-180, Pacific Southwest Forest and Range Experiment Station, Berkeley, California, 1968. 
38. Gary H. Elsner, "Computing Visible Areas From Proposed Recreation Developments. . . A Case Study," USDA Forest Service Research Note PSW-246, Pacific Southwest Forest and Range Experiment Station,

39. R. Burton Litton, "Landscape Control Points: A Procedure For Predicting and Monitoring Visual Impacts," USDA Forest Service Research Paper PSW-91, Pacific Southwest Forest and Range Experiment Station, Berkeley, California, 1973.

40. Carl Steinitz, C. J. Frederick and William Blair, The Interaction Between Urbanization and Land: Quality and Quantity in Environmental Planning and Design; Progress Report for Years One and Two, Appendix Year Two - Visual, L.A.R.O., Graduate School of Design, Harvard University, Cambridge, December 1973. 
VI. MEASURING THE SOCIAL COSTS OF TRANSMISSION TOWER LINES:

A PROPERTY VALUE APPROACH

This chapter addresses the possibility that the social costs of transmission tower lines in suburban areas are reflected in property value changes. If the social costs can be measured by a study of changes in property value, they can be added to the direct construction costs to yield the total economic impact of transmission lines. The existing literature on this subject is weak in that there is little by way of an underlying theoretical model, and the empirical analyses have been superficial. Accordingly, the consistency of the findings-that transmission tower lines (TTL) exert no negative effects on land values-are not persuasive. Moreover, the general issue of the relationship between TTL land value effects and the overall social costs of TTL has been virtually untouched in the literature.

The intent of this chapter is to see what might be learned from previous studies of measuring the "costs" of TTL in other locations and to determine the extent to which the basic approach, empirical analysis, etc. is transferable. Specifically, the theoretical conditions underlying such a property value capitalization thesis are discussed and the applicability of various empirical approaches to measuring this capitalization is examined. This will be done in a context of reviewing a small part of the substantial literature which has been directed to the land/property value effects of public investments such as airports, air pollution abatement, recreation facilities, highways, public housing projects, infrastructure improvements, and flood control projects

This chapter also presents a brief critique of the transmission tower line literature and suggestions for researching the issue. The latter includes description of a brief study approach. Note that this chapter refers to the applicability of the general property value literature to the TTL problem.

The scope of this analysis is limited in several ways. First, only a small fraction of the vast literature on land values and public investment 
location choices is reviewed. There is considerably more to be learned from a thorough review of these studies, and such review clearly should precede a major research effort on this question. Second, this review of the TTL-property value literature is similarly limited. Finally, only the effects of TTL in suburban areas are considered, with passing mention of the urban and rural land value effects.

\section{A. THE UINDERLYING THEORY AND THE TTL PROBLEM}

The basic difficulty with measuring the benefits (costs) of public investments or of alternative public investment location decisions is the absence of a market which permits estimation of the willingness of individuals to pay for public improvements. In the TTL case, the analogous problem is the absence of a market where consumers might reveal their willingness to pay to be near TTL, or their required compensation for being near TTL. Consequently, it is necessary to define a proxy market wherein preferences for these facilities are revealed. The residential land market seems to fit this need for many types of public activities, including TTL.

In general, the use of the housing market as a proxy for the $x$ (TTL) market, ${ }^{a}$ implies the possibility that the demand characteristics in the $x$ market, including consumer surplus, ${ }^{b}$ are transferred to the housing market. There are serious problems with assuming such transferability. Conceptually, it requires the argument that the land market is not characterized by imperfections which make it no better for these purposes than the $x$ market. It is clear, however, that there are imperfections in the land market. Land is not generally homogeneous, knowledge and mobility

\footnotetext{
aThe term "x market" refers to the type of public activity in question, e.g. the voter market, the pollution market, etc.

bConsumer surplus is the price which a person would be willing to pay for a thing rather than go without it; hence the satisfaction which he derives from its purchase generally exceeds that which he gives up in paying its price. He thus derives from the purchase a surplus of satisfaction. The excess of the price which he would be willing to pay rather than go without the thing, over that which he actually does pay, is the economic measure of this surplus satisfaction. An example of consumer surplus is the difference between the market value of a house, and the value which the owner places on the house, i.e., the amount it would take to induce him to sel1.
} 
are not perfect, and buyers and sellers may not be numerous. It is possible, on the other hand, that disaggregation of the land markets into sub-markets (for residences, for business, for single family homes, for certain areas of the city) may increase the homogeneity of land and market knowledge to a point where the market might be relatively free of imperfections. In general, most studies have taken the position that the major imperfections, if they cannot be overcome for these purposes, can at least be taken into account in terms of estimates of their effects on the results of the analysis.

\section{A General Mode1}

It is worthwhile to develop the general theoretical framework for the land value effects of a public investment before turning to the specifics of the TTL problem. The general model presented here is for a public investment in a water supply project as developed by Bahl, Coelen, and Warford. $(1,2)$ The discussion is easily recast in terms of pollution abatement, a recreation area, or any one of a number of benefit-generating public investments. The following section will show how the TTL problem generally fits this theoretical framework and underlines the specific problems raised.

Consider the use of land value increments as a general indicator of the benefits derived from, for example, replacing a well water-septic tank system with a piped water and sewerage system. The basic assumption here is that supplying piped water (sewerage) to a home will raise its market value and that the increase will correspond to the present worth of the consumers' surplus that is expected to be derived from purchases in the water market. Assuming perfect rationality, a person would be willing to pay only an additional $\$ 100$ for a house because it had water facilities, if the difference between the present worth of the utility he gets from the water and the present worth of the amount he expects to pay for the water (that is, the consumer surplus) equals $\$ 100$. If the amount that he expects. to pay for water exactly corresponds to the benefits he personally derives from it, there is no reason to expect him to bid up the price of the house. Clearly, the area under the demand curve for property must 
increase by whatever amount the consumer surplus in the water market increases. This is given by the traditional concept that the area under a demand curve for a good describes the willingness to pay.

The question that is now faced is whether increasing values in the property market correctly capture the effects of the demand shift. That is, it is assumed that the increased consumer surplus area in the water market is "transferred" into an equivalent shift in area under the property market demand curve. We would like to determine whether expenditures on property also increase by this common amount. If they do, then the observations on property sales may identify for us the extent to which water benefits are undervalued by revenues derived from water sales.

\section{Theoretical Framework}

A simple and familiar model suggests that there are, at least, certain assumptions under which benefits and increased expenditures on property are equal. Consider the case where the consumer surplus in the property market remains constant so that the following algebraic model is illustrative of full capitalization. In an area receiving new water supply (the project area), the housing demand function (before the project) is written generally as:

$$
q_{d}=g\left(q_{d}\right)
$$

and, again, for simplicity the housing supply is a constant:

$$
q_{S}=k
$$

It follows that the market equilibrium price can be derived as:

$$
p_{e}=f_{1}\left[g\left(q_{d}\right), k\right] \text {. }
$$

A measure of consumer surplus is:

$$
c=\left[f_{0} f^{k}\left(q_{d}\right)\right]-p_{e^{k}} \text {. }
$$

The effect of a water supply project providing each house with water can be shown through a shift in the demand curve from its initial position. For the same fixed quantity of housing, residents would now be willing to pay a higher rent-the demand curve has shifted upward. Assume that the new demand is: 


$$
q_{d}=h\left(q_{d}\right) \text {. }
$$

Consumers' surplus is now measured

$$
c^{\prime}=\left[s_{0}{ }^{k} h\left(q_{d}\right)\right]-p_{e}{ }^{k}
$$

where $p_{e}{ }^{\prime}$ is defined:

$$
p_{e}^{\prime}=f_{2}\left[h\left(q_{d}\right), k\right] \text {. }
$$

The increase in consumer surplus between the two periods $(\Delta c)$ is:

$$
\begin{aligned}
& \Delta c=c^{\prime}-c=\left[\delta_{0}{ }^{k} g\left(q_{d}\right)\right]-p_{e} e^{k}-\left\{\left[s_{0} s^{k} h\left(q_{d}\right)\right]-p_{\left.e^{k}\right\}}\right. \\
& \Delta c=\left[\delta_{0}{ }^{k} g\left(q_{d}\right)-o_{0} f^{k} h\left(q_{d}\right)\right]-\Delta p_{e} k
\end{aligned}
$$

where $\Delta \mathrm{p}_{\mathrm{e}}=\mathrm{p}_{\mathrm{e}}{ }^{\prime}-\mathrm{p}_{\mathrm{e}}$.

The increase in net benefits $(\triangle B)$ of the water project to residents of the area is equal to the increase in price times the quantity supplied $\left(\Delta \mathrm{p}_{\mathrm{e}} \mathrm{k}\right)$ plus any increase in consumer surplus; that is,

$$
\begin{aligned}
\Delta B & =\Delta p_{e} k+\Delta C=\left[\delta_{0}{ }^{k} g\left(q_{d}\right)-o_{0} \delta^{k} h\left(q_{d}\right)\right]-\Delta p_{e} k+\Delta p_{e} k \\
\Delta B & =\left[\delta_{0} \delta^{k} g\left(q_{d}\right)-{ }_{0} \delta^{k} h\left(q_{d}\right)\right] .
\end{aligned}
$$

If the shift in the housing demand function is such that $\Delta C$ is zero, that is, consumer surplus remains constant, then from (8):

$$
\begin{aligned}
& \Delta c=\left[\delta_{0}{ }^{k} g\left(q_{d}\right)-o_{0} k^{k} h\left(q_{d}\right)\right]-\Delta p_{e} k=0 \\
& \Delta p_{e} k=\left[{ }_{0} s^{k} g\left(q_{d}\right)-{ }_{0} s^{k} h\left(q_{d}\right)\right]
\end{aligned}
$$

and from $(10)$ :

$$
\Delta \mathrm{p}_{\mathrm{e}} \mathrm{k}=\Delta \mathrm{B} \text {. }
$$

If the assumptions behind this simple model are valid, then the benefits of a water supply project will be fully measured in two steps. The first is revenues derived directly through sales in the water market. The second is a measure of the transferred consumer surplus, from water to property markets, and is defined by Equation (13). Their sum gives an unbiased measure of project benefits. In Equation (13), $\Delta B$ is proportional to the increase in house prices, where the constant of proportionality is the stock of housing. If Equation (11) does not hold, then there is both a 
change in housing prices and a change in consumer surplus and the net benefits of the project are measured as in Equation (10).

Required Demand and Supply Conditions

Since the total increase in benefits must be equal to the sum of the price increase and any increase in consumer surplus, a number of conditions must be present for the land value increment to exhaust totally the benefit increment. The first is that the slope of the demand curve for housing in the project area does not change, and a second is that the supply curve is perfectly inelastic. Consider the implications of these assumptions. First, if the demand schedule for housing in the project area changes, one would expect it to become relatively more inelastic-there are fewer good substitutes now that the house has piped-in water. Thus, it would take a greater price increase to bid an individual away from a house with water than it would when the same house did not have public water supply. The implications of such a change in the slope of the demand schedule are that consumer surplus will increase; that is, the difference between the individual's and the market's valuation of the property will increase. This would mean that the sum of revenues from water sales and the property value increment due to a new water supply underestimates the true benefits of a water project. The unmeasured benefits are a return to labor-the consumer--since it is only he who can gain from the consumer surplus as he lives on the property.

For the supply conditions, it is possible that a perfectly inelastic supply is unrealistic. Some elasticity to supply would imply that, as the price of properties in the affected area is bid up, property owners in the area would be induced to offer a greater amount of housing, and ceteris paribus, causing land value increments to understate the increase in net benefits. More specifically, with any supply elasticity, the increase in demand (regardless of how the slope of the demand schedule changes) will be accompanied by an increase in total consumer surplus. Whether average consumer surplus, that is, the average return to a typical consumer, increases is not quite so clear. Similarly, a supply curve having less than perfect elasticity will result in an increase in producers' surplus, and hence a return to capital. 
If either the supply or demand conditions in this simple framework are violated, it is quite likely that the sum of land value increments and revenue from water sales will be an inaccurate measure of true benefits of a water supply. The two measures together, however, will necessarily be more accurate than water sales revenue alone, and, on the basis of the arguments presented above, the error is likely to be on the conservative side.

The TTL Problem

Attention is now turned to the question of how this general model fits the TTL problem, to the kinds of special problems which arise, and how they may be dealt with. The appropriate framework is complicated because two possibilities must be considered: 1) the TTL are installed after the homes are built and purchased, 2) the TTL are installed before subdivision. ${ }^{2}$ In either case, the land value effect argument would seem valid. If the subdivision is already occupied, the affected residents incur a cost equivalent to the sum of the decline in property value and the loss in consumer surplus. If the right-of-way is purchased before subdivision, the problem is one of placing an estimate on the probable magnitude of these losses.

Thus, the eventual consumer incurs neither benefits nor costs, since he has ful1 knowledge of the TTL and this is reflected in the price which he bids for the property. $b$ The difference between the two cases is subtle and is primarily important in terms of "cost" measurement. The thesis is that a property located adjacent to TTL will be subject to two effects: a visual annoyance or nuisance effect which will tend to depress property value, and a space or privacy effect which will tend to inflate property value. The research question addressed here is whether or not there is a net negative effect on property values.

aThroughout this analysis, only the suburban case is considered, to the neglect of the urban and rural case.

bihis point should be studied further in the course of a larger research project. 
The connection between the TTL installation and land value changes may be shown through a backward shift in the demand curve in the property market, i.e., the result of a TTL installation is that the same property is demanded at a lower price. Assume a linear demand curve, ${ }^{a}$ (AD), a perfectly inelastic supply curve (S), i.e., a fixed supply of housing, and assume that the market for property and the backward shift in the property demand curve look as pictured in Figure 3. The area $\mathrm{P}_{E} \mathrm{~Bq}_{E} \mathrm{O}$ is the expenditure on properties before the TTL installation and the total valuation placed on these properties is given as $A B q_{E} O$. Consumers' surplus is $A B P_{E}=A B q_{E} O-P_{E} B q_{E} 0$, the difference between the total valuation of the property and the market valuation.

Assume that, after the TTL, there is a reduction in demand for affected properties to $A^{\prime} D^{\prime}$. The Area, $A^{\wedge} B^{\prime} B A$, is, by definition, equivalent to the decrease in total valuation. The problem then becomes one of showing only that consumer surplus $\left(A^{-} B^{-} B A\right)$ has not changed and that total benefits are equivalent to the increase in expenditures on the property, i.e., to $P_{E} B^{\prime} P_{E} \cdot{ }^{-b}$

The important implication of this demonstration is that for a case where the demand curve shift is parallel, where the supply is perfectly inelastic and where there are no externalities, the change in expenditures

\footnotetext{
aThough linearity is assumed for ease of presentation, the general case is easily inferred, as demonstrated above.

bThe increase in expenditures is determined by $\Delta P \cdot q_{E}$ (since $q_{F}$ is constant). $\triangle P$ is the change in equilibrium: $\Delta P=P_{E}-P_{E}$. The total change in expenditures is given by the area of $P_{E} P_{E B B}$ ? It is necessary to show that $P^{\prime} P_{E} B B^{\circ}$ is equivalent to $A^{\prime} B^{\prime} B A$. From the simplest theorems of plane geometry, it can be shown that $\theta=\theta, B^{-} P_{E}=B_{E}$, and the intersections of $B_{E}$ and $B^{\prime} P E$ with $O A$ and $O A^{\prime}$ respectively are right angles. These are sufficient conditions to guarantee that the areas $A^{\prime} B^{\prime} P^{\prime}$ and $A B P_{E}$ are equa 1. Construction was made so that $A^{\prime} B^{\prime} B P_{E}-A^{\prime} B^{\prime} P{ }_{E}^{\prime}=B^{\prime} B P_{E} P_{E}^{\prime}$. It is evident that $A^{\prime} B^{\prime} B P^{\prime}-A B P_{E}=A^{\prime} B^{\prime} B A$ by construction. FinalTy, by the equal ity between $A^{\prime} B^{\prime} P_{E}^{S}$ and $A B_{E}$, the required result that $B^{\prime} B P_{E} P_{E}=$ $A^{\prime} B^{\prime} B A$ is guaranteed.
} 


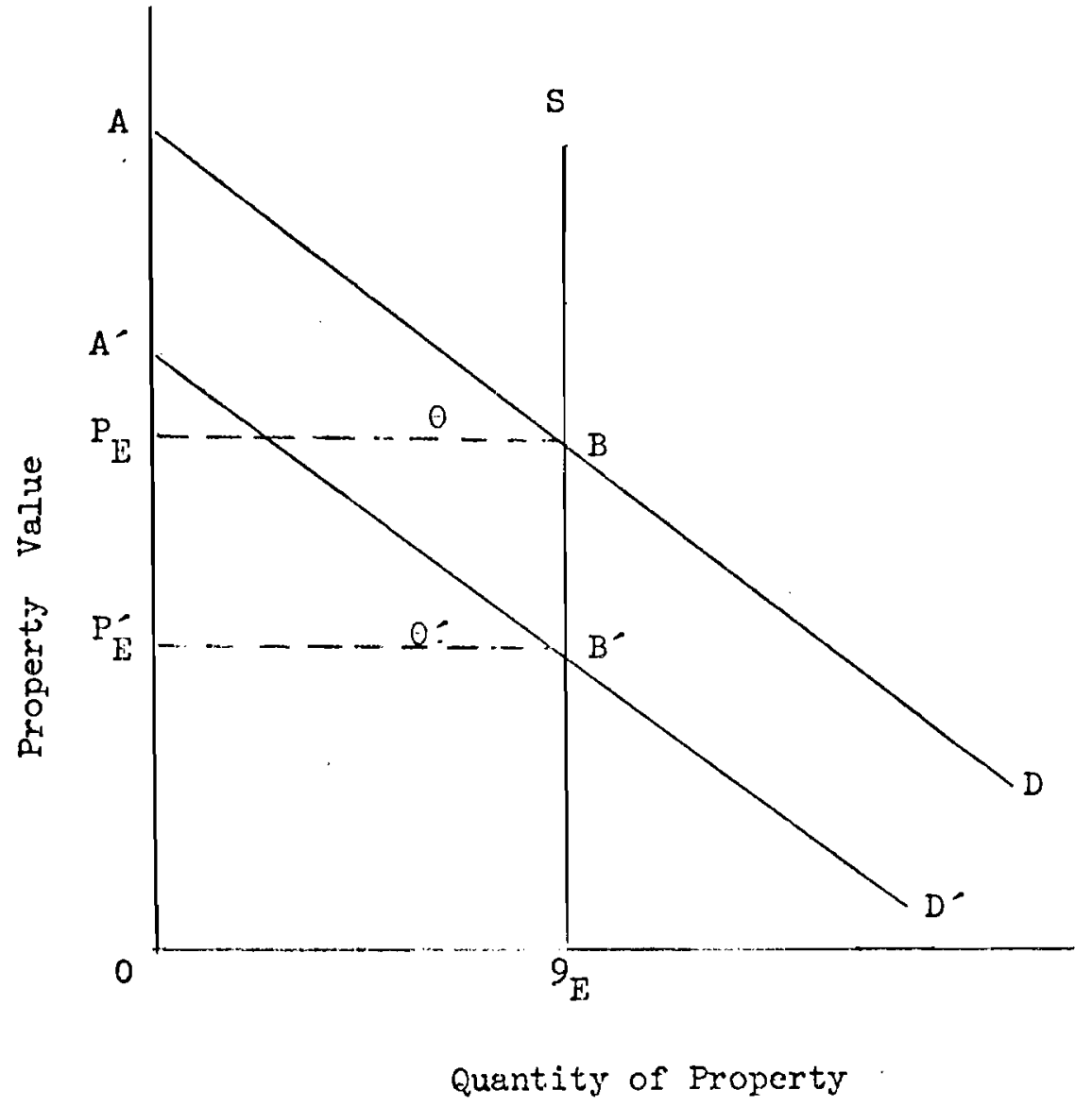

FIGURE 3. Reduction in Demand for Property Inspected by a TTL

on land values fully measures the costs of the TTL installation. If these conditions are not met, the "cost" estimation must include some valuation of consumer surplus loss and external disbenefits.

Whether this general model fits the TTL case would seem to depend on the appropriateness of the following required assumptions:

1. the demand curve shift is parallel;

2. the supply of property is perfectly inelastic;

3. homeowners are perfectly mobile;

4. no externalities are generated; and

5. there are not offsetting property value effects outside the area adjacent to the TTL. 
Given the scope of this analysis, we can only speculate about these assumptions. In general, the model seems more appropriate to the TTL case than to many cases where the traditional land value model has been applied, though some adjustments in the model would seem necessary.

The first assumption, the parallel shift in the demand curve, is required to assure that no change in consumer surplus occurs as a result of the TTL installation. ${ }^{\text {a }}$ In certain cases, this assumption is not easily made. Consider, for example, the effects of a water pollution project on the value of lakeside property. For certain individuals, le.g., water sports enthusiasts), it is conceivable that the difference between the market's evaluation of the property and their own evaluation of the property would be greater after the project, i.e., they would now derive more consumer surplus; the demand curve would have become relatively more inelastic. In such a case, the increase in property value which results from the population abatement project would tend to understate the total increase in benefits from the project. If the slope of the demand curve did not change in response to TTL installation, then it would seem reasonable to assume that demand would become relatively more elastic, i.e., it would now take less of a price increment to bid a homeowner away from his property than it would before the installation. For example, if a person had a strong dislike for a silver tower landscape in his backyard, his valuation of his property may move closer to the market valuation if TTL were installed. If such is the case, the property value method would tend to understate the total "costs" of TTL.

The assumption that the supply of housing is perfectly inelastic seems acceptable for the TTL case. This assumption becomes particularly bothersome when a public investment, e.g., a sewage system, results in lower density zoning and therefore an increase in the supply of residential property. In such a case, the increment in total benefits from the investment

aThis assumption is of primary importance in the case where the TTL are installed after subdivision. In the case where the property is purchased after TTL installation, consumer surplus need not be estimated since the lower price reflects the buyers' total valuation. 
would tend to be understated by observed increments in property values. In the TTL case, this assumption would seem generally valid. It requires only that all subdivision lots be placed on the market simultaneously. There is some evidence that developers have played the role of discriminating monopolists by offering the distant lots only after the TTLadjacent lots were sold. This supply restriction would tend to result in an understatement of the full property value effects.

The mobility assumption is essential to the analysis. If homeowners are not perfectly mobile, i.e., do not have choices of different housing without TTL, the annoyance or nuisance costs of TTL may be borne by them and, of course, will not be observed in property transaction amounts. For the normal TTL suburban case where installation occurs before subdivision, the mobility assumption seems appropriate.

This model also assumes that TTL do not generate "external" effects, i.e., that people other than affected property owners not suffer any disability. Two groups of people conceivably might be affected: homeowners in the subdivision but not adjacent to TTL and passersby who find TTL visually offensive. The model here ignores the latter. The former effect might be captured by estimating a property value effect as a function of distance from TTL, as has been done in the case of water recreation facilities where property value benefits decrease as distance from the water increases. $(3,4)$

The "offsetting property value" assumption has caused considerable problems in studies of this kind. For example, in the case of pollution abatement evaluation, the argument goes that while property values in the project area may rise because of the project, property values in areas outside the project may fall because people will now be willing to pay less for these properties. As a consequence, it is argued that the net benefits of an abatement project are the difference between the property value increase in the project area and the property value reduction outside the project area. To argue that there is a similar difficulty in the TTL case would require the following: that as a result of TTL, land values of adjacent and abutting properties are bid down by prospective home buyers, 
whereas other properties in the area are bid up because they are not in close proximity to the TTL. As long as a housing market and the inmigration of bidders are allowed, it would seem that the offsetting property value question is not relevant to the TTL problem. Hence, it is ignored and it is assumed that the change in property values for affected properties fully reflects the consequences of TTL.

In summary, the TTL problem would seem a valid application of the land value model. Moreover, since TTL installation generally takes place before subdivision, the sometimes thorny consumer surplus problems might be avoided. Finally, the possibility that few external effects are generated simplifies the measurement problems considerably.

Other Applications of the Model

The valuation of benefits/costs using land values has found widespread application and has been influential with respect to public policy. In all cases the underlying model is roughly that outlined above. The use of this technique has been controversial--there has been considerable disagreement over the appropriateness of the assumptions, the estimation techniques used and the interpretation of the results. ${ }^{a}$ In the following sections a brief review of certain of these studies is given to demonstrate the basic rationale for proposing land value effects and to summarize roughly the results of the analyses.

\section{Air Pollution}

There has been much interest in the possibility of using property values to measure the damage attributable to air pollution or the benefits to be expected from air quality improvements. The general issues surrounding this part of the 7 iterature are we 11 stated by Freeman. ${ }^{(7)}$ In theory, it would be expected that the value of property, particularly residential property, should be influenced by the quality of the environment surrounding that property. Of particular interest is the quality of

aA particularly spirited debate centered around the use of this approach in the measurement of the cost of airport noise in connection with selection of the third London Airport site. $(5,6)$ 
air, since in many urban areas air poliution is a major problem and considerable resources may be devoted to its control. Planning for air pollution control policies could be facilitated by a method for estimating the benefits of air pollution control.

Probably the best-known empirical study in this area is a case study by Ridker and Henning ${ }^{(8)}$ on the effect of air pollution on land values in St. Louis. Their main conclusion is that:

. . if the sulfation levels to which any single-family dwelling unit is exposed were to drop by $0.25 \mathrm{mg} / 100 \mathrm{~cm}^{2} / \mathrm{day}$, the value of that property could be expected to rise by at least $\$ 83$ and more 1 ikely closer to $\$ 245$. Using the latter figure and assuming the sulfation levels are $0.25 \mathrm{mg}$, but in no case below $0.49 \mathrm{mg}$ (taken as the background level), the total increase in property values for the St. Louis Standard Metropolitan Statistical Area could be as much as $\$ 82,790,000$.

The Ridker-Henning model has been readapted several times for air pollution studies. $(9,10)$ A number of instructive criticisms have been leveled at the Ridker-Henning approach by other authors. These criticisms are aimed particularly at the assumptions of inelastic supply and the ignoring of offsetting declines in property value elsewhere.

Freeman ${ }^{(7)}$ is critical of the assumptions that one might implicitly assign to the empirical model used by Ridker and Henning. First, he suggests that we cannot worry about whether the land value changes measure benefits exhaustively, when we cannot even determine whether, or to what extent, demand or supply factors are at work:

In any urban area this relationship (property valueair quality) is the result of the interaction between the availability of land with different levels of air quality (supply factor) and tastes and preferences, other prices, income, and its distribution (demand factors). For any given set of demand factors, different supply factors will lead to different patterns of property values and different regression results.

Moreover, the pollution abatement project effectively changes the supply conditions under which the relationship between property values and air quality was originally estimated; and he argues 
This equation only purports to explain the variation in mean property values among observations. The air pollution coefficient can be used to predict the difference in property values between two properties within a system under ceteris paribus conditions, and these conditions must include no change in air quality over other land in the system. But the regression equation cannot be used to predict the general pattern of property values or changes in the value of any given property when the pattern of air quality over the whole urban area has changed.

Edel (11) makes a similar criticism:

If pollution in all districts of St. Louis were reduced to the $0.49 \mathrm{mg}$ "background" level, demand for space in the formerly most polluted neighborhoods would certainly increase. But this increase might come at the expense of demand in census tracts that formerly had a unique advantage in low pollution levels. The $\$ 82,790,000$ estimate assumes that demand will increase in the newlycleaned areas to equal demand elsewhere now, without the balancing effect of demand reduction. It is therefore almost certainly an overestimate.

Ede1's analysis correctly points to the fact that, while the estimate of $\$ 82,790,000$ may or may not be a correct assessment of the value or benefits of a pollution abatement project, it is doubtful if such a change in overall property values would in fact be revealed. However, as long as each property would increase in value by $\$ 245$ if pollution levels were reduced, it makes little difference whether the increase in price really occurs or not. It is only the willingness to pay the additional amount that matters. Edel also concluded that the difference between net benefits of $\$ 82,790,000$ and the actual change in land values determines the distributional effects of the investment. Thus:

Notwithstanding the error in this prediction of property value changes, Ridker and Henning may be correct in the ir estimation of an $\$ 82,790,000$ value for the removal of pollution. If the $\$ 245$ that is now bid for the advantage of a less-polluted house represents the average of the values that all consumers would place on clean air, then multiplying this by the number of households should give the total benefit of cleaner air. The difference between this figure and the lower change in property values would be a consumer surplus accruing to the 
families whose housing costs fell. Total land price

changes would then be an inadequate measure of the

benefits of an air cleanup, although the comparison

of prices between polluted and non-polluted areas

would allow a measure of the benefits.

Another way of saying this is that the extrapolation of the increase in property values in an area that is subject to environmental improvement to the whole area may 1) overstate the total increase in property values for the whole area, because prices outside the project area might fall, but 2) still be a measure of value, the reduction in values elsewhere simply being a transfer item or redistributional effect. Strotz, however, goes further, as outlined below.

\section{Airport Noise}

The location of airports, it is argued, produces two effects on area residents. It raises the value of their property because of proximity, and it creates a noise nuisance which may be seen as a "cost." Little has been done, in a systematic way, on the former. (12) The latter has been studied using an approach such as that defined here. The Roskill Commission on the Third London Airport valued aircraft noise annoyance as the fall in house prices due to the noise. In order to estimate noise costs, the population in "noise-affected" areas around the airport is divided into three groups. The first are those who are "natural" movers in that they will leave before or during the life of the airport for reasons unconnected with the noise. When they move they are counted as suffering a cost equal to the decline in their property values due to noise. The second group are those who move because of the noise. These suffer a loss equal to the decline in their house value, the removal cost which they must incur, and a consumer surplus loss, i.e., an amount necessary to make up for the upset of leaving the house, the neighborhood, perhaps a longer journey to work, a change of job, etc. The third group are those who stay and suffer the noise. Their loss is defined as the sum of money which would just compensate them for the nuisance suffered 
and make them as well off as before. " This amount is assumed to be exactly equal to the depreciation in property value which results from the noise. The value of removal costs is estimated in a straightforward way; the consumer surplus loss is estimated through survey techniques, and the property value loss is estimated by comparing the increase in prices of houses inside and outside the Gatwick airport noise area. The results of this analysis are shown in Table 8 ; they show that the differential in price as a percentage in house value is greater for more expensive houses and greater in more noisy than in less noisy places. A very rough interpretation of this data would suggest that the "cost" of noise varies directly with income level.

TABLE 8. Percentage Depreciation of Property Values Inside and Outside the 35 NNI $^{*}$ Contour

\begin{tabular}{lrrrr}
\multicolumn{1}{c}{ Class of Property } & & $35-45$ NNI & & over 45 NNI \\
Low Priced (mean 3,000) & & 4.5 & & 10.3 \\
Medium Priced (mean 6,000) & & 9.4 & \\
High Priced (mean 10,000) & & 16.4 & & 29.0
\end{tabular}

* No ise and Number index.

The inference about the total cost of noise at alternative sites for the third airport was computed on a basis of these land values, estimated consumer surplus, estimated removal costs, and estimates about the percent of resident population in each of the candidate areas that would fall into each of these three population groups defined above. On that basis, four alternative locations were compared according to residential noise costs.

This technique, used in the third London Airport study, has been subject to considerable criticism. $(5,6)$ Basically, the critique centers

at is interesting to note, in connection with the TTL case, that those who move into the noisy area are assumed to suffer neither costs nor benefits. For them, noise annoyance is offset by a lower house price. 
around the set of assumptions which were made. These include the criticism that depreciation of house property due to noise represents marginal rather than average annoyance and is dependent on the relative supplies of quiet and noisy houses. It also indicates what someone will pay to escape noise rather than what he needs to be compensated for enduring it. It is argued that the latter amount may greatly exceed the former and, therefore, estimates of the costs incurred by the third group noted above may be artificially low.

One result of the London airport study which seems to be in conformance with other studies is that higher-income residents would appear to place a higher value on quiet than do lower-income residents. Plessas (12) reports "the low-income groups are less likely than higher-income groups to show distress with respect to noise; moreover, they are less politicized, less likely to bring pressure to bear on airport authorities." The Jamaica Bay study ${ }^{(13)}$ suggests that these phenomena are known to airline officials, who increasingly employ flight patterns over poorer residential neighborhoods.

It is clear that, in nearly all land value benefit studies, too little attention has been paid to the effects of resident-income level or the capitalization of benefits/costs into property values. Moreover, the interpretation of what work has been done in this area may be misleading.

\section{Recreation}

A third area where benefits have been assumed capitalized to land values is in connection with recreation and park facilities. The argument goes that land values will tend to be bid up in response to the location of a recreational facility, and they will be bid still higher if located closer to the facility. Caughlin and Hammer ${ }^{(3)}$ in a study of a Philadelphia Park used a regression model to find property values (house and land) to be $6.8 \%$ higher at 40 feet from the park, $1.4 \%$ higher at 1,000 feet, and $0.6 \%$ higher at 2,500 feet. Measurement problems associated with estimating these gradients are substantial, and some studies have met with little empirical success. Weicher and Zerbst, ${ }^{(21)}$ in studying five parks in the Columbus, Ohio area, use a regression model to conclude that properties facing a park se 11 for $23 \%$ more than do identical properties elsewhere. 
Hendon ${ }^{(14)}$ has studied the interesting park-school combination effect on land values. In theory, it might be expected that schools create nuisance value for residential groups who live immediately adjacent to them. On the other hand, in certain cases, parks may create increased residential property values. Hendon's study was an attempt to estimate the net property value effect of a park-school combination. Because of empirical estimation and data problems, the results of his case study in Dallas, Texas were indeterminate.

In general there is much fault to be found with the recreation benefitsland value study. Most of the criticism, however, has to do with the data used in the studies and with the specific estimation techniques. These issues will be dealt with in the empirical methods which follow.

\section{Transportation}

In the transportation field, economists and geographers have long attempted to value travel time to individuals by reference to property value variations within the city. Early studies, such as that by Mohring and Harwitz ${ }^{(15)}$ on transportation, neither looked at property value changes as a direct benefit measure nor considered the effects of different capitalization rates on the mode1. Using Mohring and Harwitz's work as an example, however, we can transform these studies into a style that does explicitly treat land value changes. Further it is easy to expose implicit assumptions that point to a rather rigid consideration of capitalization mode1s. Mohring and Harwitz explain observed variance in rent as a function of travel time differentials. Their treatment of the benefits of highway investments requires that the value of time savings be totally capitalized into land values. Their basic equation describing such benefits is:

$$
R_{i}-R_{j}=2 N\left(T_{j}-T_{j}\right) V_{T}
$$

where $R_{i}, R_{j}=$ site rents at $i, j$

$\mathrm{N}=$ number of trips taken to the central area

$T_{j}, T_{j}=$ travel time from $i$ and $j$ to the central area and $V_{T}=$ value of travel time. 
While, empirically, many other considerations of site attractiveness must be entered into the equation, Equation (14) can be solved for $V_{T}$,

$$
\frac{R_{i}-R_{j}}{2 N\left(T_{j}-T_{i}\right)}=V_{T} \text {. }
$$

In this context, the benefits of a transport improvement--the value of time saved--may be described as:

$$
\Delta T \cdot v_{T}=\Delta T \cdot \frac{R_{j}-R_{j}}{2 N\left(T_{j}-T_{i}\right)}
$$

where $\Delta T$ is the reduction in time necessary to get from $i$ or $j$ to the central area.

The assumption of full capitalization of time-saving benefits into site rents is made clearer by assuming that $i$ and $j$ are the same property but $i$ is before and $j$ after the transportation project. The value of time is assumed to be a constant and the net change in total time spent in getting from the property in question to the central area is $2 N\left(T_{j}-T_{j}\right)$, that is,

$$
\Delta T=2 N\left(T_{j}-T_{j}\right) .
$$

Applying (17) to (16) we can obtain time-saving benefits:

$$
\Delta T \cdot v_{T}=R_{i}-R_{j}=\Delta R
$$

where $\Delta R$ is the land value increment associated with this property and due to the transportation project. All benefits are reflected in this increment; that is, there is an assumption of $100 \%$ capitalization of benefits.

\section{Flood Control}

An interesting group of studies of agricultural flood control benefits and land values has been conducted by the Economic Research Service (ERS) of the United States Department of Agriculture for the Army Corps of Engineers. ${ }^{(32)}$ These studies involved developing and testing a methodology for using land values to estimate benefits to agricultural land from 
flood-control projects, and therefore they represent an attempt by the Corps to consider alternative procedures for estimating one type of water resource development benefit.

The analytical procedure adopted was the multiple-regression model to estimate the differential land value effect resulting from the reduced probability of flooding. In one of the ERS studies, the coefficients for a regression equation involving the determinants of value were estimated for land with no flood risk; these coefficients were then used to calculate the full protected value of land subject to flooding. This estimate of fully protected value permitted the calculation of a difference between the per-acre price of land in the floodplain and the price of this land if it were fully protected; this differential was used as the dependent variable in the regression analysis. In another study following the ERS methodology, the dependent variable was the per-acre value of the farm without improvements. In both tests of the methodology, a large number of variables that might be expected to influence farm land values (such as the size of the tract, acres of cropland, and quality of the soil) were employed as independent variables. To these variables a number of terms reflecting the risk of flooding were added to measure the effect of flooding on land values.

These applications or tests of the ERS methodology were made in different river basins. The first involved three study areas in the wabash River basin (upper Wabash, lower Wabash, and White River) with a considerable difference in the geographic character of the land. In the upper and lower Wabash areas, after controlling for differences in productivity, topology, location, and date of the sale, a statistically significant differential was found in the value of land per acre associated with flood risk between farms located on the floodplain and the upland area adjacent to the flood plains. In the white River analysis the differential in land values associated with flood risks could not be established. The Wabash study only partially involved an evaluation of the benefits of a particular flood-control project. There was also a quantification of the benefit that might be expected if new flood-control projects were undertaken. 
The second application of the ERS methodology was for the Saint Joseph reaches of the Missouri River. This study area contained some levees (both public and private), a fact which enabled the study to relate land values to an existing water development facility. Again three study areas were employed: an unprotected floodplain area, a protected floodplain area, and an adjacent upland area. The results of the Missouri application generally reinforced those of the Wabash application in that statistically significant differentials were established between differences in 1 and values and flood risks.

While these projects assign a dollar value to flood protection, they do so only with a rather low level of confidence. In the Missouri River study; it was found that the average premium for flood protection was $\$ 25$ per acre but the interval necessary for a $90 \%$ level of confidence was $\$ 0$ to $\$ 50$. This same sort of wide confidence interval was found in the upper Wabash study, where the value of flood protection was estimated to be $\$ 49$ per acre, with a $\$ 14$ to $\$ 84$ range required for a $90 \%$ level. In the lower wabash the flood protection was estimated to be $\$ 5.89$ per acre per year--with a range of $\$ 5.06$ to $\$ 6.72$. While these ranges are quite large and seem to have troubled the Corps, they may not be any greater than the ranges of the estimates of the Corps' benefits if a confidence interval could be calculated for its estimates.

For the Wabash study it is possible to compare the ERS estimates of benefits with independent benefit estimates made by the Corps through its standard estimating procedure. In the upper Wabash the Corps' estimate of benefits was $\$ 40$ per acre-reasonably close to the $\$ 49$ ERS estimate and we11 within the $\$ 14$ to $\$ 84$ range. For the lower wabash estimate the Corps and ERS estimates are somewhat closer ( $\$ 6.81$ versus $\$ 5.89$ ), but the Corps' estimate is slightly above the upper bound of the confidence range of $\$ 6.72$.

Thus, the ERS procedure seems to produce estimates that 1) have a relatively high standard error but 2) are within $20 \%$ or so of Corps' estimate. 


\section{Other Studies}

Scores of other studies of the effects of pub1ic investments on land values have been undertaken, with wide variations in empirical results. Nourse, (17) Rothenberg, (18) and Schafer (19) have attempted to measure the effects of increased intensity of low-income housing on neighborhood property values. Neither Nourse nor Schafer found any relationship between the incidence of low-income housing and neighborhood property values.

\section{B. THE EMPIRICAL APPROACH}

There are a number of possible methods for estimating the land value effects of public investments, or in this case, of TTL. The measurement problem is complicated by several issues, e.g., how does one obtain adequate property value data? How can the effects of "other factors" be adjusted for? Should cross-section or time series data be used? It should be noted that a completely satisfactory measurement technique has yet to be developed, and, as noted above, the many different approaches taken have yielded a substantial range of results.

The measurement problem might be divided into a) the problem of measuring the dependent, property value variable, and b) the problem of defining the appropriate estimating technique. This section will review the techniques which have been used, focusing on how these two problems have been faced in past work.

Measuring the Property Value Variable

Four different approaches have been taken to measuring the property value variable-census housing value data, tax assessor's rolls on assessed property values, judgmental appraisals by real estate agents, and actual transactions data. All four have major strengths and weaknesses.

\section{Census Data}

Ridker and Henning, (8) in their study of the benefits of air pollution abatement, used the median value of owner occupied dwelling units as reported in the decennial population census. There are some advantages 
to using census data. It is easily taken from published volumes on a census tract basis. As Henning and Ridker point out, there are some advantages to utilizing averages by census tracts instead of individual observations-errors in estimating the values of individual houses tend to cancel out; fewer explanatory variables, particularly those related to the idiocyncrasies of individual houses and their owners, need be considered; and the air pollution data may be accurately applied to neighborhoods. On the other hand, there are a number of problems with using census tract data-the values are based on homeowner estimates and consequently there is a danger that large response errors are present; the data only cover owner-occupied units and exclude renters; and these data are available only every ten years. Finally, there is the problem that census data are not presented on an individual housing unit basis and, therefore, for certain types of problems, it would not be useful. This is particularly true in the case of the TTL problem, where the property value data would need to be measured for perhaps a row of houses along a block rather than for an entire census tract. In general, the census property value information would seem to be of little use in the TTL problem.

\section{Assessed Property Values}

A number of studies have relied on property tax assessed value as a measure of property value. $(14,4)$ Assessed values have the advantage of being available on an annual basis for individual properties. Assessed value, however, compared to sales price, is an inferior proxy because it may not reflect a free market expression of different individual evaluations of property relative to other purchase options. At worst, it may reflect only what the assessor feels different features of a property are worth. In that sense, an analysis of property value differentials as might occur in response to the installation of a public facility may reveal only the assessor's evaluation of the effect of that facility on property values. Given the workload of assessors, their often judgmental approach and their susceptibility to political pressures, assessed values would seem an undesirable measure of property values for the purposes at hand. 


\section{Real Estate Appraisals}

Perhaps the least-used approach to estimating the property value effects of certain investment types is the interviewing of real estate agents. This approach was taken in the Third London Airport Study.

Clearly, there are disadvantages to this approach, the most important one being that the agent's evaluation is subjective. Particularly if the public facility in question is a relatively new phenomenon in the area, these judgments could result in little more than a guess. On the other hand, the large number of real estate agents in a particular area should be sufficient to cross-check the estimates obtained. Moreover, the basic information available to real estate agents should provide documentation of asking prices, bid prices, and final sale prices.

\section{Transaction Prices}

The most common method of measuring property values is through the use of actual sales prices. $(1,2,15,19,20,21)$ These data are readily avai1able from either the tax assessor's office or the land transactions office. Unless there is some special arrangement between buyer and seller, the stated price generally represents the market value of the property. The disadvantage, of course, is that such data on property values are available only for years in which transactions take place and consequently are influenced by market conditions in that particular year. As a result, the use of either time series or cross-section analysis requires that the observed sales value data be adjusted to reflect these peculiarities.

\section{Framing the Empirical Approach}

Two approaches have been taken to estimating the property value effects of a public investment. They are similar in that both compare property values in the affected area with those in a control area. They differ in that one uses only cross-section data while the other uses pooled cross-section and time series data.

The pure cross-section approach is straightforward in that it compares estimated property values for a set of affected and nonaffected properties 
at a given point in time. The estimated difference in the property values is taken as the effect of the public investment in question.

The pooled cross-section, time series technique is more complicated. The procedure appears quite simple on the surface. Property values in the "project" area are compared with property values in a similar "control" area over a period which includes installation of the project. The difference in property value increase observed during the relevant period is approximately the result desired here. There are, however, two relatively serious measurement problems to be dealt with in this context. The first is the adjustment of the data for differences between the control and project areas which may distort the results. The second has to do with the development of a technique for the sheer handling of such a mass of data, i.e., comparing control and project area property value increases when value observations are available for individual parcels for different years in the series. The empirical method which has been developed to deal with these problems is presented in some detail in the next section.

The theoretical model presented above suggests that an investment will have immediate property value effects in those areas where properties are intrinsically changed by the investment. Such an area is called a "project" area. In other areas where properties are not intrinsically affected by the investment, there is no general equilibrium land value reaction to the investment. That is, the investment in the project area has no effect on land value in these areas. When chosen on a basis of similarity with the project area, these nonaffected areas are designated here as "control" areas.

The choosing of a "control" area which bears appropriate similarity to the project, or study area, poses considerable difficulty. However, such similarity is of great importance because of the need to cancel out as many exogenous influences as possible without direct adjustments in the model. With respect to the objectives here, the similarity sought has to do with the mean and variance of variables such as housing and population density, income, age and value of housing, ethnic mix, and location within 
the metropolitan area. Choosing areas with these similarities should avoid direct analysis of many of the basic factors affecting land value growth. The control area is expected to react identically (to the project area) in. response to any change other than the investment itself. The control area information generally lends itself as a correction for long- and short-run secular and cyclical trends in the project area data, i.e., except for periods when the project area has been influenced by the investment, the project and control areas should have identical time trends in property values. During the periods when the investment affects property values, the time trends on project and control area property values diverge. It is this divergence which we wish to measure.

\section{ALTERNATIVE ESTIMATION MODELS}

The following descriptions illustrate the range of possibilities for statistical analysis: 1) a naive analysis, 2) a pure cross-section study, 3) a pooled cross-section time series analysis, and 4) a recreation benefits analysis where land value effects are measured in terms of distance from the recreation facility.

The Naive Approach

A naive approach, as used here, will refer to an analysis which deals with the problem on an intuitive basis and which does not present either the theoretical underpinnings of the analysis or attempt to resolve the more difficult empirical problems.

An example of a naive analysis may be drawn from the study of the effects of TTL on property values in Montergomery, Prince George, and Howard Counties, Maryland. (22) The approach taken in this study is intuitive and straightforward. In each of nine subdivisions, properties were divided into those adjacent to the transmission facilities and those not adjacent. The latter are taken as the control properties. In smaller subdivisions, al1 of the properties were included in the analysis. In larger subdivisions, a sample of comparable properties, two to four times the number of lots adjacent to the right-of-way were chosen as the control 
area. All sales records for each property in the sample were then compiled, with state and federal revenue stamps used to determine total consideration of each sale.

While the researchers were apparently careful in their attempt to select comparable control areas, at least two serious problems remain with the analysis. One is that no attempt is made to adjust the percent property value increase between sales for the year in which the sale took place. Clearly, changes in the general economy and in the housing market in particular would suggest that, for example, a four percent annual increase between 1951 and 1955 and four percent annual increase between 1961 and 1965 may not be comparable figures. The second and perhaps more important problem with this analysis is that the observed differences in the property value increase between adjacent and nonadjacent properties were never tested for significance. Since there is a substantial variation in the observed rates of property value increase, it would have been useful to determine whether the differences between adjacent and other properties, observed in mean value increase, are in fact statistically significant.

\section{A Cross-Section Approach}

A good example of the cross-section approach is the Henning-Ridker air pollution study. They attempt to measure the effects of different levels of air pollution on housing values. For pollution, they use a measure of sulfation level which is an index indicating the presence of $\mathrm{SO}_{2}, \mathrm{SO}_{3}, \mathrm{H}_{2} \mathrm{~S}, \mathrm{H}_{2} \mathrm{SO}_{4}$, and in some instances dustfall. They include a number of other independent variables to adjust for other population and housing characteristics. The results of their regressions on data for 167 census tracts are presented here in Table 9. From the equation presented in Table 9, it may be estimated that a drop in the sulfation level of $0.25 \mathrm{mg} / 100 \mathrm{~cm}^{2} /$ day would increase property values by $\$ 245$.

\section{A Pooled Cross-Section, Time Series Approach}

Another approach would compare a "project" and "control" area over a period of time to measure the land value effects. Variants of this approach are used in Bailey, Muth, and Nourse ${ }^{(23)}$ and Bahl, Coelen and Warford. $(1,2)$ 


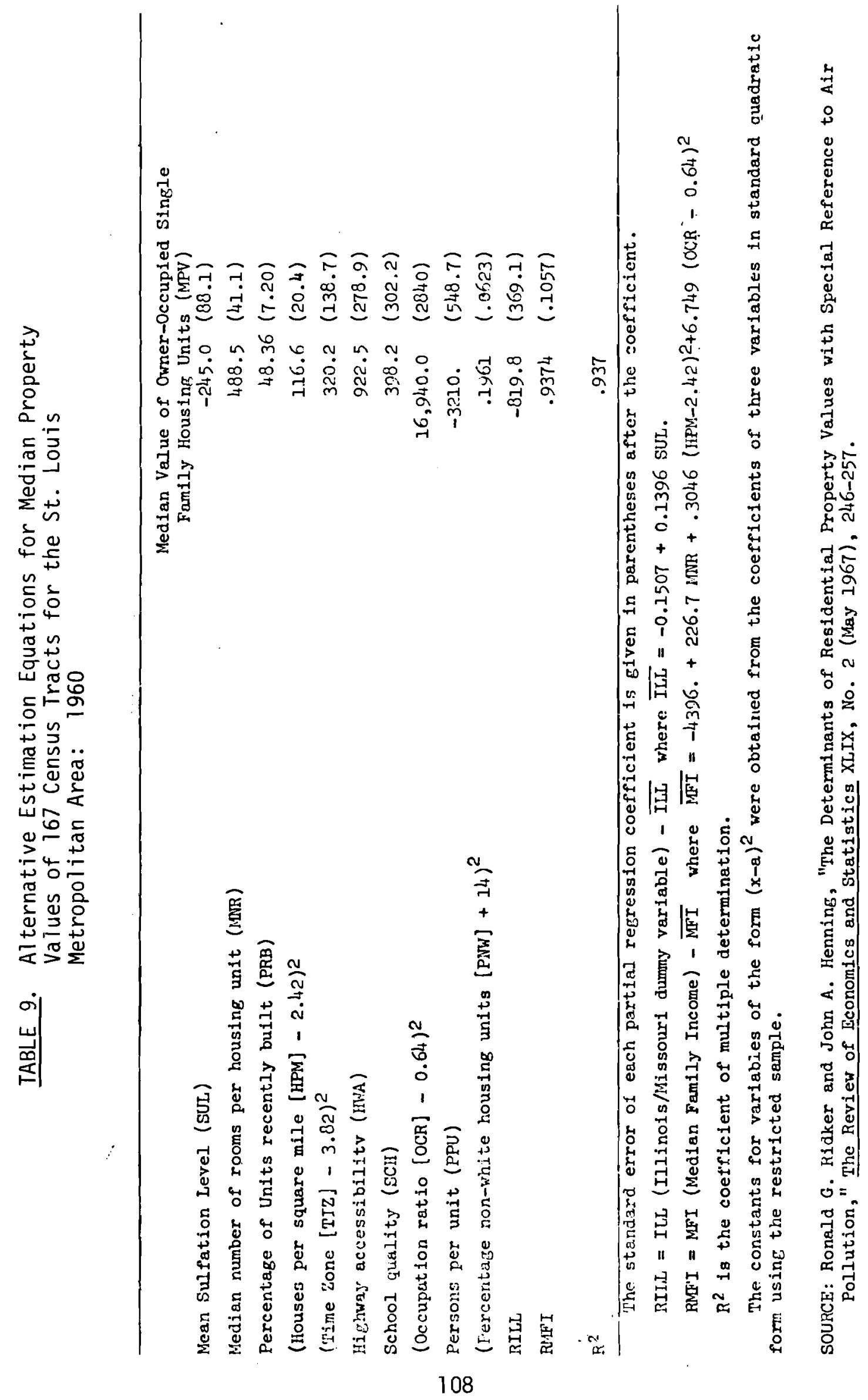


The basic data used in such an analysis are recorded sales values. However, properties sell at irregular intervals with the result that, over a study period of any given number of years, sales value data are available for different properties in different years. To illustrate the problem, assume that sales value data were recorded for $\mathrm{N}$ properties in the control and project areas over a period of $t$ years. It would be possible to compute a rate of growth in property value between any two years, for any property which sold between those two years. These rates of growth might be arrayed in the following type of table:

\begin{tabular}{|c|c|c|c|c|c|c|}
\hline $\begin{array}{c}\text { Property } \\
\text { Number } \\
\end{array}$ & & & ombina & $s$ of $Y$ & & \\
\hline 1 & $\operatorname{rog}_{12}$ & $\operatorname{rog}_{13}$ & $\operatorname{rog}_{1 t}$ & $\operatorname{rog}_{23}$ & $\operatorname{rog}_{2 t}$ & $\operatorname{rog}_{t-1, t}$ \\
\hline 2 & $\operatorname{rog}_{12}$ & $\operatorname{rog}_{13}$ & $\operatorname{rog}_{1 t}$ & $\operatorname{rog}_{23}$ & $\operatorname{rog}_{2 t}$ & $\operatorname{rog}_{t-1, t}$ \\
\hline 3 & $\operatorname{rog}_{12}$ & $\operatorname{rog}_{13}$ & $\operatorname{rog}_{1 t}$ & $\operatorname{rog}_{23}$ & $\operatorname{rog}_{2 t}$ & $\operatorname{rog}_{t-1, t}$ \\
\hline . & & & & & & \\
\hline . & & & & & & \\
\hline - & & & & & & \\
\hline K & & & & & & \\
\hline$K+1$ & & & & & & \\
\hline$K+2$ & & & & & & \\
\hline . & & & & & & \\
\hline • & & & & & & \\
\hline$\cdot$ & & & & & & \\
\hline$N$ & $\operatorname{rog}_{12}$ & $\operatorname{rog}_{13}$ & $\operatorname{rog}_{1 t}$ & $\operatorname{rog}_{23}$ & $\operatorname{rog}_{2 t}$ & $\operatorname{rog}_{t-1, t}$ \\
\hline
\end{tabular}

where $\operatorname{rog}_{12}$ is the compound rate of growth in property value between years 1 and 2 , and $\operatorname{rog}_{2 t}$ the rate of growth between year 2 and the year $t$ (the last year included in the study). If the first $k$ rows in the table represent properties in the project area, if rows $\mathrm{K}+1$ to $\mathrm{N}$ represent properties in the control area, and if property sold every year so that every rog $_{i j}$ could be calculated (i.e., every cell could be filled), the estimation 
of the property value effects of the investment would be straightforward. That is, the difference between the average rates of growth in the project and control areas around the "investment year" would yield the property value effect of the investment. In practice, the fact that all properties do not sell every year complicates the estimation process considerably. It becomes necessary to use those data on sales values which are available to impute values for the missing $\operatorname{rog}_{i j}$, i.e., to estimate on the basis of existing data on rates of growth in value what the rate of growth in value would have been had each property sold every year. The comparison between project and control area property value growth rates may then proceed using the mixture of observed and imputed growth rates.

The total procedure requires eight steps. First, the observed rate of growth between any 2 years when the property sold is calculated. If a property sold in years 1, 7, and 12, of say, 20 years studied, then growth rates in value may be computed between years 1 and 7,1 and 12 , and 7 and 12. Second, the growth rates between every combination of 2 years for which data are available are averaged separately for the control and project areas. For example, if five control area properties sold in both years 2 and 5 and had annual percent growth rates in value of $4,5,5,5$, and 6 respectively, then these are averaged to show a 5\% growth rate for the control area between years 2 and 5 . Computed in this fashion, the result of the second step is one rog (for the control and project areas separately) for each pair of years in which some property sold.

The third step involves adjustment of these average growth rates for underlying differences between the control and project areas which may affect the rate of growth in property values. Specifically, a linear regression is used (separately for the project and control areas) to determine the systematic relationship between differences in observed rates of growth in value between pairs of years and the corresponding differences in the age of housing, the area of housing, the area of the property, and in the extent of building activity on vacant lots. The residuals from this regression are thought to be "clean" estimates of control and project area differences in rates of land value growth. 
To this point, the analysis only uses data on the rate of growth between years in which sales actually took place, and there are no observed rates of growth for those pairs of years in which some property did not sell. The fourth step uses those data which are available-the residuals described above-to impute rates of growth for all possible pairs of contiguous years. Since, for example, the rate of growth between years 2 and 5 is some product of the rates of growth between 2 and 3,3 and 4 , and 4 and 5, it follows that, if the growth rates between some pairs of these years are known, the others may be calculated or statistically estimated. This is done for every pair of contiguous years, separately for the project and control areas. By using the rog in the first year in the study as a base and assigning it a value of 100 , every rog may be transformed into an index number, again separately for the project and control areas. At the end of this step there is one index number for every year in the study. For example, if 12 years were being studied, there would be index numbers for the rate of growth between 1 and 2,2 and 3,3 and $4, \ldots \ldots \ldots$ 11 and 12.

The fifth step is to determine the time trend in these index numbers for the control area. This is done by simply regressing the rog indices against a time dummy variable, e.g., for the value index of year 1, the independent variable takes on a value of one, for year 2 a value of two, etc. In step six, this time trend is applied to the project area indices in order to clear the project area of all cyclical and secular trends since it is assumed that the control and project areas are subject to the same kinds of cyclical and secular influences. Using this time trend, a set of residuals may be calculated for the project area, each residual being the difference between the actual project area index and the index estimated on the basis of the control area time trends.

If the public investment has no effect on property values, the mean of these residuals will be equal for the period before and after the project; but if there is a property value effect, the mean residual will be greater after the year of the investment. The seventh step involves 
measuring the difference in the mean residuals before and after the investment year. The eighth and final step involves translating the difference in these mean residuals into land value terms.

Steps 5 through 8 might be clarified with a hypothetical graphical analysis. The index numbers for each contiguous-year rate of growth are plotted for the control area as in Figure 4, the same kind of scatter diagram for the project area indices being shown in Figure 5 . For the control area, a least-squares linear regression of the index is fitted against the years (where 1-2 assumes a value of 1), and the resulting equation is plotted in Figure 4. Now superimpose the control area equation on the project area scatter diagram, as in Figure 5. Calculate the algebraic mean of the residuals in the project area before the project year (i.e., the a values), and the algebraic mean after the project year (i.e., the $\underline{b}$ values). If the investment has no effect on-property values, the project area scatter points would be distributed randomly about the control area equation both before and after the project year--there would be no significant difference in the mean of the residuals. The graphical example, of course, shows a positive effect on property values, i.e., the residuals are greater after the project year.

\section{A Recreation Model}

Discussion of a recreation model would seem particularly useful here since it estimates the property value effects as a function of distance from the recreation facility. Estimation in the TTL problem may eventually borrow from this approach. Examples of this technique may be found in Coughl in and Hammer (3) and Darling. (4)

Coughl in and Hammer concentrate on the relationship between the benefits of a recreation project and the distance from the house to the recreation area. The use which residents make of a recreational facility is thought to be a function of the distance between the house and the facility. Hence the facility might result in a bidding-up of property values, particularly for properties closer to the recreational facility. The estimation 


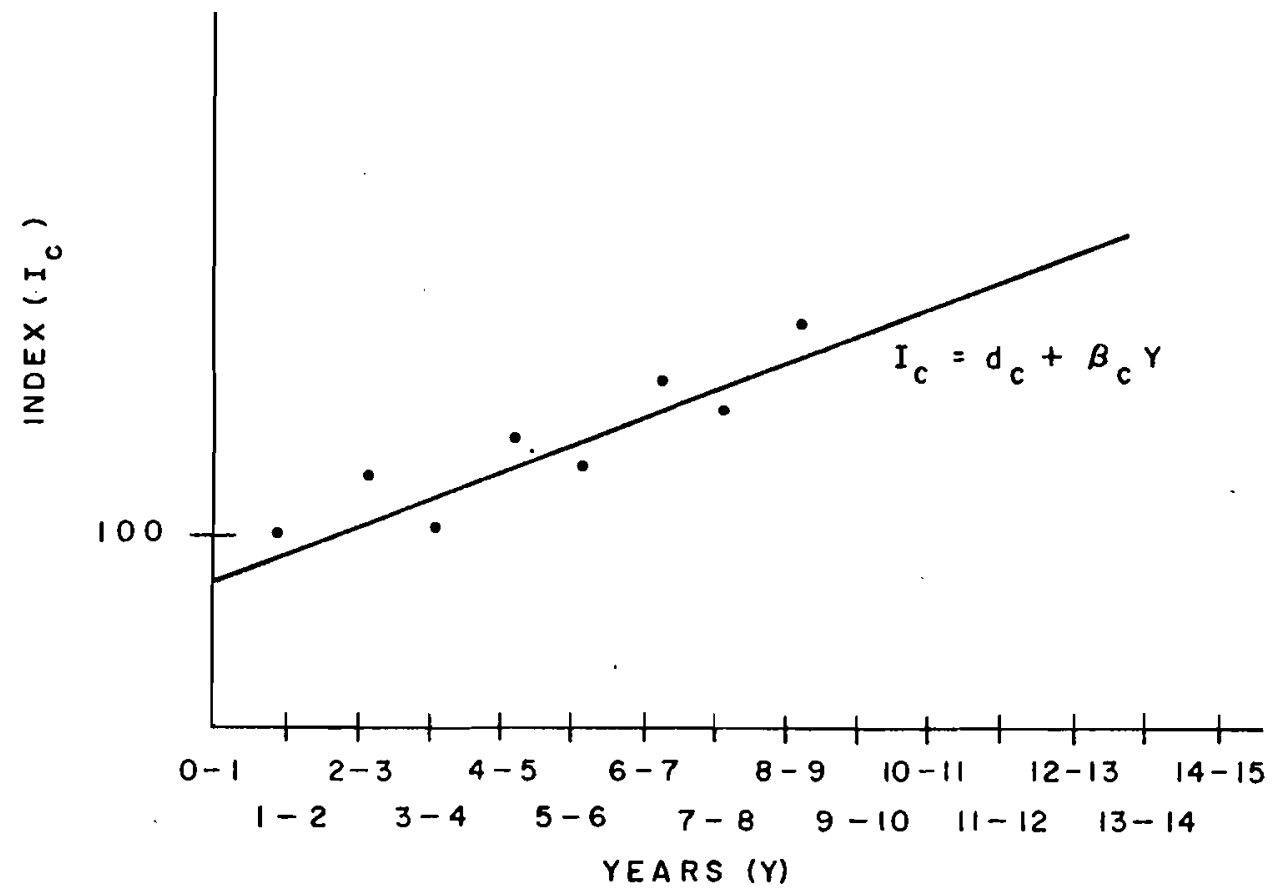

FIGURE 4. Indices for a Hypothetical Control Area

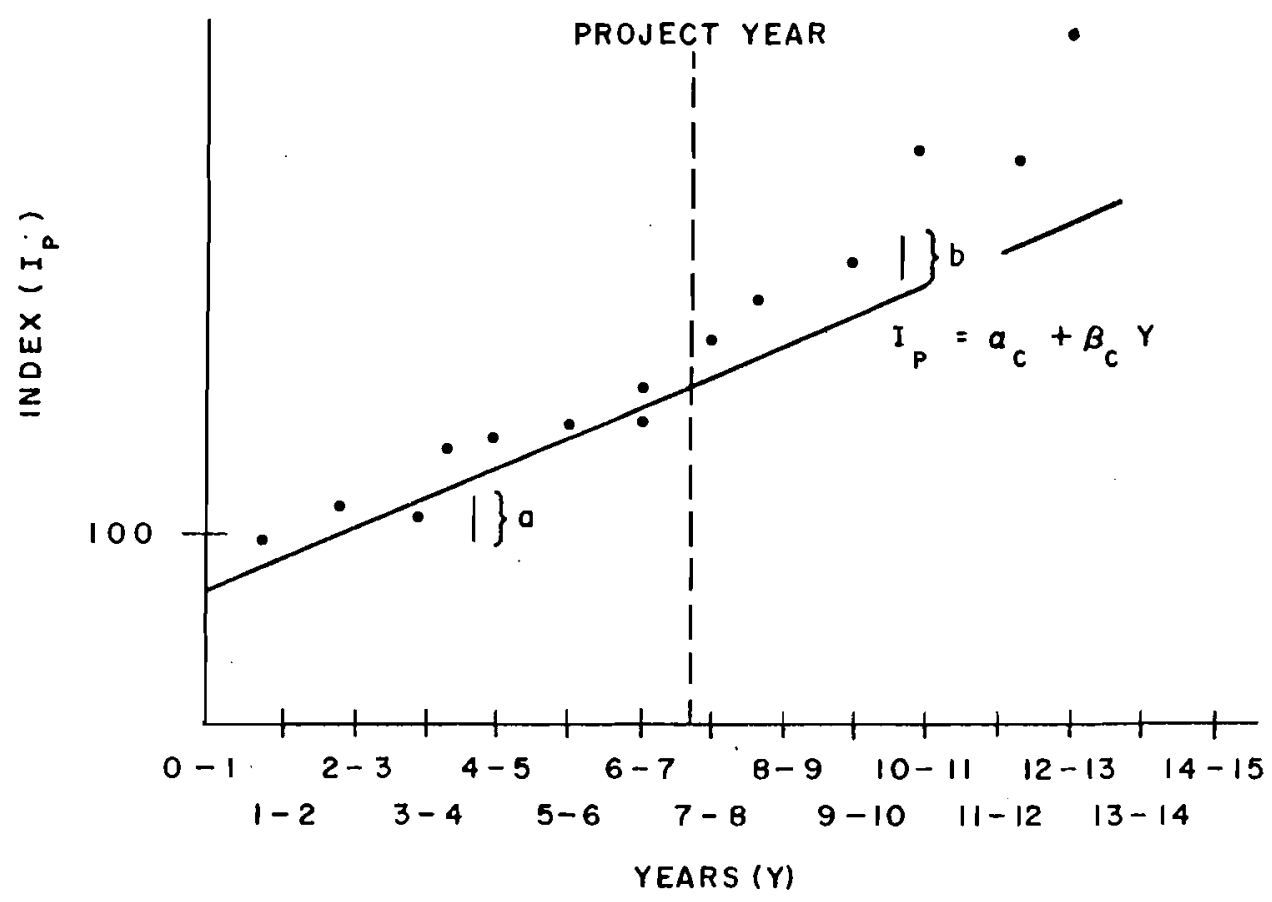

FIGURE 5. Indices for a Hypothetical Project Area 
in the Coughlin-Hammer model is straightforward. Property values (as estimated from sales transactions) are entered as the dependent variable with the type of house structure, the base property value (that is, the extrapolated value when distance from the park is infinite), and distance from the park as independent variables. The coefficient of the distance variable in this case shows that the "rent" ranges from about $\$ 1,171$ per property at 40 feet from the park to $\$ 104$ per property at 2500 feet from the park.

\section{THE TTL LITERATURE}

The effect of TTL on property values has been studied numerous times. Summaries of 36 such studies are reported in the EEI Library of Economic Studies $^{(24)}$ and 42 relevant studies are cited in a 1965 University of Connecticut study. (25) The review presented here should be viewed as cursory and as a supplement to a recent unpublished paper by Ramsey. (26)

In general, there are two basic problems with the TTL 1 iterature on this subject: ${ }^{a}$ first, the conceptual basis for a TTL effect on land values apparently has not been thought out and consequently, the results obtained have not always been appropriately interpreted. Second, the estimation methods have been very general, sometimes no more than impressionistic; hence, the results obtained have sometimes been misleading. For these reasons, it is suggested here that the overwhelming conclusion of these studies - that TTL do not affect property values ${ }^{b}$-may not be valid, and that a comprehensive study of this question is called for.

In no study reviewed was there any evidence of a model or a statement about the assumptions required for the empirical analysis. It must be presumed that the "costs" of TTL are thought to be fully reflected in property value differentials, i.e., there is no loss in consumer surplus, that the

\footnotetext{
aThis author has only reviewed the small number of studies cited here.

$b_{\text {The }}$ literature reviewed in the University of Connecticut study shows that only five of the 42 studies considered found any negative impact on property values. $(22)$
} 
supply of housing is perfectly inelastic, there are no externalities, etc. Perhaps an even more important conceptual and empirical problem in these studies is not adjusting the model to test the possibility that the "costs" of TTL vary directly with income level.

The University of Connecticut Study, ${ }^{(25)}$ also reported in Kinnard, is the most comprehensive work reviewed. There is no basic theoretical model for the analysis; the general approach is intuitive; and the interpretation of the results is impressionistic. " Their study of subdivisions around Hartford, Connecticut consists of investigating the following twelve hypotheses about the impact of TTL:

1. There is a measurable negative impact on the sales prices of residential properties that are close to a tower line right-ofway in comparison with the sales prices of otherwise identical properties more distant from the right-of-way. This impact varies inversely with the distance from the right-of-way.

2. Larger lots are generally associated with properties in proximity to a tower line right-of-way. Therefore, lower unit values are also encountered among these properties.

3. The financing terms under which mortgages are available to impacted properties are less favorable to the borrower, and mortgage financing is generally more difficult to acquire.

4. Major improvements and additions are less likely to occur on properties which are close to tower line rights-of-way, in part because home owners believe that the investment in these improvements will not be realized upon resale.

5. Resale of existing properties close to tower line rightsof-way is generally more difficult than for otherwise similar but more distant properties. This difficulty manifests itself both in terms of reduced sales prices and in terms of longer periods of exposure on the market.

6. Properties close to tower line rights-of-way generally require a longer period of market exposure before they sell at any price.

\footnotetext{
${ }^{a}$ Though it was stated early in the report that simple T-tests and certain nonparametric techniques would be applied to the data, the results appeared generally to be interpreted without the benefit of such statistical analysis.
} 
7. The negative impact of proximity to tower line rights-of-way is lessened when the area is growing rapidly, land is scarce, and land is therefore relatively expensive.

8. The negative effect of proximity to a tower line right-of-way increases as the width of the right-of-way itself increases.

9. The negative effect of proximity to tower 1 ine right-of-way is more apparent among higher-priced properties than among lower-to-middle-income properties.

10. The negative impact of proximity to tower line rights-of-way is increased when the structures within the right-of-way are not screened from the view of the adjacent residential properties.

11. Builders generally avoid, or develop last, acreage which is traversed or abutted by a tower line right-of-way because fewer units may be developed in a given area, and profitability of development is therefore decreased.

12. When subdivisions are developed, properties closest to the tower line right-of-way are developed last, are sold more slowly because of slower market absorption, and are generally improved with the less-expensive units in the subdivisions.

Using both sales value data and interviews, a number of conclusions were reached about the impact. On the one hand, the value of most residential properties is neither appreciable nor measurably affected adversely if adjacent to or intersected by overhead electric transmission lines rightsof-way. On the other hand, there are typically larger lot sizes for abutted and impacted properties as well as lower assessed values. The same sale price for properties with larger lots and with lower property assessments would seem indicative of compensation for a "cost" of the TTL facility. That is, the larger lot size and the lower assessment may be taken as an amount necessary to compensate the home owner for living adjacent to the transmission power lines.

Another important finding reached in the study is that higher income subdivisions are more likely to show negative property values as a result of proximity to the right-of-way. In particular, it was found substantially larger lot sizes are exhibited on lots closest to the tower 
right-of-way. Though this is far from conclusive evidence, it does not contradict the hypothesis that the "costs" of TTL may be directly related to income level.

Other literature on the subject seems to consist of a number of small case studies. The Smith study ${ }^{(22)}$ of Maryland counties has already been mentioned. The approach here is basically intuitive. As noted, there is no conceptual framework for this study. It simply asks the question, "Do properties adjacent to TTL facilities increase in value at a slower rate than do similar neighborhood properties not adjacent to TTL facilities?" The approach is straightforward: A11 properties are grouped into adjacent and nonadjacent; all sales since 1950 are recorded and from every pair of sales an annual percent increase is estimated; a11 outliers (properties where there have been major improvements) are excluded and the average rates of growth of adjacent and nonadjacent properties are compared. The results are based on this simple comparison of means and are interpreted as showing that TTL facilities have no effect on property values. No mention is made as to whether lot sizes tend to be larger for adjacent lots, or whether there seems to be a differential effect on land values depending on income level in the subdivision.

Very similar studies carried out in another Prince George :Maryland subdivision, (28) around Bethlehem, Pennsylvania, (29) and in the Detroit area $^{(30)}$ are also interpreted as showing that TTL do not affect land values. Again, these are case studies, and the statistical analysis is basically a discussion of property value increases of various plots, adjacent to and distant from the TTL. A case study in Danvers, Massachusetts ${ }^{(31)}$--taking the same impressionistic approach--shows no effect on property values, though it does show larger lot sizes for properties adjacent to TTL. 


\section{REFERENCES}

1. Roy W. Bahl, Stephen Coelen and Jeremy J. Warford, Estimation of the Economic Benefits of Water Supply and Sewerage Projects, Prepared for the Public Utilities Department of the International Bank for Reconstruction and Development, Syracuse, New York: Metropolitan and Regional Research Center, October 1973.

2. Roy W. Bahl, Stephen P. Coelen and Jeremy J. Warford, "Land Value Increments as a Measure of the Net Benefits of Urban Water Supply Projects in Developing Countries," Government Spending and Land Values - Public Money and Private Gain, Edited by C. Lowell Harriss, Madison: The University of Wisconsin Press, 1973.

3. Robert E. Coughlin and Thomas R. Hammer, "Estimating the Benefits of Stream Valley and Open Space Preservation Projects," Government Spending and Land Values - Public Money and Private Gain, Edited by C. Lowe11 Harriss, Madison: The University of Wisconsin Press, 1973.

4. Arthur H. Darling, "Measuring Benefits Generated by Urban Water Parks," Land Economics, XLIX, No. 1, pp. 22-34, February 1973.

5. Nathaniel Lichfield, "Cost-Benefit Analysis in Planning: A Critique of the Koskill Commission," Benefit Cost Analysis 1971, Edited by Arnold C. Harbuger, Robert Hoveman, Julius Margolis, William A. Niskanen, Ralph Turvey, Richard Zeckhauser, Chicago: Aldine Atherton, 1971.

6. M. E. Paul, "Can Aircraft Noise Nuisance be Measured in Money?," Oxford Economic Papers, pp. 297-322, September 1971.

7. A. Myrick Freeman III, "Air Pollution and Property Values: A Methodological Comment," Review of Economics and Statistics, Vol. 73, No. 4, p. 415-416, December 1971 .

8. John A. Henning and Ronald G. Ridker, "The Determinants of Residential Property Values with Special References to Air Pollution," Review of Economics and Statistics, Vol. 69, No. 2, pp. 246-257, May 1967.

9. Robert L. Spore, "Property Values and Air Pollution Damage Costs: Some Results for the Pittsburgh Metropolitan Area," Unpublished Ph.D. dissertation, Pennsylvania State University, 1972.

10. Kenneth Wieand, "Property Values and Air Pollution Levels in the St. Louis Metropolitan Area," Unpublished Ph.D. dissertation, Washington University, St. Louis, Missouri, 1970. 
11. Matthew Edel, "Land Values and the Costs of Urban Congestion: Measurement and Distribution," Paper presented at "Man and His Environment," a symposium on Political Economy of the Environment, Paris, France, July 1971 .

12. Demetrius J. Plessas, "Airport Noise: Analytic and Policy Perspectives," Land Economics, XLIX, No. 1, pp. 14-21, February 1973.

13. Jamaica Bay and Kennedy Airport: A Multi-Disciplinary Environmental Study, Environmental Studies Board, National Academy of Sciences and National Academy of Engineering, Vols. 1 and 2, Washington, D.C., 1971 .

14. William S. Hendon, "Property Values, Schools, and Park-School Combinations," Land Economics, XLIX, No. 2, pp. 216-218, May 1973.

15. Herbert Mohring and Mitchell Harwitz, Highway Benefits: An Analytical Framework, Evanston, Illinois: Northwestern University Press, 1962.

16. Darwin W. Daicoff, "Capitalization of the Benefits of Water Resource Development," Government Spending and Land Values - Public Money and Private Gain, Edited by C. Lowell Harriss, Madison, The University of Wisconsin Press, 1973.

17. Hugh 0. Nourse, "The Effect of Public Housing on Property Values in St. Louis," Unpublished Ph.D. dissertation, University of Chicago, 1962.

18. Jerome Rothenberg, "Economic Evaluation of Urban Renewal," Washington D.C.: The Brooking Institution, 1967.

19. Robert Schafer, "The Effect of BMIR Housing on Property Values," Land Economics, XLVIII, No. 3, pp. 282-286, August 1972.

20. Paul B. Downing, "Factors Effecting Commercial Land Values: An Empirical Study of Milwaukee, Wisconsin," Land Economics, XLIX, No. 1, pp. 44-56, February 1973.

21. John $C$. Weicher and Robert H. Zerbst, "The Externalities of Neighborhood Parks: An Empirical Investigation," Land Economics, XLIX, No. 1, pp. 99-105, February 1973.

22. Herbert H. Smith Associates, "An Economic Research Study for the Potomac Electric Power Company," Electric Transmission Lines and Property Values, August 1965.

23. Martin J. Bailey, Richard F. Muth and Hugh 0. Nourse, "A Regression Method for Real Estate Price Index Construction," American Statistical Association Journal, Vol. 58, pp. 933-942, December 1963. 
24. Edison Electric Institute, Summaries: EEI Library of Land Economics Studies, New York: Edison Electric Institute, 1968.

25. William N. Kinnard, Jr. and G. Ross Stephens, Transmission Line Rights of Way and Residential Values, Volume I: Text Storrs, Connecticut: Institute of Urban Research, University of Connecticut, 1965.

26. William Ramsay, "Transmission Line Externalities and Property Values," (Submitted to Land Economics).

27. William N. Kinnard, Jr., "Tower Lines and Residential Property Values," The Appraisal Journal (American Institute of Real Estate Appraisers), p. 269, Apri1 1967.

28. Potomac Electric Power Company, Land Economic Study, Cool Spring Heights Sub-Division.

29. R. C. Zundel, "A Study of the Effects Which an Existing Transmission Line Has on the Development of the Immediate Area for Residential Housing," Pennsylvania Power and Light Company, 1959.

30. Charles W. Layton, A Study of Land Values Adjacent to Steel Tower Transmission Line Easements, Detroit Edison Company, December 1960.

31. New England Power Service Company, "Land Economic Study - Urban Residential - Harbor View Sub-Division, Danvers, Massachusetts."

32. U.S. Department of Agriculture, Economic Research Service, The Relationship between Land Values and Flood Risk in the Wabash River Basin, Report 69-4, to U.S. Army Corps of Engineers, Alexandria, VA, 1969. 


\section{ACKNOWLEDGEMENTS}

Special thanks are extended to Dr. William Ramsay of the AEC for his assistance and cooperation in the preparation of this report. His prior work on the impact of transmission lines on property values led to the inclusion of Chapter VI in the report. The authors also appreciate the editorial assistance provided by Priscilla Cannon and Judy Harris of Battelle-Northwest. 
APPENDIX A

ENVIRONMENTAL GUIDELINES

FOR TRANSMISSION LINES 
APPENDIX A

ENVIRONMENTAL GUIDELINES

FOR TRANSMISSION LINES

Environmental guidelines were abstracted from the following sources:

1. Transmission and Distribution Rights-of-Way Selection and Development, Johnson, Johnson and Roy, for Consumers Power Company, 1970.

2. Environmental Guideline for Electric Transmission Lines (Above Ground), New York State Department of Environmental Conservation, 1973.

3. Environmental Criteria for Electric Transmission Systems, U.S. Department of Interior, 1970.

4. A Visual Analysis System to Assist in Locating Transmission Corridors, Alan Vaughan, Ontario Hydro, 1974.

5. Guidelines for the Protection of Natural, Historic, Scenic and Recreational Values in the Design and Location of Rights-of-Way and Transmission Facilities, U.S. Federal Power Commission, 1970.

These guidelines have been arranged to facilitate easy use and comprehension of their intent in a systematic manner; additional guidelines may be included from other sources and practical experience. The guidelines are presented in the following sections with the source for each indicated by the number in parenthesis:
1-14 General Planning Policy
15-25 Physiography
26-43 Vegetation
44-54 Sensitive Areas
55-63 Roads

GENERAL PLANNING POLICY

1. Properly sited established right-of-way should be used where warranted for the location of additions to existing transmission facilities.

2. The joint use of electric transmission facilities and rights-of-way by two or more utilities should be encouraged, when feasible, to reduce the total number of transmission lines constructed and rightsof-way taken. 
3. A phased retirement and upgrading of existing lower voltage transmission circuits should be required to allow construction of higher voltage, higher capacity circuits on the existing right-of-way. There may be exceptions where existing lines flagrantly violate landscape values and conflict with future planned land uses. Where existing lines in the general area of proposed new lines do violate landscape values, consideration should be given to properly locating the proposed line to allow dismantling of existing lines and reclamation of the right-of-way, while still continuing to provide power to the affected service areas.

4. The relative advantages and disadvantages of locating a new line either contiguous to or widely separated from existing transmission lines should be considered. Right-of-way boundaries should be so located as to avoid creating unusable hiatus areas.

5. Rights-of-way should be selected to preserve the natural landscape and minimize conflict with present and planned uses of the land on which they are to be located.

6. Rights-of-way should avoid parks, monuments, scenic, recreation, or historic areas. If a line must be located in or near these areas, the feasibility of placing the line underground should be clearly determined. If the line must be placed overhead, it should be located in a corridor least visible to public view. Other criteria or conditions as necessary to minimize adverse impacts may be imposed by the agency administering the lands involved.

7. Where practical, rights-of-way should avoid the national historic places listed in the National Register of Historic Places and natural landmarks 1 isted in the National Register of Natural Landmarks maintained by the Secretary of the Interior, and parks, scenic, wildlife and recreational lands, officially designated by duly constituted public authorities. If rights-of-way must be routed through such historic places, parks, wildlife or scenic areas, they should be located in areas or placed in a manner so as to be least visible from areas of public view and so far as possible in a manner designed to preserve the character of the area.

8. Where the transmission rights-of-way cross areas of land managed by Government agencies, state agencies or private organizations, these agencies should be contacted early in the planning of the transmission project to coordinate the line location with their land-use planning and with other existing or proposed rights-of-way.

9. Rights-of-way should avoid intensively managed timber lands, viable agricultural crop lands, steep or unstable slopes, shelter belts, scenic areas, stream courses, and lakes and ponds. 
10. Open expanses of water, wetlands, and marine bays, particularly those used as flight lanes by migratory waterfowl and as heavily used corridors by other birds should be avoided. Areas of wildlife concentrations, such as nesting and rearing areas, and endangered species habitat should also be avoided.

11. Rights-of-way should not parallel rivers or streams and should avoid proximity to scenic lakes, ponds and shorelines. Crossing bodies of water should occur at low areas and be as nearly perpendicular as possible.

12. Rights-of-way should be located along edges of land units to avoid dividing land uses; this respects the integrity of each land unit and facilitates the efficient provision of service to each conform to existing landforms and land use patterns (field/forest edges, parallel to gridded roads and agricultural patterns, etc). (1)

13. Crossing near boundary areas of districts which contain sharp contrasts in activity patterns should be avoided.

14. Alignments which require the erection of numerous angle and deadend towers should be avoided.

(4)

\section{PHYSIOGRAPHY}

Guidel ines 1-5, 9, and 12, plus the following:

15. Transmission lines should generally be located parallel to the contours of the land and in conformance with the prevalent directions or patterns of topographic features. In rough or hilly country, alignments should change direction in keeping with the scale of the topographic change.

16. Alignments should avoid crossing hills at right angles to the contours. Crossings at crests of wooded hills should retain as much vegetation as possible to avoid a "notch" in the silhouette, and crossings should be made at an oblique angle to the contours.

17. Rights-of-way should not cross hills and other high points at the crests. To avoid placing a transmission tower at the crest of a ridge or hill, space towers should be spaced below the crest or in a saddle to carry the line over the ridge or hill. The profile of facilities should not be silhouetted against the sky.

18. Route alignments should be located along the edges of a valley (near the foot of the valley walls) rather than centering the alignment down the middle of a valley. 
19. Transmission facilities should be located part way up slopes to provide a background of topography and/or natural cover where possible. These facili.ties should be screened from highways and other areas of public view to the extent possible with natural vegetation and terrain. (3)

20. Long views of transmission lines parallel to existing or proposed highways should generally be avoided. Alternative routes away from highways should be considered. Where ridges or timber areas are adjacent to highways or other areas of public view, overhead lines should be placed beyond the ridges or timber areas. (3)

21. Long views of transmission lines perpendicular to highways, down canyons and valleys or up ridges and hills should be avoided. The lines should approach these areas diagonally and should cross them at a slight diagonal. (3)

22. Transmission lines should cross canyons up-slope from roads which traverse the length of the canyon. (3)

23. Avoid traversing west facing slopes with transmission lines. North facing slopes present the optimal sun exposure for reducing the visual impact of transmission lines.

24. Access and construction roads should be located to preserve natural beauty and minimize erosion. Road grades and alignments should follow the contour of the land with smooth, gradual curves when possible. Commensurate with the topography, construction roads should be located for later use as maintenance access roads or to provide access to recreational areas. Existing roads should be used to the maximum extent possible. Agencies administering the right-of-way lands involved may limit access and construction roads due to certain fragile or conservation aspects of the lands and associated resources. (3)

25. When crossing a canyon or valley in a forest, high, long-span towers should be used to keep the conductors above the trees and to minimize the need to clear all vegetation from below the lines. clearing in the canyon should be limited to that which is necessary to string the conductors. (3)

\section{VEGETATION}

Guidelines $1-5,9,12,16,17,19,20$ and 25 , plus the following:

26. Clearing of natural vegetation should be limited to that material which poses a hazard to the transmission line. Determination of a hazard in critical areas such as park and forest lands should be a joint endeavor of the utility company and the area manager in keeping with the National Electric Safety Code, state or other electric safety and reliability requirements. (3) 
27. Trees and brush should be cleared only when necessary to provide electrical clearance, line reliability or suitable access and construction roads for operation, maintenance, and construction. Straight swath appearance should be avoided.

28. Special care should be used when clearing through shelter belts, orchards, natural stands of trees, or other special areas with high exposure to public view which cannot be avoided.

29. Where rights-of-way enter dense timber from a meadow or where they cross major roadways, streams or rivers in forested areas, a screen of natural vegetation should be retained along the right-of-way.

30. Where lines cross roads or streams, the right-of-way should be left in its natural state as far back from the road or stream as possible.

31. Where rights-of-way cross major highways, rivers, and marine areas, the clearing should be done in such a way that a screen of natural vegetation is left in the right-of-way on each side of the road or river. If natural vegetation is such that a screen cannot be left, the planting of native types of plants, low-growing trees, etc. should be considered to provide screening. (3)

32. The forest edge should be sensitively adjusted during the right-ofway clearance procedures so as to appear natural. The aim in presentation of existing vegetation and the replanting of vegetation should be the achievement of a convincingly natural assymmetry that will reduce the unnatural symmetry of the lines and towers.

33. Where possible, right-of-way strips through sensitive forest and timber areas should be cleared with curved, undulating boundaries. The notched effect of a right-of-way cross section should be avoided. Selective removal, careful topping and pruning of trees can contribute to this. Also, trees and plants should be used to feather back the rights-of-way from grass and shrubbery to larger trees. If the rightsof-way are through dense areas of timber where trees are of equal height and the right-of-way must be cleared to a straight line, the maintenance plan should provide for ultimately reaching the above desired results through seeding, planting and selective cutting of native material. Consideration should be given to the establishment of native vegetation of value as food and cover for wildlife.

34. It may be desirable to occasionally deflect right-of-way strips through scenic forest or timber areas. The resulting irregular patterns prevent the rights-of-way from appearing às tunnels cut through the timber. 
35. Major roadways should be crossed as near to perpendicular as possible to allow maximum tower setbacks and right-of-way screening by vegetation. Higher long span towers can be used at road crossings to allow for successful screening.

36. The use of helicopters for the construction and maintenance on rightsof-way should be considered in mountainous and scenic areas where consistent with reliability of service. This would permit rights-ofway to be located in more remote areas and would reduce disturbance of the ground and the number of access roads. (5)

37. Choice of conductor material should be carefully considered to avoid sheen or too strong a silhouette and to provide the best selection for blending the conductors into any given setting through which the line must pass.

38. Clearing and grubbing should be minimal and performed in a manner which will protect or benefit existing natural beauty, conserve natural resources, minimize scarring of the landscape, and prevent degrading of streams and wetland areas. Trees, shrubs, grass and other natural features not removed should be protected from damage during construction.

39. If underground transmission lines must be located near the crests of hills or other high points, trenching should be done with small equipment in order to minimize the width of the rights-of-way clearings. (5)

40. The use of "brush blades" instead of dirt blades on bulldozers is recommended in clearing operations where such use will preserve the the cover crop of grass, low growing brush, etc.

41. Brush and other materials cleared from the rights-of-way during construction will not be disposed of by burning. Alternate disposal methods such as sale of timber, chipping, burial, on-site stacking, or piling of brush and tree branches for wildlife protective cover at specific locations should be employed.

42. The time and method of clearing and grubbing rights-of-way should consider such factors as soil stability, the protection of natural habitat for wildlife, fish spawning seasons, silt deposition in water courses, and stream flow.

43. Roads used during construction should be stabilized without undue delay by erosion control measures and the planting of appropriate grass and other vegetation. These roads should be designed for proper drainage, and water bars to control soil erosion should be installed. (5) 


\section{SENSITIVE AREAS}

Guidelines 1-34, 36-43, plus the following:

44. Avoid crossing transmission line corridors through well-defined enclosed spaces.

45. Avoid crossing transmission lines perpendicularly to a sequence of lines of sight on a landmark.

46. Towers should be located a minimum of three times the height of the structure away from the edge of road or viewer position to better allow the tower to be in scale with the viewer. (4)

47. In open agricultural areas the right-of-way should not be located close to important local scale-giving features such as farm buildings and vertical elements like windmills and silos. The comparison between relative sizes increases the visual impact of transmission structures.

48. Where rights-of-way cross rivers and major highways, the transmission line towers should be strategically located for minimum visibility.

49. All rivers should be crossed underwater and towers should not be visible from the water surface.

50. Where rights-of-way cross streams or other bodies of water, the banks should be stabilized to prevent erosion. Construction on rights-ofway should not damage shorelines, recreational areas or fish and wildlife habitats.

51. The right-of-way alignment should be deflected a short distance from the viewing position (road, river crossing, etc.) to limit the depth of view along the right-of-way.

52. Coloring of transmission line towers to blend with the landscape may be desirable where they must be located in or near areas of high scenic value.

53. The materials used to construct transmission towers should harmonize with the natural surroundings. Self-protecting bare steel is appropriate in many areas. Towers constructed of material other than stee1, such as concrete, aluminum, or wood, should be considered.

54. The use of high strength conductors should be considered, particularly at road, waterway and canyon or gorge crossings to pick up the line sag and allow for straighter line profiles. 
$\underline{\text { ROADS }}$

Guidelines $1-6,9,11-38,44-54$, plus the following:

55. Where rights-of-way cross major highways, the transmission line towers should be strategically located for minimum visibility.

56. At road crossings of two or more circuits, and where only a portion of the line is visible from the highway, the use of multiple circuit towers may be effective in minimizing the impact of the lines at that point. (3)

57. Crossing should not be at high points in the road where towers would be seen from a great distance. Instead, where possible, the highway should be crossed between two high points, at a dip, or on a curve in the road.

58. Crossing over or near roads which have steep vertical slopes should be avoided.

59. Roads should be crossed at right angles to the motion of the viewer. (4)

60. Crossing should not be near or over roads beside barriers (e.g., tunnels, underpasses, steep road cuts) which restrict or block the viewer's vision temporarily.

61. Crossing over or near objects around which a road may deviate should b be avoided. (4)

62. Crossing should not occur near points of decision on roads (such as controlled intersections and interchanges) where screening vegetation and landforms are typically absent. (4)

63. When lines are adjacent to highways, guyed towers should be avoided whenever possible. (3) 
APPENDIX B

VIEWSCAPE QUESTIONNAIRE 
APPENDIX B

\section{VIEWSCAPE QUESTIONNAIRE}

A. PRE-EVALUATION TECHNIQUE: The overall visual quality of a viewscape may be evaluated on a scale ranging from I (very high visual quality) to 100 (very low visual quality) once a scale of comparison is agreed upon, depending on the observer's immediate reaction or visual response. Is the viewscape highly scenic--visually stimulating? Is it a moderate or low visual quality, being visually dull, unstimulating and of low distinction. Or, is its visual quality very low, presenting a visual array which is disturbing and disjointed and of little or no scenic value? Viewscapes of the Grand Canyon, Yosemite Falls, or the Grand Tetons might be given scores close to 1 , while viewscapes of unrestored strip mines, active landfill operations, or highly polluted wastelands might be given scores close to 100 . The evaluator should be objective and impartial in his judgment, attempting to separate his preference or dislike of the viewscape from a true evaluation of the visual merits or drawbacks of the viewscape. Rate the visual quality of this viewscape "before" and "after" the facility. (Note: throughout this questionnaire, low numerical scores (i.e., 1) are given to qualities which are of best or highest quality; high scores (i.e., 100) are reserved for those attributes of low quality. Please remember: "Big numbers are bad scores.")

Overall visual quality before____(1-100). Overall visual quality after_(1-100).

B. INTACTNESS EVALUATION: Intactness is the relative degree of natural condition of a viewscape or its elements. Intactness may be evaluated by considering the level of urbanization and degree of 
encroachment present; intactness scores are highest when man-made development and visual disturbances are absent, as discussed and illustrated in the accompanying text.

1) Rate the intactness of the overall viewscape by checking the appropriate box in each column below; place one check for "before" and one for "after".

Before After

1. Very highly intact/no alteration.

2. Highly intact/little alteration.

(x) 3. Moderately highly intact/moderately little alteration.

4. Moderately intact/moderately altered.

(x) 5. Moderately low intactness/moderately highly altered.

6. Low intactness/highly altered.

7. Very low intactness/very highly altered.

2) Rate the intactness of each major element of the viewscape, as identified in the viewscape sketch. In the "after" viewscape, do not rate the facility's intactness, but consider its effect on the visual intactness of viewscape elements which it physically alters or visually blocks from view, in part or as a whole. Use the numerical intactness rating system from above in scoring the intactness of each viewscape element.

\begin{tabular}{lccc}
\multicolumn{2}{l}{ Element Name } & & \multicolumn{2}{c}{ Intactness Score } \\
\cline { 2 - 3 } & & Before & After \\
A. Sky & 2 & 3 \\
B. Etc. & & \\
C. & & & \\
D. & & &
\end{tabular}


C. VIVIDNESS EVALUATION: Vividness is the memorability of visual impression of the overall viewscape or its elements. Vividness is high in viewscapes when there is distinction of prominence resulting from high contrast or from mutual accentuation of visually diverse elements. In rating vividness, consider the levels of definition of viewscape boundary, diversity of spatial enclosure, degree of topographic relief, diversity of vegetative pattern, prominence of natural features, prominence of waterforms, vividness of sky, and vividness of man-made elements, as discussed in the accompanying text.

1) Rate the vividness of each major element of the viewscape, as identified in the viewscape sketch. In the "after" viewscape, rate the vividness of the facility as well as its effects on the vividness of the other viewscape elements which have been visually blocked, physically altered, or affected by visual contrast or legibility with the addition of the facility. Use the numerical vividness rating system from above in scoring the vividness of each viewscape element.

Element Name

Before After
A. River 3
4
B. Etc.
C.
D.
E.
$\mathrm{F}$.
G. Facility

D. UNITY EVALUATION: Unity is the degree to which individual elements in the viewscape join together to form a single coherent harmonious visual unit. Unity refers to the level of compositional harmony or visual intercompatibility of the individual elements which comprise the viewscape. Unity does not require similarity or blandness, 
but may depend rather on visua 1 dominance and subordinance of viewscape elements with some level of integrating organization between them. It must be remembered that unity deals only with visual coherence and compositional integrity between viewscape elements, and should be clearly distinguished from both "intactness" and "vividness" rated above. (See accompanying text).

1) Rate the unity of the overall viewscape by checking the appropriate box below for "before" and "after" conditions.

$$
\begin{aligned}
& \text { Before After } \\
& \text { ___ Very high overal1 unity. } \\
& \text { 2. High overall unity. } \\
& \text { (x) 3. Moderately high overal1 unity. } \\
& \text { 4. Moderate overall unity. } \\
& \text { (x) 5. Moderately low overall unity. } \\
& \text { 6. Low overal1 unity. } \\
& \text { 7. Very low overa11 unity. }
\end{aligned}
$$

2) Rate the level of unity or degree of harmonious visual integration between man-made and natural elements in the viewscape, considering the facility as an additional man-made element in the "after" viewscape. Check the appropriate box below for "before" and "after" conditions.

\section{Before After}

1. Man-made elements very highly unified with natural/ absent

(x) 2. Man-made elements highly unified with natural.

3. Man-made elements moderately highly unified with natural.

(x) 4. Man-made elements moderately unified with natural.

5. Man-made elements of moderately low unity with natural. 
6. Man-made elements of low unity with natural.

7. Man-made elements of very low unity with natura1.

E. IMPORTANCE EVALUATION: Visual importance is the level of visual contribution an element makes to the overall viewscape after the facility has been introduced into it. An element's visual importance may be due to its size, number, singularity, contrast, or position in the viewscape. In the "after" viewscape rate the visual importance of each major element, using the importance rating scale from 1 to 7 provided below. ${ }^{a}$

\begin{tabular}{cr}
\hline & \multicolumn{2}{c}{ Element Name } & After \\
\hline & \\
A. & 2 \\
B. & 4 \\
C. & 1 \\
D. & 5 \\
E. & 3 \\
F. Facility & - \\
G. Facer
\end{tabular}

7 Element very high in visual importance to viewscape.

6 Element high in visual importance to viewscape.

5 Element moderately high in visual importance to viewscape.

4 Element of moderate visual importance to viewscape.

3 Element of moderately low visual importance to viewscape.

2 Element of low visual importance to viewscape.

1 Element of very low visual importance to viewscape.

a

Importance score is the only score which is numerically reversed, i.e. $\underline{7}=$ element very high in visual importance to viewscape. Please note this single exception to the rule that "big numbers are bad scores." 
APPENDIX C

DESCRIPTIONS OF THE IMPACTS OF OVERHEAD

TRANSMISSION LINES FOR SEVEN CRITERIA 
APPENDIX C

\section{DESCRIPTIONS OF THE IMPACTS OF OVERHEAD TRANSMISSION LINES FOR SEVEN CRITERIA}

General descriptions are given here of the impacts of overhead electric power transmission lines for the seven criteria to be weighted in importance by members of the public. ${ }^{a}$ Additional impacts are associated with underground lines. The seven criteria are:

Economics

Water Quality

Air Quality

Animal/Plant

Cultural/Recreational

Heal th/Safety

Aes thetics

The descriptions would have to be altered to indicate the impact for specific transmission line route alternatives prior to public response testing to measure the relative importance of each criterion.

\section{ECONOMICS}

There are two elements to the economics criterion. The first element is the direct cost to acquire easements and construct the transmission lines. The second element is the indirect impact which transmission lines have on property values. The potential for measuring the impact of transmission lines on property values is discussed in Chapter VI.

The economics criterion captures much of the land use impact of transmission lines. For example, it will generally be more expensive to acquire an easement for productive land than for nonproductive land. The indirect cost associated with transmission 1 ines will also reveal transmission line

\footnotetext{
${ }^{a}$ Much of the descriptive material presented here is adapted from the draft fiscal year 1975 Environmental Impact Statement for the General Construction and Maintenance Program of the Bonneville Power Administration, pp. 33-48.
} 
routes which have substantial detrimental impact on land value. High direct and indirect costs.will tend to show that the transmission line is incompatible with existing land use.

\section{WATER QUALITY}

The impact of transmission lines on water quality results primarily from soil erosion and exposure of water to direct sunlight in normally forested areas. Removal of ground vegetation and disturbance of topsoil during construction accelerates erosion with the resulting siltation of natural drainage systems. Increased turbidity can occur in lakes, rivers, and streams in the vicinity of rights-of-way.

Water temperature increases can be caused by increased exposure of water surfaces to the sun's rays as a result of removing streamside vegetation. The shade provided by streamside vegetation is a major factor influencing changes in water temperatures. Transmission 1 ines normally do not parallel streams but rather cross them at a single point. The amount of vegetation removed and consequently the amount of stream surface exposed can thereby be kept to a minimum. Vegetation along stream banks should be left intact for a minimum width of 100 feet whenever possible.

Roads and road construction activities are significant sources of sediment, and erosion from clearing and slash burning can also contribute to increased sedimentation. Poorly placed culverts can result in increased sediment loads.

The effects of transmission lines on aquatic life can also be included under this criterion. The principal impact of transmission lines on aquatic life results from changes in the oxygen content of water and the introduction of herbicides. Higher water temperatures reduce the oxygen-holding capacity of water and increase the metabolic rates of animals which further reduces the oxygen levels. The increased metabolic rates are particularly important when debris is present. In these situations, bacteria greatly reduce dissolved oxygen to levels critical to fish. The situation is further aggravated when the debris is sufficient to impound sections of the stream and reduce flow rates. Reduced light penetration associated with

\section{C.2}


turbidity can decrease primary production and its associated oxygen production. The buildup of fine sediments and organic matter in stream bottom gravels, even when not sufficient to bury fish eggs and bottom invertebrates, may suffocate or drive them away due to reduced flows and/or oxygen levels. Thus, even small additions of soil can produce significant changes in a stream fauna.

Herbicides used to control growth under transmission lines can also reach water courses and detrimentally affect water quality and aquatic life. Herbicides which are resistent to leaching and which break down rapidly are normally used to minimize these impacts.

\section{AIR QUALITY}

The principal air quality impact associated with transmission lines results from construction activities. Construction activities that can adversely affect air quality include combustion byproducts from burning, dust from disturbed soil, vehicle and equipment exhaust emissions, and objectionable fumes and odors from miscellaneous operations. The impacts of these construction activities on ambient air quality are normally localized and short-lived.

Slash and unmerchantable timber is produced during the right-of-way preparation and construction operation for transmission facilities. Contractors installing lines commonly use open burning to dispose of this material where and when permitted by local, state, and Federal air pollution regulations. Open burning introduces combustion byproducts, including water vapor, particulates, hydrocarbons, carbon monoxide, and carbon dioxide, into the atmosphere. Relatively high concentrations of these products near the sites of the fires decrease rapidly to ambient levels in all directions. Particulates in the smoke may reduce visibility in the immediate vicinity of the fire. Adverse weather conditions can create potential problems. Burning operations are normally conducted in locations away from urban areas. 
The amount of dust produced by construction activities depends on soil types, weather conditions, types of equipment, and rates of vegetation recovery. Wetting down construction sites in dry areas significantly reduces the amount of dust in the air.

Exhaust emissions from vehicles and equipment are normally related to the difficulty of access and the amount of hauling of materials and equipment. Mountainous and timbered areas will normally require more extensive access road construction which can mean more equipment operation and rightof-way preparation. Emissions from both gasoline and diesel-powered construction machinery such as chain saws, bulldozers, cranes, and automotive equipment will occur.

Objectionable fumes and odors could come from fuels, volatiles, chemicals, paints, or other items found at most construction sites. Normally, they would only create a localized temporary nuisance.

\section{ANIMAL/PLANT}

Plant and forest growth is removed from transmission line easements during construction. Some regrowth is permitted as long as the vegetation does not pose a hazard to the lines or towers.

The Bonneville Power Administration removes vegetation by the following methods:

a. Foliage sprayed treatment which consists of spraying a herbicide diluted with water on the foliage. This method is confined to application on easy-to-kill plants and noxious weeds where brownout of clumps or individual trees is acceptable.

b. Basal treatment which consists of applying a mixture of herbicide and carrier on the lower stem of the tree from about knee high to the ground line. When applied during the dormant season treated trees will not normally leaf out during the following growing season, thereby avoiding a vegetative brownout. 
c. Fri11, notch, or cup method where a cut through the bark is made to the cambium layer forming a series of cuts around the circumference of the tree. Dry, powdered, or raw liquid herbicide is poured into the notches. This can be done at any time of year, but is most effective when performed during the dormant season. This is the safest method near streams, sensitive plants, or other areas of concern.

d. Pelleted herbicides are broadcasted within the drip base of the tree. Some pellets sterilize the soil for a short period while others affect only the plants around which applied. This is an excellent method for controlling individual trees during working patrol in locations inaccessible to vehicles.

e. Cutting and stump treatment is a method by which a tree is cut down mechanically. The stump may require herbicide application to prevent sprouting. A problem in this method is the disposal of the chipped material. It also requires that the chipper be hauled to the work site or the vegetation dragged to the chipper. In either case damage may be caused to desirable plants. The remaining slash must be removed, burned, chipped, or scattered.

Construction of transmission facilities will also have some impacts on wildlife. These impacts will occur primarily through the disturbance of wildlife and elimination of habitat. Impacts will be most intense in or near forested areas where major vegetation disturbance will occur during construction of transmission 1 ines and access roads.

In timbered areas, the 1 and cleared for right-of-way will experience physical changes due to exposure to sunlight, winds and precipitation. These changes will undoubtedly bring about shifts in understory growth, animal associations, and other biological patterns. Secondary succession will normally occur in those areas in which the climax vegetation has been removed. Initially, the new cover will consist of pioneer species such as grasses and weeds, followed by low shrubs and herbs. The open spaces created in timberland will provide food and cover for a variety of small 
species including quail, grouse, rabbits, and rodents. Deer and elk will browse on the grasses and legumes within the open area, using the bordering woods for cover.

Disturbance of daily wildlife behavior immediately adjacent to transmission corridors, access roads, or substations will occur during the construction phase due to human activity, noise, dust, and other disturbances associated with construction. Wildlife may leave the area temporarily but should return after construction activities cease. Undoubtedly, some individual animals will be eliminated by construction activities. Construction during nesting and rearing seasons would be expected to have a greater impact than at other times.

In discussing impacts on wildlife, it is important to consider the concept of individual animals and their total population. Individual animals will be eliminated either directly by stress produced during construction or by loss of habitat. However, one must judge this impact relative to the availability of similar habitat and the total population of each species in the study area. Loss of individual "common species" such as pheasant, rabbits, or deer would not be as critical as loss of an endangered or rare species, or a species with limited distribution in the area. In most cases, effects from construction of transmission facilities are expected to be temporary and should have no measurable effect on wildlife populations. However, loss of habitat, particularly critical habitat, will reduce wildlife populations dependent on that habitat.

Wildlife migration patterns may be influenced by the creation of open transmission corridors through timbered areas. Game may use these cleared paths to establish new migration routes, and increased populations of some animals may result in some areas. Where the new areas serve as a municipal watershed the increase in herbivore populations may increase pollution of water resources. There have also been suggestions that some species of wildlife may avoid crossing cleared areas and modify their movements accordingly. 
Long-term effects on game will also result from introduction of improved hunter access in forested areas crossed by the proposed lines and the resulting increase in hunting pressure. Wildlife in these areas may be disturbed by recreation vehicles, such as off-road vehicles, trail bikes, and snowmobiles on cleared rights-of-way. Although steps are taken to limit public use of private access roads and rights-of-way on private land, these efforts have never been completely successful.

The application of herbicides will affect the availability of forage for wildlife. Forage will be temporarily reduced or in some cases eliminated depending on the variety of brush found in the areas treated.

Vegetation-control activities are cyclic and vegetation will recover depending on the type of herbicide used, the resistance of different vegetation, and the area involved. The loss of forage on treated lands will place stress on the wildlife that have become dependent on the right-of-way vegetation. Use of herbicides will also reduce nesting and resting areas along the rights-of-way. However, the elimination of tall-growing species may promote the growth of desirable low-growing browse species.

In areas where large numbers of birds may congregate such as on wildlife refuges, seep lakes, and other major nesting and feeding areas, there is the possibility of individual birds flying into transmission lines, particularly during times of poor visibility or during takeoff or landing of large flocks.

There have also been reports of large birds being killed by simultaneous contact with an energized conductor and grounded hardware on transmission lines, poles, or towers. These reports are usually limited to lines operating at voltages below 115,000 volts. A few small mammals (primarily squirrels) and birds come in contact with energized substation equipment and are killed.

\section{CULTURAL/RECREATIONAL}

The commitment of land for a transmission right-of-way may limit the potential and growth of a recreation facility. A development of this nature 
can reduce an area's potential recreational designation or classification, such as wilderness area. The visual impacts created may be sufficiently adverse to prevent an area's development for a specific recreational purpose. An existing area's potential for expansion can also be reduced by lines adjacent to or paralleling its boundaries. However, the creation of transmission utility corridors would present possible recreational opportunities for bicycle trails, snowmobile and all-terrain vehicle routes, nature study, and some open-space areas.

Since most utilities obtain easements rather than fee-ownership of the rights-of-way, recreational uses depend on the willingness, interest, and cooperation of the landowners. Unauthorized or uncontrolled use of transmission line rights-of-way by recreational vehicles will likely have detrimental effects such as erosion, disturbance to wildlife, fire hazards, and annoyances to landowners.

The principal cultural impact of transmission 1 ines is on historic and archeological resources. The primary impact would be visual, although it is also possible that a transmission line could physically interfere with a historical site.

A final cultural/recreational impact of transmission lines is audible noise and electromagnetic interference which affect radio and television reception. The effect is primarily limited to areas adjacent to the transmission lines. Foul weather can aggravate the problem.

\section{HEALTH/SAFETY}

Several hazards are associated with transmission lines which pose health and safety risks to humans. These health hazards include the danger of energized transmission lines falling to the ground, metal objects coming into contact with lines, induced voltage and currents in metallic objects adjacent to lines, the possible health hazard for workmen who repair lines, the ozone and nitrous gases produced by high voltage lines, the noise associated with transmission line construction and operation, and the danger of impact with aircraft. 
Energized conductors falling to the ground can occur because of vandalism or severe weather. When this occurs, lines are generally automatically switched off. During such failures, current flows through the earth for a short interval. Because of the earth's resistance, a voltage appears in the vicinity of the tower involved which may present a localized hazard.

The electrostatic and electromagnetic field associated with high-voltage lines can induce voltage and currents in metallic fences, structures, and equipment near the line. This includes wire communications facilities or utility systems which may be in the near proximity of the power line. The magnitude of the induced voltage and associated ground-discharge current due to the electrostatic field depend on the line voltage, the size of the object being charged, and the object's distance from the line conductors. The magnitude of induced current due to the electromagnetic field depends on the load current in the conductors, the orientation and length of the object, and $i$ ts distance from the conductors. Procedures for grounding metal structures and equipment along with other precautions can reduce the possible hazard and nuisance from these sources.

All transmission lines pose an inherent hazard if objects such as irrigation pipe, construction booms, or other conducting materials are brought into contact with the line. Because conductor height from the ground increases with voltage, the probability of such accidents is greatest with low-voltage lines. However, construction of any transmission line across agricultural 1 and does create a hazard and farm operators must observe basic safety precautions in their activities underneath and immediately adjacent to the lines.

The evidence as to whether humans, or other life forms, suffer 111 effects from exposure to the electrical fields present in the vicinity of transmission lines is inconclusive at this time. An extensive study noted no $i 11$ effects in linemen who worked on high voltage lines and were exposed to very strong electrical fields. ${ }^{(1)}$ No detrimental effects were apparent when mice were exposed to electrical fields in one study. (2) 0ther studies have noted possible detrimental effects in both humans ${ }^{(3)}$ and animals. (4) 
The noise associated with transmission lines is not severe enough to be a health hazard, but it can be an annoyance. During construction, the noise created by heavy equipment and chain saws can be particularly annoying. Helicopters are frequently used to inspect routes and their noise can also be an annoyance. Small irregularities on the conductor surface of energized transmission lines result in a corona effect which can produce audible noise in the immediate vicinity of transmission lines.

Corona currents also generate ozone and nitrous gases. Ozone in high enough levels may affect growth of vegetation and may possibly be hazardous to humans. However, recent tests have indicated that a high-voltage transmission line is an inefficient generator of these gases. Tests recently made adjacent to $765 \mathrm{KV}$ lines indicate that the ozone concentration is only 2 to 3 parts per billion by volume. ${ }^{(5)}$ The increase would be less for lower voltage lines.

Transmission lines pose a potential obstruction to aircraft. This problem is particularly acute in geographic areas characterized by frequent low visability. In general, however, most lines are below the minimum flight altitudes allowed by the Federal Aviation Administration (FAA) except for special operations such as crop dusting. FAA standards are followed in marking lines and structures. Additional precautions employed on large river crossings usually include airway beacon lights on towers, colored spherical markers on conductors, and airway marker paint colors on towers.

\section{AESTHETICS}

The aesthetic impact of transmission lines, access roads, substations, and related structures is a significant environmental impact. The degree of impact created will vary with the scenic quality of the area, the design of the structure and right-of-way, and the visual significance of the landscape to the viewer.

Major visual impacts include cleared corridors through forested areas, "skylining" towers along the crest of a ridge, rows of towers visible for 
several miles in areas of sparse vegetation, and congestion of towers of different size and design along multiple rights-of-way or in the vicinity of generation sites. Because of their linear nature, transmission lines pass near and sometimes cross designated scenic highways, rivers and trails. Painting and weathering of towers can help reduce the visual impact of these structures.

Vegetation management programs will result in dead vegetation within the controlled corridors. In some cases this is limited to a single tree or clumps of trees. When aerial spraying is used a brown path will be visible until new growth appears, usually from a few months to a full growing season.

In one sense, underground transmission lines have minimal aesthetic impact since towers and lines are not visable. However, the impact of the corridor can be severe in that it requires extensive excavation and normaliy does not permit the establishment of trees or shrubs along the right-of-way. Underground lines cost approximately eight times as much as overhead lines. 


\section{REFERENCES}

1. M. W. Singewald, 0. R. Langworthy and W. B. Kouwenhoven, "Medical Follow-Up Study of High Voltage Linemen Working in AC Electric Fields," Paper No. T 73 154-2, IEEE Power Engineering Society Winter Meeting, New York, New York, January 28-February 2, 1973.

2. G. G. Knickerbocker, W. B. Kouwenhoven and H. C. Barnes, "Exposure of Mice to a Strong AC Electric Field - An Experimental Study," IEEE Transactions on Power Apparatus and Systems, pp. 498-505, Apri1 1967.

3. V. P. Korobkova, Y. A. Morozov, M. D. Stolarov, Y. A. Yakub, "Influence of the Electric Field in 500 and $750 \mathrm{KV}$ Switchyards on Maintenance Staff and Means for its Protection," CIGRE Paper 23-06, International Conference on Large High Tension Electric Systems, Paris, August 28September 6, 1972 .

4. C. Meda, V. Carrescia, S. Cappa, "Experimental Results from Exposure Animals to AC Electric Fields," Second International Colloquium on the Prevention of Occupational Risks Due to Electricity, Koln, Germany, November 30, 1972.

5. M. Frydman, "Oxidant Measurements in the Vicinity of Energized $765 \mathrm{KV}$ Lines," IEEE Transactions, Vol. PAS-92. No. 3, p. 1145, May 1-June 1, 1973. 


\section{DISTRIBUTION}

OFFSITE

AEC Chicago Patent Group

U. S. Atomic Energy Commission

Argonne, IL 60439

A. A. Churm

100 Directorate of Regulatory Standards

U. S. Atomic Energy Commission

Washington, D. C. 20545

Dr. William Ramsey (100)

1 Division of Biomedical and Environmental Research

U. S. Atomic Energy Commission

Washington, D. C. 20545

J. L. Liverman

196 AEC Technical Information Center

2 Jones and Jones Landscape Architects

105 S. Main Street

Seattle, WA 98104

$$
\text { Brian Gray (2) }
$$

2

The Maxwell School

Syracuse University

607 University Avenue

Syracuse, NY 13210

Dr. Roy W. Bahl (2)

2 Battelle Human Affairs Research Center

4000 N. E. 41st Street

Seattle, WA 98105

Dr. William Maynard

1

Oak Ridge National Laboratory

P. 0. Box X

Building 2024

Oak Ridge, TN 37830

Carey Rosemarin

ONSITE

AEC Richland Operations Office

B. J. Melton

Battelle-Northwest

\begin{tabular}{|c|c|c|c|c|}
\hline & & & & \\
\hline & Brandstetter & $\mathrm{JC}$ & Fox & Wilfert \\
\hline $\mathrm{JB}$ & Burnham & $\mathrm{JL}$ & Harris & JR Young \\
\hline JW & Currie & PL & Hendrickson (15) & Technical Info (3) \\
\hline & Deonigi & MH & Karr & Technical Pub1 (1) \\
\hline
\end{tabular}

